\title{
Linker histone H1.8 inhibits chromatin-binding of condensins and DNA topoisomerase II to tune chromosome length and individualization
}

\section{Pavan Choppakatla1, Bastiaan Dekker ${ }^{2}$, Erin E. Cutts ${ }^{3}$, Alessandro Vannini ${ }^{3,4}$, Job Dekker ${ }^{2,5}$ and Hironori Funabiki, ${ }^{1, *}$}

${ }^{1}$ Laboratory of Chromosome and Cell Biology, The Rockefeller University, New York, NY 10065, USA.

${ }^{2}$ Program in Systems Biology, Department of Biochemistry and Molecular Pharmacology, University of

Massachusetts Medical School, Worcester, MA 01605, USA.

${ }^{3}$ Division of Structural Biology, The Institute of Cancer Research, London SW7 3RP, UK.

${ }^{4}$ Fondazione Human Technopole, Structural Biology Research Centre, 20157 Milan, Italy

${ }^{5}$ Howard Hughes Medical Institute, Chevy Chase, MD 20815, USA.

*Correspondence: funabih@ rockefeller.edu

\section{Summary}

DNA loop extrusion by condensins and decatenation by DNA topoisomerase II (topo II) are thought to drive mitotic chromosome compaction and individualization. Here, we reveal that the linker histone H1.8 antagonizes condensins and topo II to shape mitotic chromosome organization. In vitro chromatin reconstitution experiments demonstrate that H1.8 inhibits binding of condensins and topo II to nucleosome arrays. Accordingly, H1.8 depletion in Xenopus egg extracts increased condensins and topo II levels on mitotic chromatin. Chromosome morphology and Hi-C analyses suggest that H1.8 depletion makes chromosomes thinner and longer through shortening the average loop size and reducing the DNA amount in each layer of mitotic loops. Furthermore, excess loading of condensins and topo II to chromosomes by H1.8 depletion causes hyper-chromosome individualization and dispersion. We propose that condensins and topo II are essential for chromosome individualization, but their functions are tuned by the linker histone to keep chromosomes together until anaphase.

\section{Keywords}

Chromosome compaction, chromatin, mitosis, linker histone, nucleosome, condensin, DNA topoisomerase, Hi-C, Xenopus

\section{$\underline{\text { Introduction }}$}

Genomic DNA in eukaryotes is compacted by orders of magnitude over its linear length. The extent and mode of the packaging change between interphase and mitosis to support the cell cycle dependent functions of the DNA. While loosely packed DNA allows efficient decoding of genetic information in interphase, mitotic compaction of DNA enables efficient distribution of genetic information to daughter cells. In addition, chromosome individualization during mitosis ensures that all duplicated chromosomes are independently moved by microtubules and are equally distributed to daughter cells. Despite these common functional requirements of mitotic 
chromosomes and evolutionary conservation of major known regulators of mitotic chromosome structures, the size and shape of chromosomes vary among species and developmental stages. For example, rod-like individual mitotic chromosomes can be readily visualized in fission yeast Schizosaccharomyces pombe, but not in budding yeast Saccharomyces cerevisiae (Guacci et al., 1994; Umesono et al., 1983). During early embryogenesis in Xenopus and C. elegans, mitotic chromosome lengths become shorter (Ladouceur et al., 2015; Micheli et al., 1993). The mechanistic basis of mitotic chromosome shape regulation remains largely speculative (Heald and Gibeaux, 2018).

Classical experiments on mitotic chromosomes indicated that DNA is organized into loops around a central protein scaffold (Earnshaw and Laemmli, 1983; Paulson and Laemmli, 1977). Two major chromosome-associated ATPases play pivotal roles in mitotic chromatid formation: DNA topoisomerase II (topo II) and the structural maintenance of chromosomes (SMC) family complex, condensin (Kinoshita and Hirano, 2017; Kschonsak and Haering, 2015). Data obtained with chromosome conformation capture assays are consistent with the model that mitotic chromosomes are arranged in a series of loops organized by condensins (Elbatsh et al., 2019; Gibcus et al., 2018; Naumova et al., 2013). Vertebrate cells express two forms of the condensin complex, condensin I and condensin II (Hirano et al., 1997; Ono et al., 2003). Condensin I is loaded onto chromatin exclusively during mitosis, whereas condensin II retains access to chromosomes throughout the cell cycle(Hirota et al., 2004; Ono et al., 2004; Walther et al., 2018). Condensin II plays a role in maintaining chromosome territories in Drosophila nuclei (Bauer et al., 2012; Rosin et al., 2018) and drives sister chromatid decatenation by topo II (Nagasaka et al., 2016). It has been proposed that condensin II acts first in prophase to anchor large outer DNA loops, which are further branched into shorter inner DNA loops by condensin I (Gibcus et al., 2018). This proposal is consistent with their localization determined by super-resolution microscopy (Walther et al., 2018). In chicken DT40 cells, condensin II drives the helical positioning of loops around a centrally located axis thus controls the organization of long distance interactions (6- $20 \mathrm{Mb}$ ), whereas condensin I appears to control shorter distance interactions (Gibcus et al., 2018). This organization of the condensin I and II loops is also consistent with their roles in maintaining lateral and axial compaction respectively (Bakhrebah et al., 2015; Green et al., 2012; Samejima et al., 2012). In Xenopus egg extracts, in the presence of wildtype condensin I levels, condensin II depletion does not appear to change mitotic chromosome length, suggesting a reduced role for condensin II on these chromosomes (Shintomi and Hirano, 2011).

The prevailing model suggests that mitotic chromatin loops are formed by the dynamic loop extrusion activity of condensins (Alipour and Marko, 2012; Nasmyth, 2001; Riggs, 1990), although the molecular details of the process remain unclear (Banigan and Mirny, 2020; Cutts and Vannini, 2020; Datta et al., 2020). Single molecule experiments using purified recombinant yeast and human condensin complexes demonstrated ATP-dependent motor activity and loop extrusion by yeast and human condensins (Ganji et al., 2018; Kong et al., 2020; Terakawa et al., 2017). Condensin dependent loop extrusion in a more physiological Xenopus extract system has also been shown (Golfier et al., 2020). In silico experiments further suggest that a minimal combination of loop extruders (like condensin) and strand passage activity (such as topo II) can generate well resolved rod-like sister chromatids from entangled, interphase like DNA fibers (Goloborodko et al., 2016a).

These demonstrations of loop extrusion by purified condensins and cohesin were all largely performed on naked DNA substrates. However, loops that comprise metazoan mitotic chromosomes contain 100-200 kb of DNA (Banigan and Mirny, 2020), which represents hundreds of nucleosomes. Since condensins prefer to bind nucleosome-free DNA (Kong et al., 2020; Shintomi et al., 2017; Toselli-Mollereau et al., 2016; Zierhut et al., 2014), it remains unknown if loop extrusion can proceed on chromatin. Human condensin complexes are capable of loop extrusion through sparsely arranged nucleosomes in vitro (Kong et al., 2020). However, mitotic chromatin adopts a more compact fiber structure (Grigoryev et al., 2016; Ou et al., 2017). Furthermore, large protein complexes such as RNA polymerases are able to limit loop extrusion by SMC protein complexes, such as bacterial condensins and eukaryotic cohesins (Brandão et al., 2019; Hsieh et al., 2020; Krietenstein et al., 2020). Nucleosomes also restrict the diffusion of cohesin in vitro (Stigler et al., 2016). Therefore, the effect of higher order chromatin fiber structure and other mitotic chromatin proteins on processive loop extrusion by condensin remains unknown. 
Interphase nuclei are segmented to chromosome territories, each of which contain highly entangled sister chromatids after replication (Cremer and Cremer, 2010; Farcas et al., 2011; Sundin and Varshavsky, 1981). Replicated pairs of chromatids are linked by cohesin during interphase, and cohesin removal during prophase (except at centromeres and other limited protected loci) promotes resolution of sister chromatids, together with actions of condensin II and topo II (Gandhi et al., 2006; Nagasaka et al., 2016). Different chromosomes are also largely unentangled in interphase HeLa cells (Goundaroulis et al., 2020; Tavares-Cadete et al., 2020), and Ki-67 localization on chromosome peripheries may act as a steric and electrostatic barrier to prevent interchromosomal entanglement during mitosis (Cuylen et al., 2016). However, some interchromosomal linkages were observed in metaphase (Marko, 2008; Potapova et al., 2019). Although it has been shown that active transcription at rDNA results in mitotic interchromosomal links (Potapova et al., 2019), it remains unclear if mitotic chromosome compaction is coupled to resolution of these interchromosomal linkages.

One of the most abundant chromatin proteins beside core histones is the linker histone, which binds to the dyad of the nucleosome and tethers the two linker DNAs emanating from the nucleosome (Arimura et al., 2020; Bednar et al., 2017; Zhou et al., 2015, 2021). In reconstitution experiments, linker histones cluster oligo- nucleosomes (Li et al., 2016; White et al., 2016), and promote liquid-liquid phase separation (Gibson et al., 2019; Shakya et al., 2020). In vivo, linker histones are also enriched in highly compact chromatin (Izzo et al., 2013; Parseghian et al., 2001; Th'ng et al., 2005). While core histones are evolutionarily highly conserved in eukaryotes, linker histones are much more diversified (Izzo et al., 2008). In the human and mouse genome, $11 \mathrm{H} 1$ paralogs are found, among which some combination of six variants (H1.0-H1.5) are widely expressed in somatic cells (Hergeth and Schneider, 2015). In vertebrate oocytes and early embryos, H1.8 (also known as $\mathrm{H} 1 \mathrm{OO}, \mathrm{H} 1 \mathrm{foo}, \mathrm{H} 1 \mathrm{M}$ and $\mathrm{B} 4)$ is the major linker histone variant (Dworkin-Rastl et al., 1994; Wühr et al., 2014). Immuno-depletion of H1.8 from Xenopus egg extracts made mitotic chromosomes thinner and longer, causing defective chromosome segregation in anaphase (Maresca et al., 2005). However, the mechanism by which the linker histone affects large scale chromosome length changes remains unknown.

Here we demonstrate that the linker histone H1.8 suppresses enrichment of condensins and topo
II on mitotic chromosomes. In a reconstitution system with purified components, H1.8 inhibits binding of topo II and condensins to nucleosome arrays. Through a combination of chromosome morphological analysis and $\mathrm{Hi}-\mathrm{C}$, we show that $\mathrm{H} 1.8$ reduces chromosome length by limiting condensin I loading on chromosomes, while H1.8 limits chromosome individualization by antagonizing both condensins and topo II. This study establishes a mechanism by which the linker histone tunes the compaction and topology of mitotic chromosomes.

\section{$\underline{\text { Results }}$}

\section{Linker histone H1.8 limits enrichment of condensins and topo II on mitotic chromatin}

Depletion of linker histone H1.8 in Xenopus egg extracts makes chromosomes thinner and elongated (see Figure 3C, Maresca et al., 2005). We asked if this phenotype may reflect the potential role of $\mathrm{H} 1.8$ in regulating condensins and TOP2A (the dominant topo II isoform in Xenopus egg extracts, Wühr et al., 2014), which are essential for mitotic chromosome compaction in Xenopus egg extracts (Adachi et al., 1991; Cuvier and Hirano, 2003; Hirano and Mitchison, 1994). In silico simulation analysis suggests that increasing the number of loop extruders (such as condensin I) on DNA, beyond a minimum threshold, makes chromosomes longer and thinner (Goloborodko et al., 2016a). Reducing condensin I levels on chromatin also made chromosomes shorter experimentally (Elbatsh et al., 2019; Fitz-James et al., 2020; Shintomi and Hirano, 2011). Although it has been reported that $\mathrm{H} 1.8$ depletion does not affect chromosomal enrichment of major chromatin proteins (Maresca et al., 2005), we therefore attempted to quantify chromatin-bound levels of condensins and TOP2A.

To investigate whether $\mathrm{H} 1.8$ regulates chromatin levels of condensins and topo II, we prepared mitotic chromosomes in Xenopus laevis egg extracts depleted of H1.8. Demembranated Xenopus laevis sperm nuclei were added to either mock $(\Delta \mathrm{IgG})$ or $\mathrm{H} 1.8$ depleted $(\Delta \mathrm{H} 1)$ extracts from eggs arrested at meiotic metaphase II by cytostatic factor (CSF extracts) (Figure 1A, 1B). 
bioRxiv preprint doi: https://doi.org/10.1101/2020.12.20.423657; this version posted April 12, 2021. The copyright holder for this preprint (which was not certified by peer review) is the author/funder, who has granted bioRxiv a license to display the preprint in perpetuity. It is made available under aCC-BY-NC-ND 4.0 International license.

Choppakatla et al., April 2021-preprint copy- BioRxiv

A

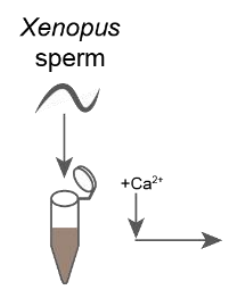
$\Delta \mathrm{lgG} / \Delta \mathrm{H} 1$
$\mathrm{CSF}$ extract
Interphase nucleus
CSF extract
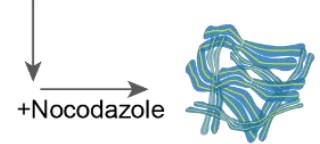

Replicated

mitotic chromosomes

C

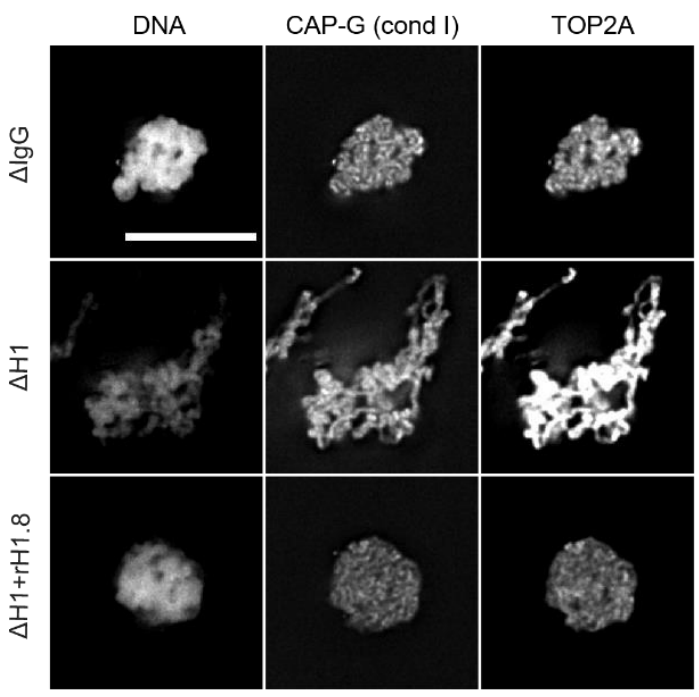

$\mathbf{F}$

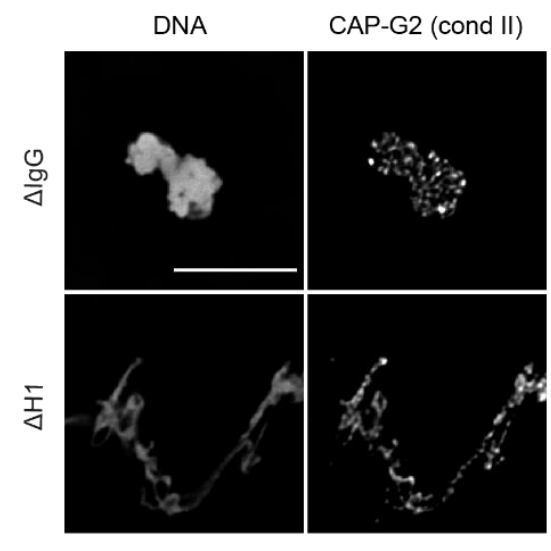

B

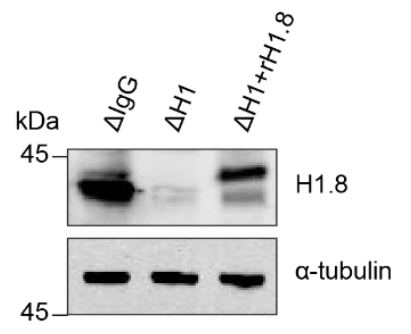

D

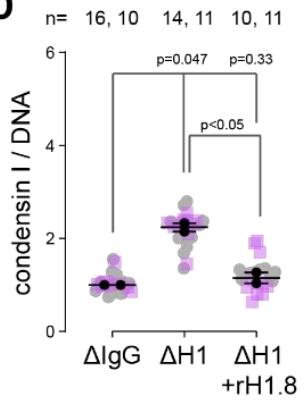

$n=16,12 \quad 14,7 \quad 10,14$

$\mathbf{E}$
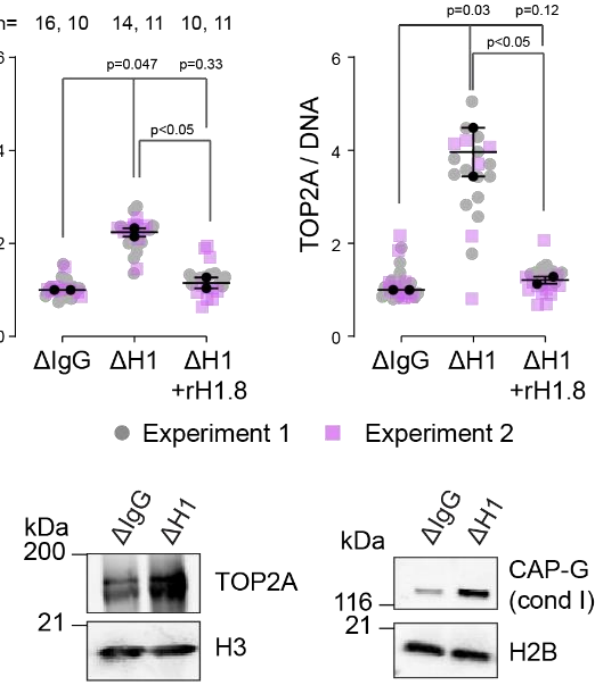
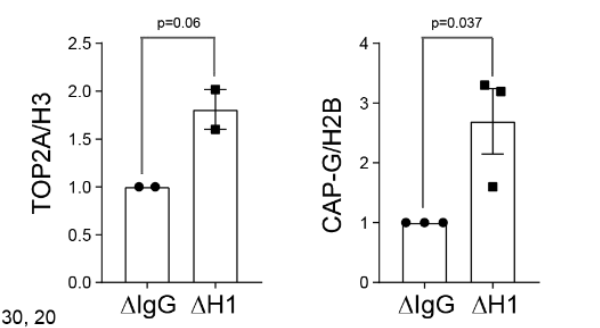

G $30,21 \quad 30,20$

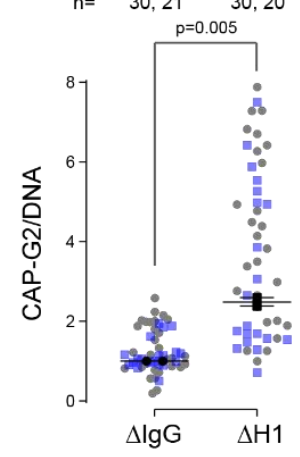

H

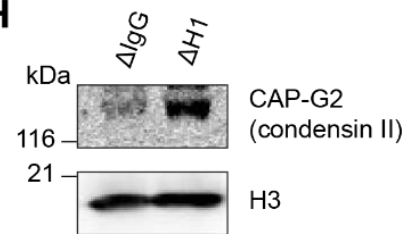

Figure 1. Linker histone H1.8 suppresses enrichment of condensins and TOP2A on mitotic chromatin

A) Experimental scheme to generate replicated chromosomes in Xenopus egg extracts. B) Western blots of total extracts showing depletion of H1.8 from Xenopus egg extracts and rescue with recombinant $\mathrm{H} 1.8$ (rH1.8). C) Representative images of DNA (Hoechst 33342), CAP-G (condensin I) and TOP2A immunofluorescence on chromosomes in metaphase extracts treated with nocodazole in the indicated conditions. Chromosomes in each nucleus remain clustered in the presence of nocodazole. Bar, $10 \mu \mathrm{m}$. D) Quantification of CAP-G (condensin I) and TOP2A immunofluorescence signals normalized to the DNA (Hoechst) signal for the indicated conditions. Each grey or magenta dot represents the average signal intensity of a single chromosome cluster (from one nucleus). Each black dot represents the median signal intensity from a single experiment. Bars represent mean and range of the medians of two independent experiments. E) Western blots of mitotic chromatin purified from mock ( $\triangle \mathrm{IgG}$ ) and H1.8-depleted $(\Delta \mathrm{H} 1)$ extracts (top) and quantification of band intensities normalized to $\mathrm{H} 3$ and $\mathrm{H} 2 \mathrm{~B}$ (below). Mean and SEM from 3 experiments. F) Representative images of CAP-G2 (condensin II) immunofluorescence on chromosomes in metaphase extracts with nocodazole in the indicated conditions. Bar, $10 \mu \mathrm{m}$. G) Quantification of the CAP-G2 (condensin II) normalized to the DNA (Hoechst) signal for the indicated conditions. Each grey or purple dot represents the average signal intensity of a single chromosome cluster (from one nucleus). Each black dot represents the median signal intensity from a single experiment. Bars represent mean and range of the median of two independent experiments. H) Western blots of mitotic chromatin purified from mock $(\Delta \operatorname{IgG})$ and H1.8-depleted $(\Delta \mathrm{H} 1)$ extracts. The statistical significance of the changes in each immunofluorescence experiment was assessed by a Mann Whitney $U$-test and the p-values 
shown in D, E and G are calculated by an unpaired Student's $t$-test of the aggregate medians (immunofluorescence) or blot intensities of each single experiment. The number of nuclei imaged in D and $\mathrm{G}$ in each condition for each experiment are indicated in the figure.

Figure S1- H1.8 depletion does not lead to global accumulation of DNA-binding proteins

Table S1-High abundance proteins with the highest increases in $\Delta \mathrm{H} 1$ depleted chromosomes

Table S2- High abundance proteins with the highest decreases in $\Delta \mathrm{H} 1$ depleted chromosomes

Calcium was added to cycle the extract into interphase and induce functional nuclear formation, in which chromosomes were replicated. The corresponding depleted CSF extract was then added to generate metaphase chromosomes (Shamu and Murray, 1992). To eliminate the microtubuledependent change in chromosome morphology, which may affect quantitative analyses of chromatin proteins, spindle assembly was inhibited using nocodazole. Chromosomes were fixed and the levels of TOP2A and condensin I subunit CAP-G were measured by immunofluorescence (Figure 1C). Depletion of H1.8 increased the levels of both CAP$\mathrm{G}$ and TOP2A on mitotic chromosomes, while adding back recombinant $\mathrm{H} 1.8$ rescued the phenotype (Figure 1D). Identical results were obtained when immunofluorescence signal normalization was done by the minor groove DNAbinding dye Hoechst 33342, or by fluorescent dUTP that was incorporated during replication (Figure S1A-C). The dUTP quantitation also confirmed that H1.8 depletion did not affect DNA replication (Figure S1B) , as reported previously (Dasso et al., 1994). The apparent increased signal intensities of CAP-G and TOP2A on chromatin in $\triangle \mathrm{H} 1$ extracts were not the general consequence of elongated chromosome morphology, as H1.8 depletion did not affect a panel of other chromatin proteins, regardless of their binding preference to nucleosomes or nucleosome-free DNA (Zierhut et al., 2014)(Figure S1D) . Enhanced chromosome binding of condensin I and TOP2A in $\triangle \mathrm{H} 1.8$ extracts was biochemically confirmed by quantifying their levels on purified metaphase chromosomes by western blotting and by mass spectrometry (Figure 1E, S1E, Table S1, S2). Mass spectrometry data also confirmed that H1.8 depletion did not result in a global enrichment of all chromatin bound proteins. Condensin II levels on chromosomes also showed similar increases in $\Delta \mathrm{H} 1$ extracts by immunofluorescence and western blots on purified chromosomes, although peptides of condensin II specific subunits were not detected by mass spectrometry (Figure 1F-H, S1E).
Linker histone H1.8 reduces binding of condensins and TOP2A to nucleosome arrays

Since linker histone depletion does not change the nucleosome spacing in Xenopus egg extracts (Ohsumi, Katagiri, \& Kishimoto, 1993), we hypothesized that $\mathrm{H} 1.8$ depletion results in an increase in linker DNA that becomes accessible to condensins and TOP2A. To test this possibility, we reconstituted nucleosome arrays with purified histones, and asked if $\mathrm{H} 1.8$ interferes with binding of recombinant human condensins and $X$. laevis TOP $2 \mathrm{~A}$ (Kong et al., 2020; Ryu et al., 2010) (Figure 2A). The nucleosome array was composed of 19 tandem repeats of 147 bp Widom 601 nucleosome positioning sequence and 53 bp linker DNA (Lowary and Widom, 1998), where full occupancy of the array by nucleosome core particle (NCP) and $\mathrm{H} 1.8$ to each repeat unit was confirmed by native polyacrylamide gel electrophoresis (PAGE) (Figure S2A). As previously shown with human condensin I purified from HeLa cells (Kimura et al., 2001), our recombinant human condensin I, but not the ATPbinding defective Q-loop mutant (Hassler et al., 2019; Hopfner et al., 2000; Kong et al., 2020; Löwe et al., 2001), was able to rescue mitotic chromosome morphology defects caused by condensin I depletion in Xenopus extracts (Figure S2B), demonstrating that the recombinant human condensin I can functionally replace Xenopus condensin I. The recombinant Xenopus laevis TOP2A used was also able to rescue chromatid formation in $\triangle \mathrm{TOP} 2 \mathrm{~A}$ extracts and was able to perform ATP dependent kinetoplast decatenation in vitro (Figure S2C, D).

Condensin I binds weakly to mononucleosomes with linker DNA (Kong et al., 2020). We observed similar weak binding of condensin I to nucleosome arrays and this weak binding was stimulated by ATP (Figure S3A). Since this enhancement was not seen when magnesium concentration was higher than the ATP concentration (Figure S3B), we hypothesized that ATP might have enhanced condensin binding to the nucleosome arrays by chelating magnesium, which is known to induce chromatin compaction 
bioRxiv preprint doi: https://doi.org/10.1101/2020.12.20.423657; this version posted April 12, 2021. The copyright holder for this preprint (which was not certified by peer review) is the author/funder, who has granted bioRxiv a license to display the preprint in perpetuity. It is made available under aCC-BY-NC-ND 4.0 International license.

Choppakatla et al., April 2021-preprint copy- BioRxiv

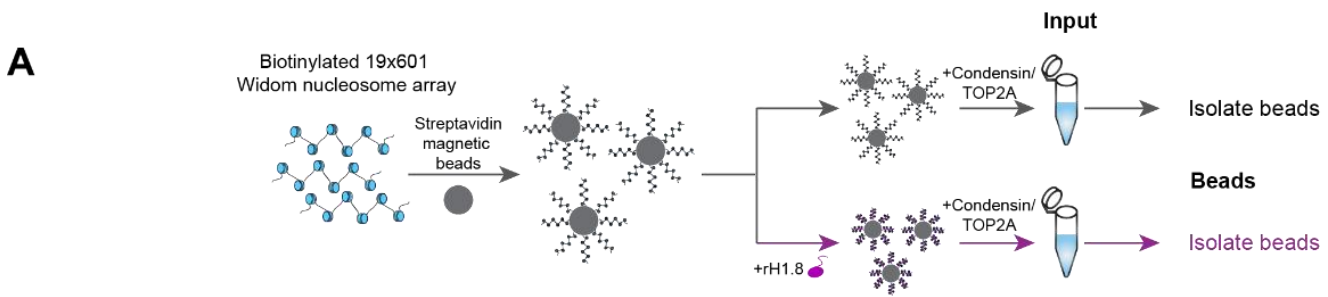

B

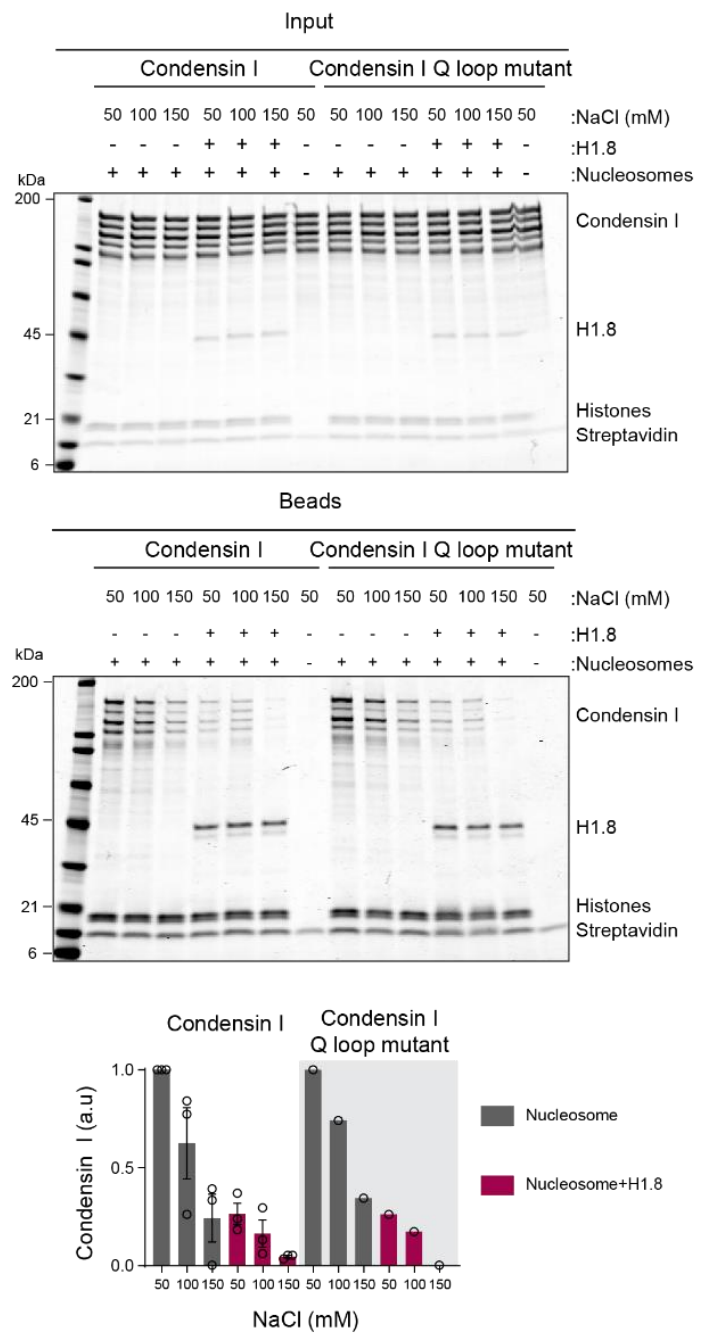

C
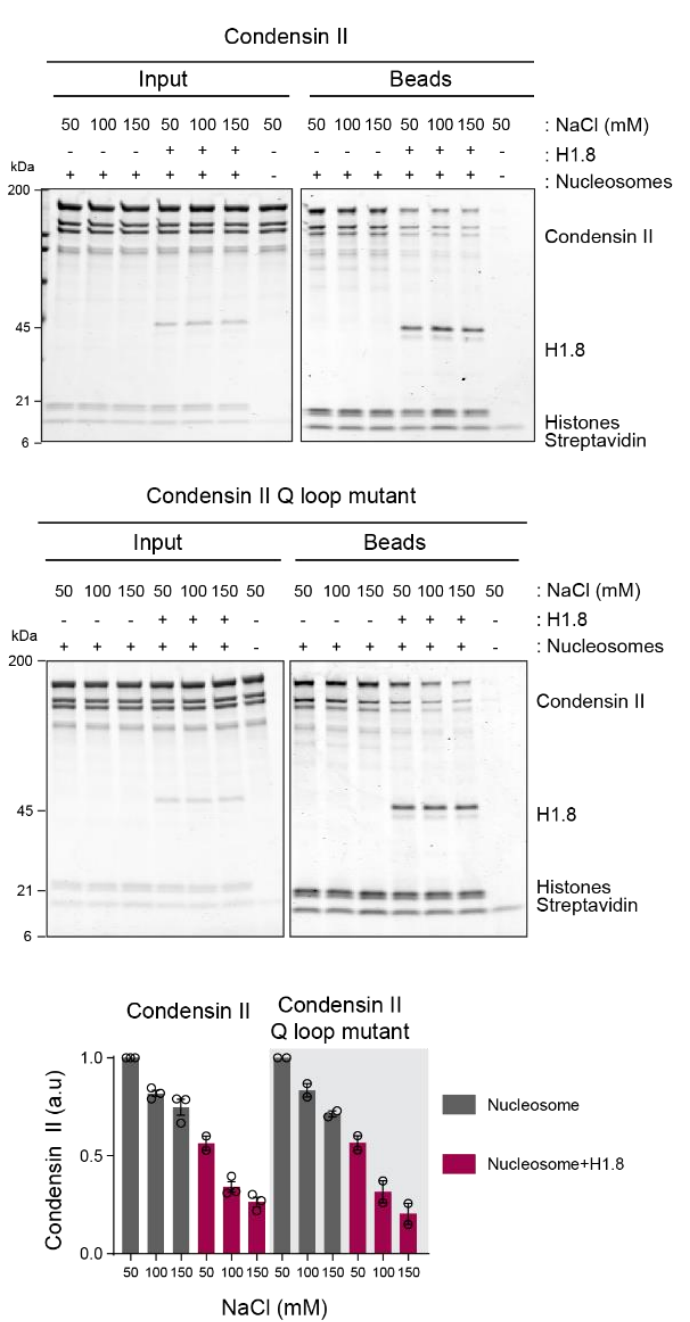

D
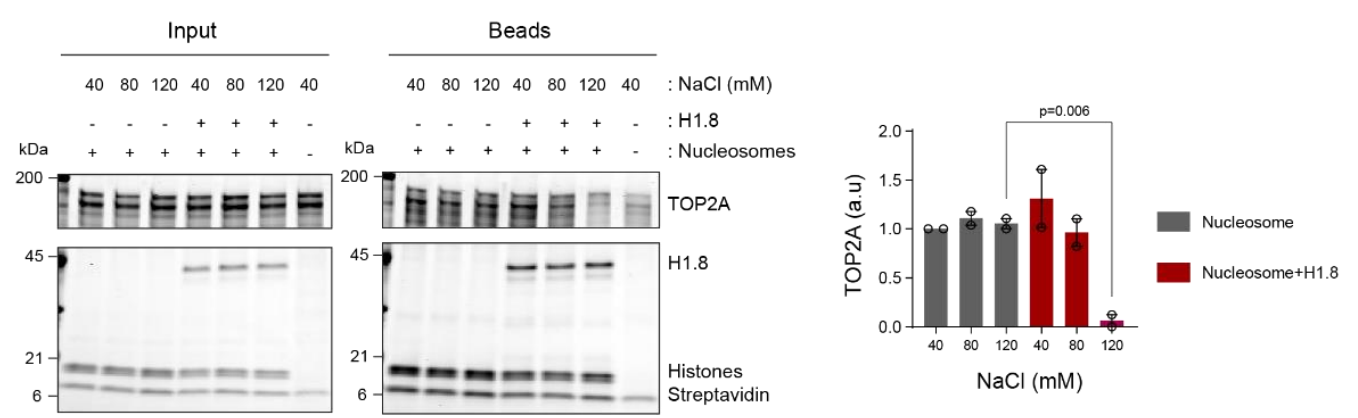

Figure 2. Linker histone inhibits binding of condensins and TOP2A to nucleosome arrays

A) Experimental scheme for testing the effect of recombinant $\mathrm{H} 1.8$ ( $\mathrm{rH} 1.8)$ on binding of purified condensins and TOP2A to arrays of nucleosomes assembled on the Widom 601 nucleosome positioning sequence. B) Coomassie staining of SDS-PAGE gels, showing input (top) and nucleosomearray bound fraction (middle) of condensin I, rH1.8 and core histones. The right most lanes represent the streptavidin beads only negative control. Buffer contains $2.5 \mathrm{mM} \mathrm{MgCl}, 5 \mathrm{mM}$ ATP and indicated concentrations of $\mathrm{NaCl}$. The band intensities of condensin I subunits were normalized to the histone bands and the binding at $50 \mathrm{mM} \mathrm{NaCl}$ for nucleosome arrays without H1.8. Mean and S.E.M of three independent experiments are shown (bottom). C) Same as B, except that nucleosome array binding of condensin II is shown. Mean and S.E.M (wildtype)/range (Q-loop mutant) of three (wildtype) or two (Q-loop mutant) independent experiments are shown. D) Same as B, except that nucleosome array binding of TOP2A in buffer containing $1 \mathrm{mM} \mathrm{MgCl} 2$ is shown. Mean and range of two independent experiments are shown. The p-value in D was calculated using an unpaired Student's t-test. 
Figure S2- Recombinant human condensin I and X. laevis TOP2A are functional

Figure S3- Condensin I binding is inhibited by magnesium

Figure S4- H1.8 inhibits condensin I binding to mononucleosomes

(Eltsov et al., 2008; Finch and Klug, 1976). Indeed, both EDTA and ATP, which chelate magnesium, increased binding of the Q loop mutant of condensin I to the nucleosome array (Figure S3C), suggesting that condensin binding to the nucleosome array is sensitive to high magnesium concentration and not due to ATP binding of condensin I. In contrast, ATP did not stimulate condensin I binding to mononucleosomes (Figure S3D), indicating that excess magnesium may limit condensin binding through compaction of the nucleosome array.

In the buffer condition where excess ATP was present over magnesium, both wild-type and the Q-loop mutant of condensin I showed reduced binding to nucleosome arrays loaded with $\mathrm{H} 1.8$ at physiological salt concentrations $(50-150 \mathrm{mM}$ $\mathrm{NaCl}$ ) (Figure 2B). H1.8 also suppressed binding of condensin II and its Q-loop mutant to the nucleosome array (Figure 2C), though, as expected (Kong et al., 2020), condensin II showed higher affinity to the nucleosome array than condensin I. This reduced binding of condensins in the presence of $\mathrm{H} 1.8$ can be explained by either direct competition between $\mathrm{H} 1.8$ and condensins for the linker DNA or by H1.8mediated formation of a higher order structure of the nucleosome array (Song et al., 2014). The direct competition model can be tested by using mononucleosomes with linker DNAs instead of the nucleosome array, since $\mathrm{H} 1.8$ binding to mononucleosomes does not promote higher order structure or aggregation (White et al., 2016). Supporting the direct competition model, H1.8 reduced binding of condensin I to mononucleosomes (Figure S4).

We also examined if $\mathrm{H} 1.8$ interferes with binding of the recombinant Xenopus TOP2A to nucleosome arrays. As compared to condensins, TOP2A showed more stable binding to the nucleosome array, and H1.8 had no effect on TOP2A binding at low salt concentrations. However, H1.8 did reduce nucleosome array binding of recombinant Xenopus TOP2A at $120 \mathrm{mM} \mathrm{NaCl}$ (Figure 2D). Altogether, these data demonstrate that preloaded H1.8 on nucleosomes can directly interfere with binding of condensins and TOP2A to chromatin.

Chromosome elongation by $\mathrm{H1.8}$ depletion is due to increased chromatin bound condensin I
If the increased amount of condensin I on chromatin is responsible for the chromosome elongation phenotype observed in $\Delta \mathrm{H} 1$ extracts, reducing condensin I levels should reverse this phenotype. To measure lengths of mitotic chromosomes formed in Xenopus egg extracts, we assembled replicated metaphase chromosomes in extracts depleted with mock IgG, H1.8, CAP-G (condensin I) or CAP-D3 (condensin II) antibodies. These extracts were then diluted to disperse individualized chromosomes (Figure 3A, 3B) (Funabiki and Murray, 2000). As reported previously (Maresca et al., 2005), average chromosome length increased by $\sim 50 \%$ by $\mathrm{H} 1.8$ depletion (Figure 3C, 3D). Supporting our hypothesis, when condensin I was co-depleted $(\Delta \mathrm{H} 1 \Delta \mathrm{CAP}-\mathrm{G})$, chromosomes became even shorter than chromosomes in mock depleted extracts $(\triangle \mathrm{IgG})$ (Figure 3C, 3D). In contrast, condensin II codepletion $(\Delta \mathrm{H} 1 \Delta \mathrm{CAP}-\mathrm{D} 3)$ did not change the chromosome length (Figure 3D). Chromosome length in condensin II-depleted extracts ( $\triangle$ CAP-D3) was also indistinguishable from mock depleted chromosomes (Figure S5A), consistent with the negligible effect of condensin II depletion in the presence of normal levels of condensin I in Xenopus egg extracts (Shintomi and Hirano, 2011).

If $\mathrm{H} 1.8$ regulates chromosome length by a mechanism independent of its role in condensin I inhibition, we expect that the chromosome lengths in $\Delta \mathrm{CAP}-\mathrm{G}$ extracts and $\Delta \mathrm{H} 1 \Delta \mathrm{CAP}-\mathrm{G}$ extracts would be different. Unfortunately, since severe defects in chromosome individualization in $\triangle \mathrm{CAP}-\mathrm{G}$ extracts prevented us from measuring chromosome lengths, this comparison was not possible (see Figure 5B). To circumvent this issue, we asked if similar condensin I levels on both $\Delta \mathrm{IgG}$ and $\Delta \mathrm{H} 1$ chromatin would result in similar chromosome lengths. Since condensin I binding to chromosomes is suppressed by $\mathrm{H} 1.8$, to load condensin I to chromosomes in $\Delta \mathrm{H} 1.8$ extracts at the levels seen in control $(\Delta \operatorname{IgG})$ extracts, we assembled chromosomes in extracts where condensin I was partially depleted (Figure S5B). When mitotic chromosomes were assembled in $\Delta \mathrm{H} 1.8$ extracts that contain $40 \%$ (of $\Delta \operatorname{IgG}$ ) condensin I (CAP-G), condensin I level on these chromosomes was equivalent to that on chromosomes in control ( $\Delta \operatorname{IgG})$ extracts (Figure 3E). Consistent with the hypothesis that $\mathrm{H} 1.8$ does not 
bioRxiv preprint doi: https://doi.org/10.1101/2020.12.20.423657; this version posted April 12, 2021. The copyright holder for this preprint (which was not certified by peer review) is the author/funder, who has granted bioRxiv a license to display the preprint in perpetuity. It is made available under aCC-BY-NC-ND 4.0 International license.

Choppakatla et al., April 2021-preprint copy- BioRxiv

A

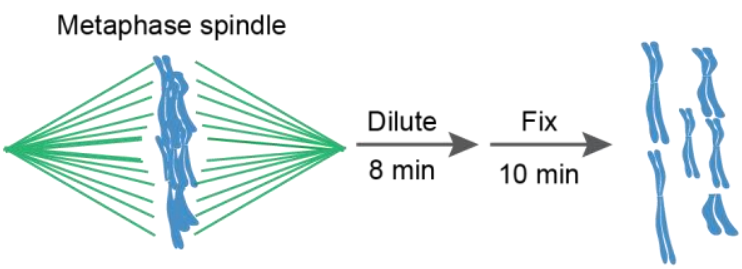

C
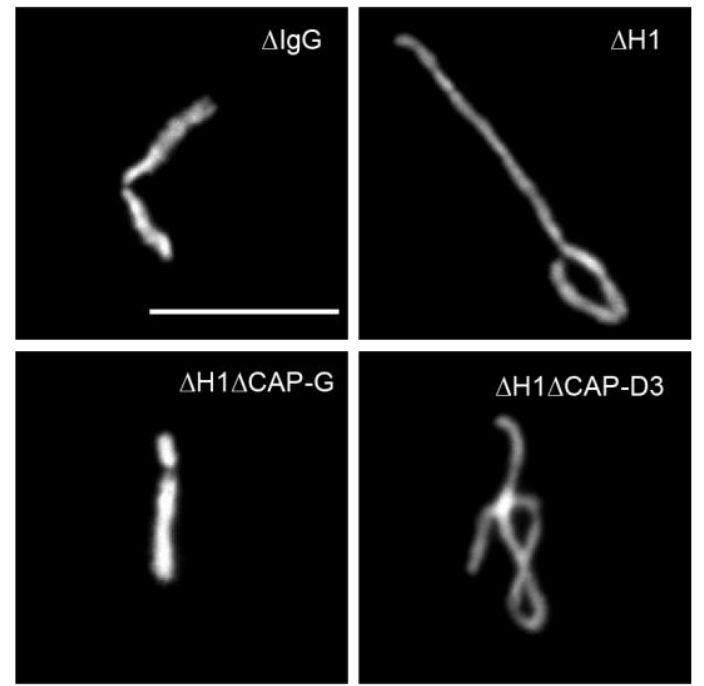

$\mathbf{E}$

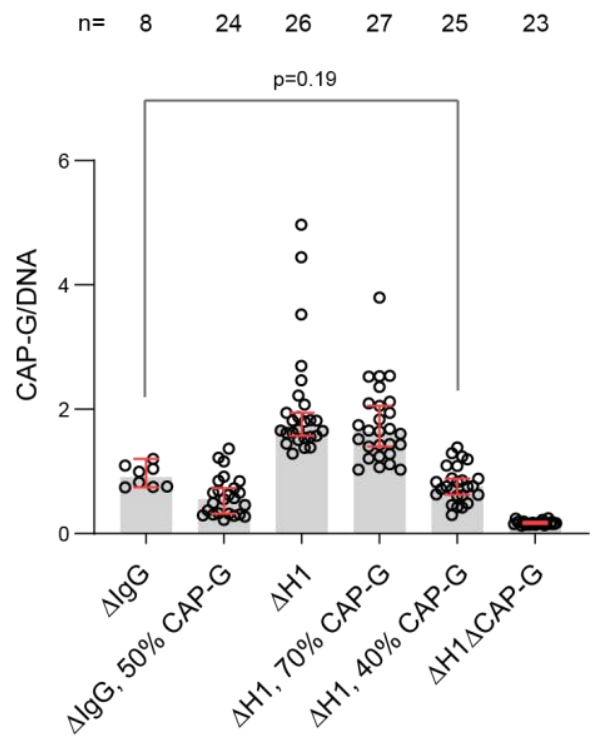

B

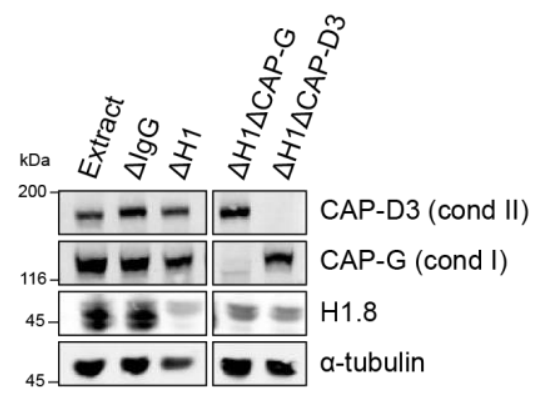

D

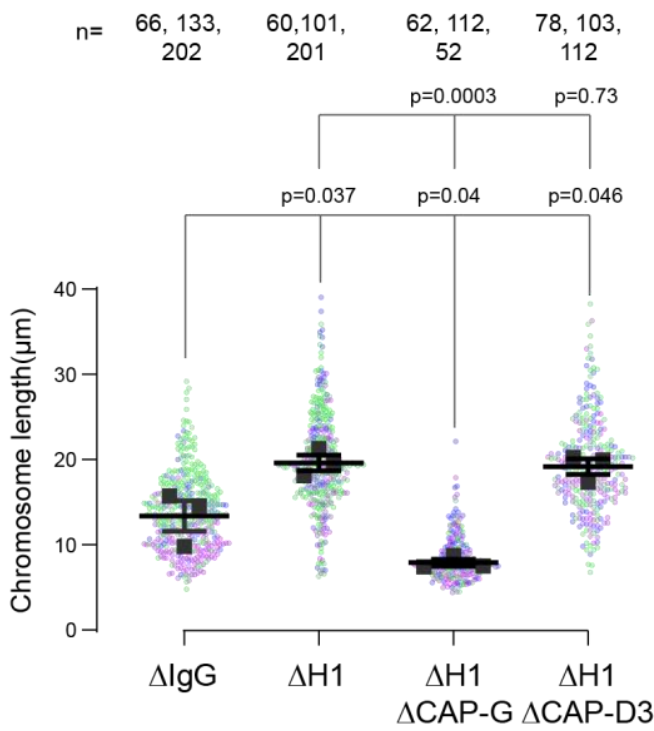

$\mathbf{F}$

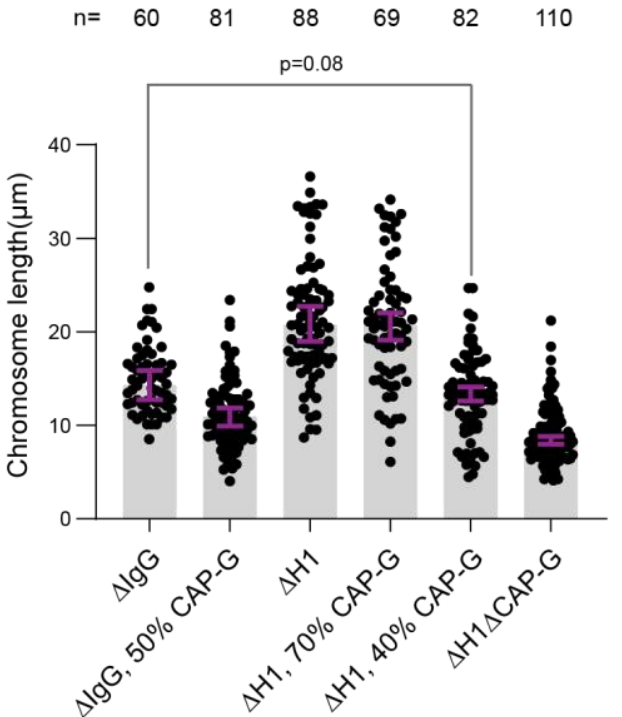

Figure 3. Chromosome elongation by H1.8 depletion is due to enhanced condensin I loading on chromatin

A) Schematic of extract dilution to disperse individualized chromosomes. B) Western blots of total egg extracts showing depletions of indicated proteins. C) Representative images of mitotic chromosomes after dilution of indicated extracts. Bar, $10 \mu \mathrm{m}$. D) Quantification of the chromosome length. Data distribution of the length of individual chromosomes from three independent experiments (green, purple, grey) is shown. Each black dot represents the median length of chromosomes from a single experiment. Bar represents mean and S.E.M of three independent experiments. E) Quantification of CAP-G levels normalized to DNA signal (Cy3-dUTP) in the indicated conditions by immunofluorescence. Each dot represents the mean of CAP-G intensity normalized to DNA intensity of a single chromosome cluster (from one nucleus). The data plotted is median $+/-$ $95 \%$ C.I. F) Chromosome lengths in the indicated condition. Each dot represents length of a single chromosome. Bars represent median $+/-95 \%$ C.I. The p-values in D compare the median chromosome lengths in each condition and were calculated using an unpaired Student's t-test and those in E, F compare the median values in a single experiment and were calculated using a two-tailed Mann-Whitney $U$ test. The number of nuclei (E) or chromosomes (D, F) imaged in each condition for each experiment are indicated above the figure.

Figure S5. Condensin II depletion does not affect chromosome length 
contribute to chromosome length regulation independently of condensin I, average chromosome length was essentially identical between these two conditions $(\Delta \mathrm{H} 140 \% \mathrm{CAP}-\mathrm{G}$ and $\Delta \mathrm{IgG})$ (Figure 3F). In summary, these results demonstrate that $\mathrm{H} 1.8$ controls mitotic chromosome lengths primarily through limiting the chromosome binding of condensin I.

\section{H1.8 increases condensin I driven mitotic loop layer organization}

Experimental and simulation studies have shown that mitotic chromosome length and width are sensitive to the number of condensin I molecules on a chromosome, through affecting the loop size (FitzJames et al., 2020; Gibcus et al., 2018; Goloborodko et al., 2016b, 2016a). Low levels of condensin I are predicted to result in fewer and larger loops, while higher levels of condensin I will lead to a larger number of smaller loops. Therefore, if linker histone H1.8 decreases chromosome length through limiting condensin I association with chromatin, we expect that the average size of mitotic condensin loops decreases upon $\mathrm{H} 1.8$ depletion. As an alternative way to quantitatively assess the effect of H1.8 and condensins on mitotic chromosome organization, we used the chromosome conformation capture assay Hi-C (Lieberman-Aiden et al., 2009).

Hi-C contact probability maps were generated from replicated metaphase Xenopus laevis sperm chromosomes $60 \mathrm{~min}$ after cycling back into mitosis in the presence of nocodazole. As seen in mitotic chromosomes in somatic cells (Gibcus et al., 2018; Naumova et al., 2013) and in early stages of mouse development (Du et al., 2017), all the Hi-C contact maps showed no checkerboard pattern commonly associated with interphase chromosome compartments, and lacked any sign of topologically associating domains (TADs) (Szabo et al., 2019) (Figure 4A- Data available at GEO under accession no. GSE164434). Hi-C interaction maps are characterized by the decay in contact probability, $P$, as a function of the genomic distance, $s$. To derive quantitative information about the polymer structure of the mitotic chromosomes, we plotted the genomewide average $P(s)$ (Figure 4B). $P(s)$ plots were consistent among two biological replicates (Figure S6A) and among different chromosomes (Figure S6B). The interaction decay profile of the control $(\Delta \mathrm{IgG})$ chromosomes was also qualitatively similar to mitotic chromosomes in both DT40 and human cells (Elbatsh et al., 2019; Gibcus et al., 2018; Naumova et al., 2013). Condensin I depletion ( $\triangle \mathrm{CAP}-\mathrm{G})$ caused a major change in the Hi-C map (Figure 4A), reflecting its severe morphological defects in mitotic chromosomes in Xenopus egg extracts (Hirano et al., 1997). Unlike in DT40 cells, where depletion of condensin I and condensin II reduces interactions at shorter $(<6 \mathrm{Mb})$ and longer (> $6 \mathrm{Mb}$ ) distances respectively (Gibcus et al., 2018), condensin I depletion affected interactions at longer distances $(\sim 10 \mathrm{Mb})$, whereas condensin II depletion $(\triangle \mathrm{CAP}-\mathrm{D} 3)$ did not cause recognizable changes in interactions at both long and short distances (Figure S6C). A second diagonal band, which is indicative of a strong helical organization in the chromosome axis (Gibcus et al., 2018), was not seen in Xenopus egg extracts (Figure 4A, S6C), likely reflecting the minor contribution of condensin II in this system or perhaps due to a prolonged arrest in mitosis (Gibcus et al., 2018). In H1.8-depleted extracts $(\Delta H 1)$, a dramatic decrease in interactions at long genomic distances (1-10 Mb) was observed (Figure 4A, 4B), as expected from the thinner chromosomes (Figure 3).

$P(s)$ plots are useful to determine the underlying polymer structure of the chromosome such as average loop size (Gibcus et al., 2018). Specifically, the first derivative (slope) of the $P(s)$ plots can reveal both the average loop size and the amount of DNA per layer of the rod-shaped mitotic chromosome (layer size) (Abramo et al., 2019; Gassler et al., 2017; Gibcus et al., 2018) (Figure 4C). Average loop size can be estimated from the peak value in the derivative plot (Gassler et al., 2017; Patel et al., 2019). As the derivative plot in our data showed a peak in the $10 \mathrm{~kb}-1 \mathrm{Mb}$ range, we estimated that this peak location reflects the average loop size. Unlike mitotic chromosomes in DT40 or HeLa cell lines (Abramo et al., 2019; Gibcus et al., 2018), metaphase chromosomes from Xenopus extracts had a flattened peak (Figure S6D), possibly due to a larger variation in loop sizes. Although it is difficult to estimate the exact loop size from these plots, chromosomes from $\Delta \mathrm{H} 1$ extracts showed a reproducible shift of the peak towards smaller genomic distances (Figure S6D). This is consistent with a decrease in loop size due to increased condensin I accumulation on chromatin upon H1.8 depletion. Derivative plots generated from Hi-C maps of dispersed chromosomes in diluted extracts (Figure 3A) showed a similar shift in peak towards smaller genomic distances upon 
bioRxiv preprint doi: https://doi.org/10.1101/2020.12.20.423657; this version posted April 12, 2021. The copyright holder for this preprint (which was not certified by peer review) is the author/funder, who has granted bioRxiv a license to display the preprint in perpetuity. It is made available under aCC-BY-NC-ND 4.0 International license.

Choppakatla et al., April 2021-preprint copy- BioRxiv

A

$\Delta \lg G$
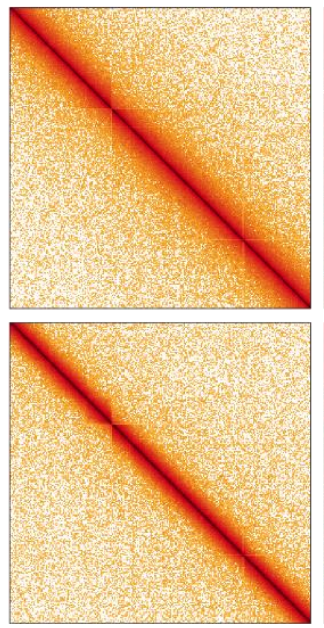

$\Delta \mathrm{H} 1$ $\triangle \mathrm{CAP}-\mathrm{G}$
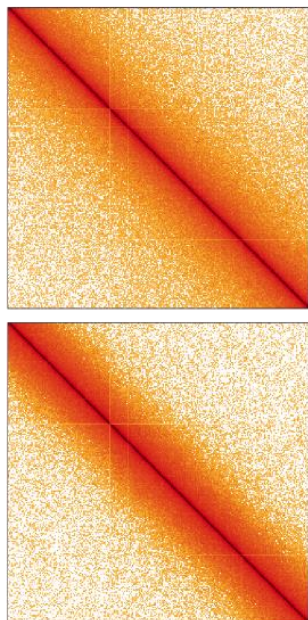

$\Delta \mathrm{H} 1 \Delta \mathrm{CAP}-\mathrm{G}$ $\triangle$ CAP-D3
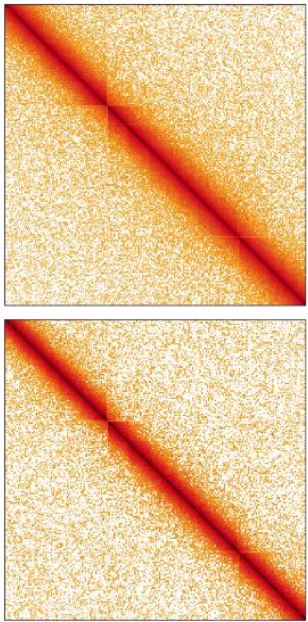

$\Delta \mathrm{H} 1 \Delta \mathrm{CAP}-\mathrm{D} 3$ $\triangle$ CAP-G $\triangle$ CAP-D3
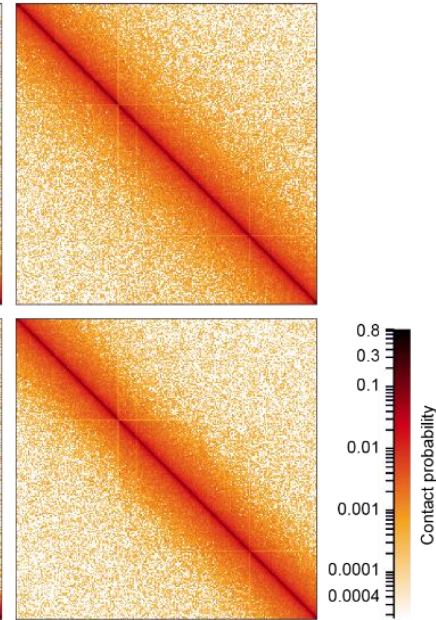

$\Delta \mathrm{H} 1 \Delta \mathrm{CAP}-\mathrm{G} \Delta \mathrm{CAP}-\mathrm{D} 3$
B

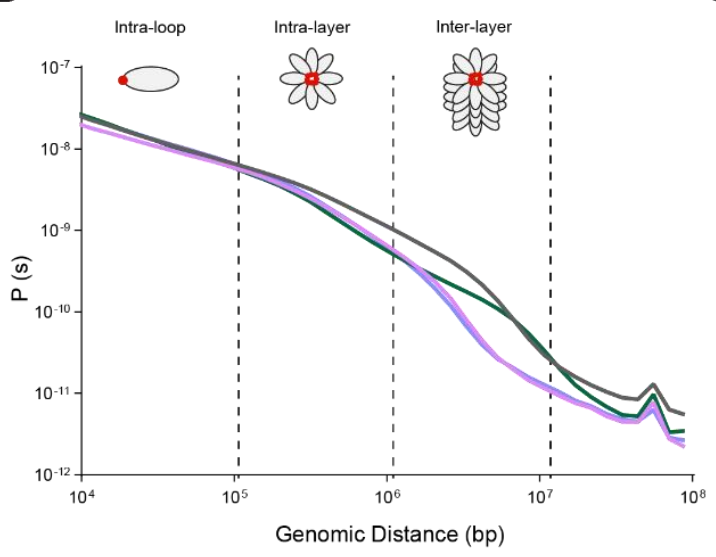

$-\Delta \operatorname{lgG}-\Delta \mathrm{H} 1-\Delta \mathrm{H} 1 \Delta \mathrm{CAP}-\mathrm{G}-\Delta \mathrm{H} 1 \Delta \mathrm{CAP}-\mathrm{D} 3$

D

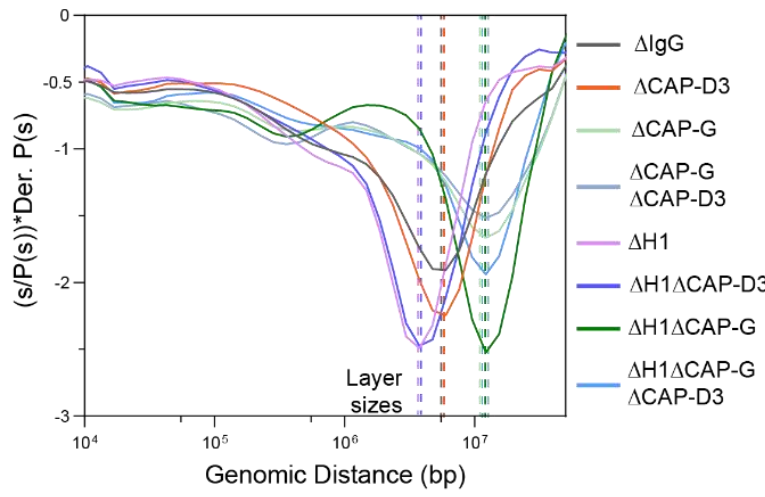

C

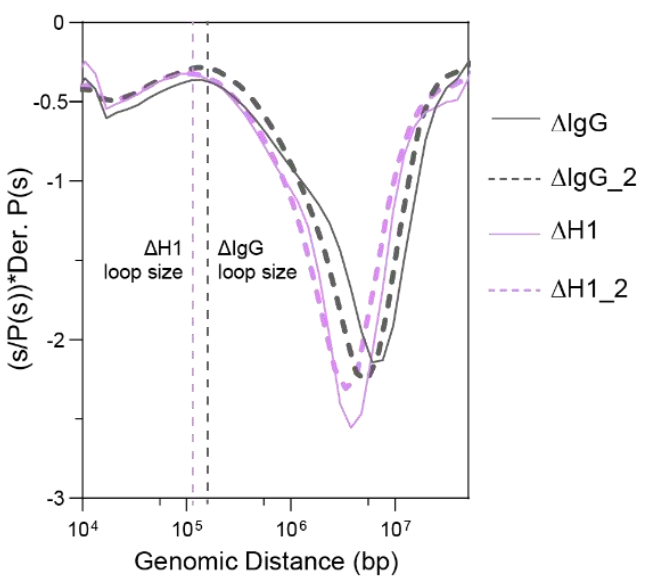

E

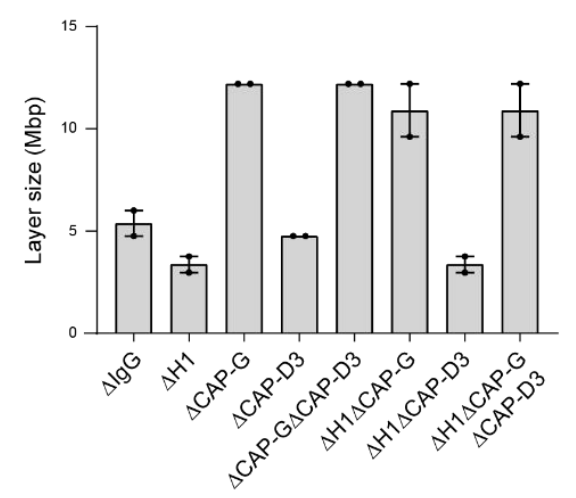

Figure 4. Effects of $\mathrm{H1}$ and/or condensin I, II depletion on mitotic genome folding

A) Hi-C maps of metaphase $X$. laevis chromosome $3 \mathrm{~S}$, binned to $250 \mathrm{~kb}$, in the indicated condition. B) Genome wide average contact probability decay curves for the indicated conditions showing the changes in longer distance interactions. C) Derivative plots of the average contact probability decay curves for dispersed chromosomes from mock $(\Delta \mathrm{IgG})$ and $\mathrm{H} 1.8$ depleted extracts $(\Delta \mathrm{H} 1)$ showing the change in estimated loop size. The solid and dotted lines are from two independent biological replicates. D) Derivative plots of the genome wide average contact probability decay curves in the indicated conditions. The dotted lines indicate the layer sizes for each plotted condition. E) Estimates of layer size from derivatives of genome wide probability decay curves upon depletion of H1.8 and CAP-G (condensin I) or CAP-D3 (condensin II). The mean and range of two biological replicates is shown.

Figure S6- Effects of H1, condensin I and condensin II depletion on mitotic genome folding

Figure S7- H3-H4 depletion leads to even smaller loop sizes 
H1.8 depletion (Figure 4C). The derivative plots from these dispersed chromosomes showed a betterdefined peak, allowing a more precise loop size estimate of $140 \mathrm{~kb}$ in $\Delta \mathrm{IgG}$ extracts and $110 \mathrm{~kb}$ in $\Delta \mathrm{H} 1$ extracts. These loop sizes are comparable to the estimated size of condensin I-driven loops in DT40 and HeLa cells (Gibcus et al., 2018; Naumova et al., 2013).

$P(s)$ plots for mitotic chromosomes display three regimes that are typical for relatively stiff rodshaped conformation (Gibcus et al., 2018; Naumova et al., 2013): for small genomic distance the contact probability is dominated by interactions between pairs of loci located within loops (up to 1-200 kb). For loci separated by up to a few megabases, the contact probability decays slowly with genomic distance. These interactions mostly reflect contacts between loci located in different loops which are relatively closely packed as a radial layer of loops around the central axis (intra-layer regime). The third regime is characterized by a steep decay in contact probability at several megabases. This represents pairs of loci separated by a relatively large distance along the axis of the rod-shaped chromosome so that they very rarely interact (inter-layer regime). The size of these layers can be obtained from the derivative of $P(s)$, where the steep drop in contact probability curve is marked by sharp drop in the derivative value. For control chromosomes the average amount of DNA in each layer of loops (layer size) was approximately $5 \mathrm{Mb}$, given the steep decay in contact probability observed for loci separated by more than $5 \mathrm{Mb}$ for both replicates (Figure 4B, 4D). For H1.8 depleted chromosomes we observed a smaller layer size of around 3.5 Mb (Figure 4B, 4D). This 1.5-fold reduction of DNA content of each layer would explain the observed 1.5-fold increase in chromosome length (Figure 3D). Further, we can derive the number of loops per layer by dividing the layer size by the loop size in the corresponding condition. In both control $(\Delta \mathrm{IgG})$ and $\mathrm{H} 1.8$ depleted extracts $(\Delta \mathrm{H} 1)$, the number of loops per layer was $\sim 40$. This indicates that the change in the layer size upon $\mathrm{H} 1.8$ depletion is a result of decreased loop size, while the number of loops per layer is not affected.

The layer size in H1.8/condensin I co-depleted extracts $(\Delta \mathrm{H} 1 \Delta \mathrm{CAP}-\mathrm{G})$ was larger than those in control extracts $(\Delta \operatorname{IgG})$ (Figure $4 \mathbf{D}, \mathbf{4 E})$. This is consistent with the shorter chromosomes in $\Delta \mathrm{H} 1 \Delta \mathrm{CAP}-\mathrm{G}$ extracts than in control $\Delta \mathrm{IgG}$ extracts (Figure 3D, 3F). Condensin II co-depletion $(\Delta \mathrm{H} 1 \Delta \mathrm{CAP}-\mathrm{D} 3)$ did not affect the layer size $(3.5$ $\mathrm{Mb}$ ) and also the chromosome length (Figure 4D, 4E,
3D). Condensin II depletion alone ( $\triangle$ CAP-D3) also did not affect the layer size, consistent with the observed lack of change in the chromosome length (Figure 4D, 4E, Figure S5A). Taken together, these data support the hypothesis that H1.8 limits the condensin I level on chromatin and shortens chromosome lengths, allowing each condensin I to form a longer loop, and consequentially tuning the amount of DNA present in each layer. The data also suggest that unlike in chicken DT 40 cells, condensin I and not condensin II plays the dominant role in the organization of loop layers (Gibcus et al., 2018).

Since condensin I binding to DNA is also limited by nucleosomes (Kong et al., 2020; Shintomi et al., 2017; Zierhut et al., 2014), we expected that loss of nucleosomes would similarly reduce the loop and layer sizes. To test this, we depleted $\mathrm{H} 3-\mathrm{H} 4$ tetramers using an antibody to acetylated lysine 12 of histone H4 (H4K12ac)(Zierhut et al., 2014), and generated metaphase chromosomes for Hi-C (Figure S7A). Since $X$. laevis sperm contains preloaded paternal H3-H4 (Shechter et al., 2009), the number of nucleosomes in our metaphase chromosomes was expected to be reduced by at most $50 \%$. As nucleosomes occupy a large majority of the genomic DNA (Chereji et al., 2019; Lee et al., 2007), even a partial histone depletion $(\Delta \mathrm{H} 3-\mathrm{H} 4)$ increased chromatin bound condensin I beyond that of H1.8 depletion $(\Delta H 1)$ (Figure S7B). Consequentially, the layer size in $\Delta \mathrm{H} 3-\mathrm{H} 4$ extracts became much smaller (around $500 \mathrm{~kb}$ ) than in $\Delta \mathrm{H} 1$ extracts (Figure S7C). Assuming that the number of loops per layer is similar in these chromosomes ( 40), the loop size estimate is $12 \mathrm{~kb}$, which is much shorter than in $\mathrm{H} 1.8$ depletion. Altogether these results suggest that global occupancy of nucleosomes and linker histones can affect DNA loop size and chromosome through controlling the number of condensin molecules on the chromatin fiber. 
bioRxiv preprint doi: https://doi.org/10.1101/2020.12.20.423657; this version posted April 12, 2021. The copyright holder for this preprint (which was not certified by peer review) is the author/funder, who has granted bioRxiv a license to display the preprint in perpetuity. It is made available under aCC-BY-NC-ND 4.0 International license.

Choppakatla et al., April 2021-preprint copy- BioRxiv
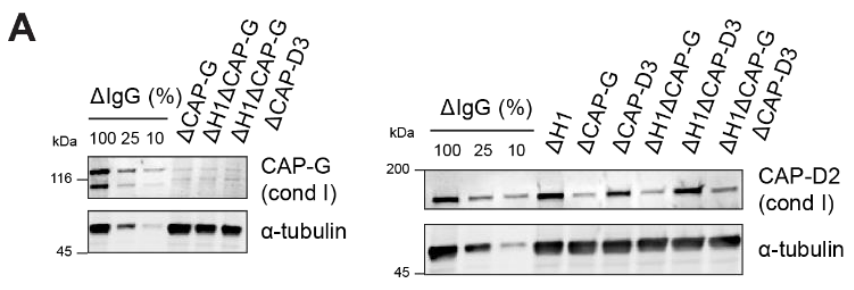

B

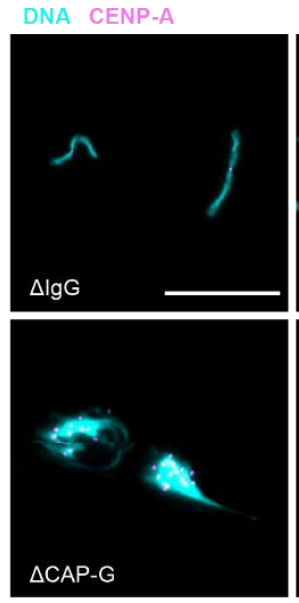

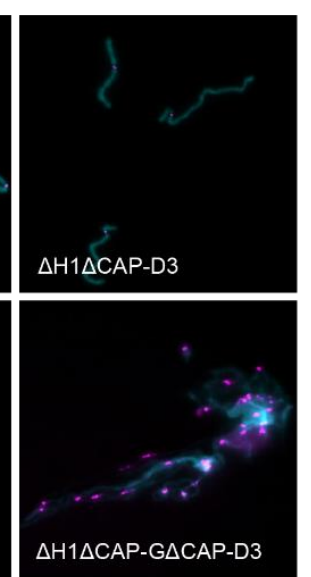

C
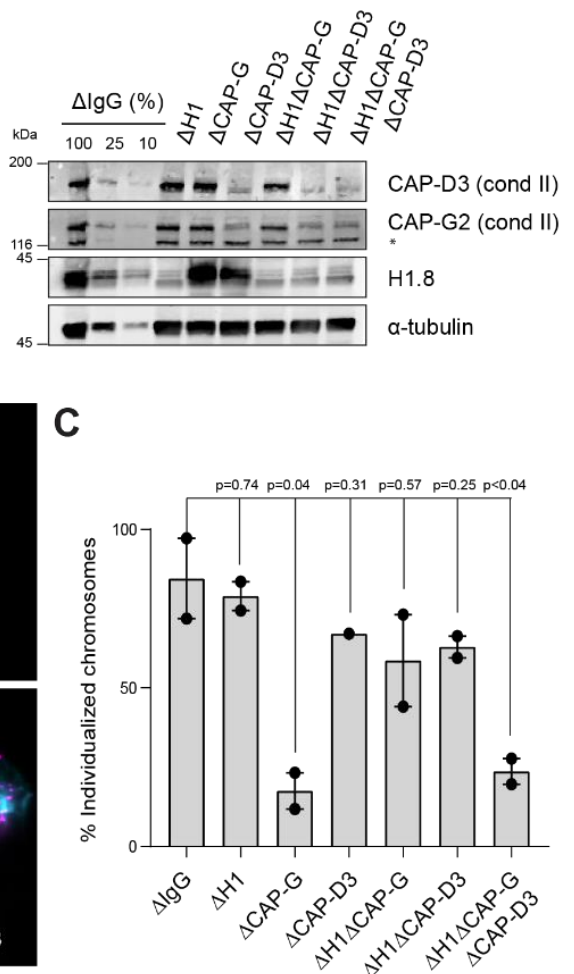
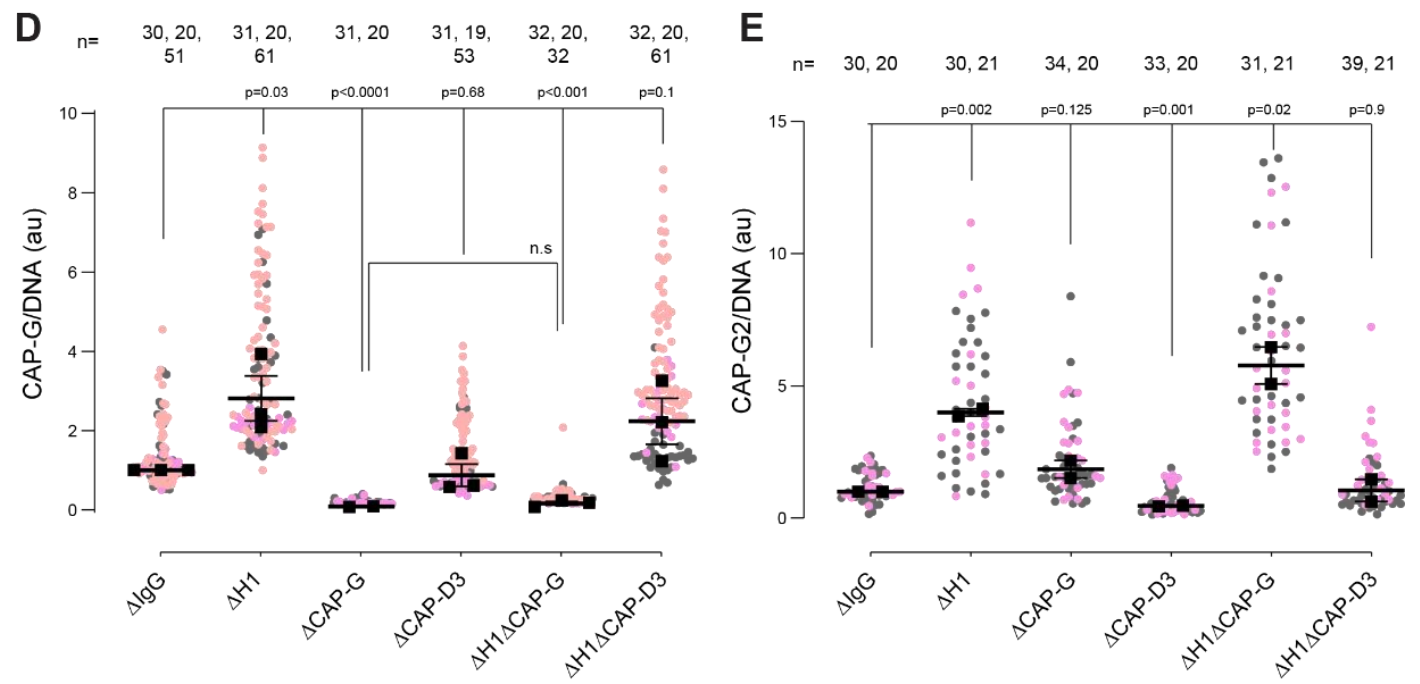

Figure 5. H1.8 suppresses condensin to limit chromosome individualization

A) Western blots of total egg extracts showing depletion levels in extract of condensin I and condensin II using the CAP-G and CAP-D3 antibodies respectively. * represents non-specific band B) Representative images of chromosomes after extract dilution, which disperses individualized chromosomes. DNA and centromere-associated CENP-A immunofluorescence are shown. Bar, $20 \mu \mathrm{m}$. C) Percent frequency of individualized chromosomes (chromosomes in DNA masses with <4 CENP-A foci) in the indicated conditions. A large majority of DNA masses with no CENPA foci are derived from $\triangle$ CAP-D3 extracts, where CENP-A loading is compromised (Bernad et al., 2011). DNA masses and CENP-A foci were identified using Otsu's thresholding algorithm and CENP-A foci in a binarized DNA mask were counted. The numbers of DNA masses counted in each condition were as follows: $\Delta \operatorname{IgG}(502,643), \Delta \mathrm{H} 1(1279,839), \Delta \mathrm{CAP}-\mathrm{G}(447,170), \Delta \mathrm{CAP}-\mathrm{D} 3(937), \Delta \mathrm{H} 1 \Delta \mathrm{CAP}-\mathrm{G}(1565,301)$, $\Delta$ H1 $\Delta$ CAP-D3 $(1536,300), \Delta$ H1 $\Delta$ CAP-G $\Delta$ CAP-D3 $(300,156)$. D) Quantification of CAP-G (condensin I) immunofluorescence normalized to the DNA signal for the indicated conditions. Each grey or orange dot represents the average signal intensity of a single chromosome cluster (from one nucleus). Each black dot represents the median signal intensity from a single experiment. Bars represent mean and range of the medians of two independent experiments. E) Quantification of CAP-G2 (condensin II) immunofluorescence intensity, normalized to the DNA signal for the indicated conditions. Each grey or magenta dot represents the average signal intensity of a single chromosome cluster (from one nucleus). Each black dot represents the median signal intensity from a single experiment. Bars represent mean and range of the medians of two independent experiments. The p-values in C, D and E were calculated by an unpaired Student's $t$-test. The number of nuclei imaged in each condition in D and $\mathrm{E}$ in each experiment are indicated above the figures.

Figure S8- Regulation of chromosome individualization by topo II, condensins and H1.8 in Xenopus egg extracts 


\section{H1.8 suppresses condensin-driven mitotic chromosome individualization.}

Condensins and topo II act in concert to generate mitotic chromosomes from decondensed interphase nuclei (Cuvier and Hirano, 2003). Both experimental observations and in silico experiments also suggest that condensin can drive complete decatenation of sister-chromatids (Goloborodko et al., 2016a; Marko, 2009; Nagasaka et al., 2016). Condensin is also required to keep decatenating sister chromatids in metaphase (Piskadlo et al., 2017). Although it has been suggested that condensin-mediated chromosome compaction promotes chromosome individualization (Brahmachari and Marko, 2019; Sun et al., 2018), it remains to be established if different linear chromosomes (non-sisters) are catenated with each other even after completion of mitotic compaction since Ki-67 on chromosome surfaces may act as a barrier to prevent interchromosomal DNA interaction during mitosis (Cuylen et al., 2016). To investigate if substantial interchromosomal entanglements exist in metaphase Xenopus egg extracts, we examined if the topo II inhibitor ICRF-193 blocks chromosome individualization after mitotic chromosome compaction (Figure S8A). While chromosomes clustered on the metaphase spindle in DMSO-treated control extracts were effectively dispersed into individualized chromosomes after diluting extracts, most chromosomes remained clustered when ICRF193 was added at the beginning of mitotic induction and incubated for $50 \mathrm{~min}$ (Figure S8B, C, ICRF-50 min). Even when ICRF-193 was added to metaphase egg extracts after completion of metaphase spindle formation, but 2 min before extract dilution (Figure S8A, bottom), efficiency of chromosome individualization decreased (Figure S8B, C, ICRF-2 min). These results suggest that substantial interchromosomal topological catenations remain unresolved in metaphase.

We then asked if H1.8-mediated suppression of condensins limits chromosome individualization and resolution of interchromosomal linkages. If so, H1.8 depletion may reduce the minimum required level of condensin activities to support chromosome individualization. In metaphase mock-depleted $(\Delta \mathrm{IgG})$ and $\mathrm{H} 1.8$-depleted $(\Delta \mathrm{H} 1)$ extracts with replicated chromosomes, the dilution procedure (Figure 3A) resulted mostly in physically separated single chromosomes but also a small number of clumped chromosomes (Figure 5B, Figure S9B). To better quantify chromosome individualization, we measured the number of CENP-A foci in each distinct chromatin mass (Figure S8D). Note that each centromere pair in a chromosome is counted as one focus, and we defined individualized chromosomes as chromosomes present in DNA masses containing less than 4 CENP-A foci (Figure 5C; this threshold was to include largely individualized chromosomes that stochastically come into contact- counting chromosomes in DNA masses having $<2$ foci yielded a similar result- Fig S8E). Condensin I depletion ( $\triangle \mathrm{CAP}-\mathrm{G})$ resulted in defective chromosome individualization, suggesting that condensin I activity drives resolution of interchromosomal entanglements, and that condensin II is not sufficient to resolve these interchromosomal links in this background. Strikingly, co-depletion of H1.8 and condensin I ( $\Delta \mathrm{H} 1 \Delta \mathrm{CAP}-\mathrm{G})$ almost completely rescued chromosome individualization without detectable CAP-G on chromatin (Figure 5AD). This apparent bypass of condensin I requirement in chromosome individualization required condensin II as chromosome individualization failed in the triple-depleted extracts $(\Delta \mathrm{H} 1 \Delta \mathrm{CAP}-\mathrm{G} \Delta \mathrm{CAP}-\mathrm{D} 3)$ (Figure 5B, C). The increased condensin II in $\Delta \mathrm{H} 1 \Delta \mathrm{CAP}-\mathrm{G}$ extracts may replace the function of condensin I by condensin II in the absence of H1.8 (Figure 5E). These results demonstrate that H1.8mediated suppression of condensin enrichment on chromatin limits chromosome individualization during mitosis.

\section{H1.8 prevents chromosomes from hyper- individualization by suppressing condensins and topo II}

We next examined the functional significance of H1.8-mediated suppression of TOP2A enrichment on mitotic chromosomes (Figure 1C-E), asking if H1.8 depletion could reduce the required TOP2A level in extracts for chromosome individualization. Complete loss of TOP2A inhibits decompaction of sperm nuclei, a process associated with replacement of protamines with histones (Adachi et al., 1991), so we addressed this question using extracts partially depleted of TOP2A (Figure 6A). We first generated nuclei with replicated chromosomes in extracts containing the normal level of TOP2A, and then the extracts were diluted with $\triangle \mathrm{TOP} 2 \mathrm{~A}$ extracts to reduce the total TOP2A level to $25 \%$ (Figure S9A). Under this condition, the level of chromosomeassociated TOP2A also reduced to $25 \%$ (Figure 6B). 
bioRxiv preprint doi: https://doi.org/10.1101/2020.12.20.423657; this version posted April 12, 2021. The copyright holder for this preprint (which was not certified by peer review) is the author/funder, who has granted bioRxiv a license to display the preprint in perpetuity. It is made available under aCC-BY-NC-ND 4.0 International license.

Choppakatla et al., April 2021-preprint copy- BioRxiv

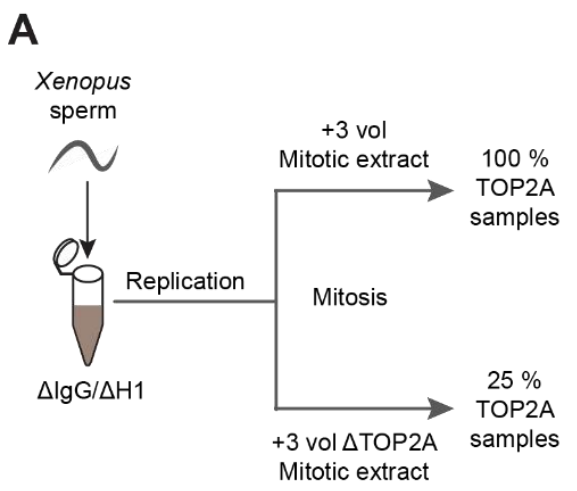

D

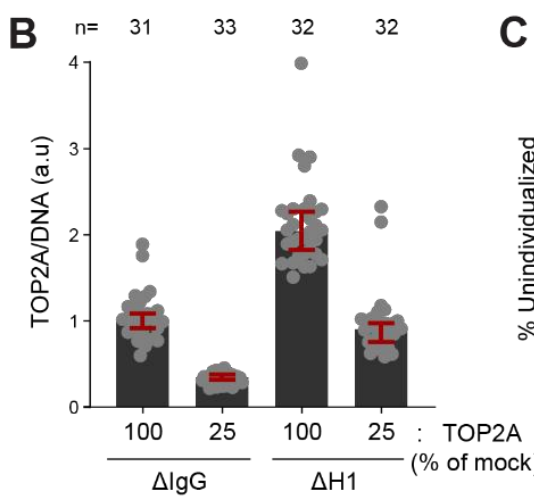

E

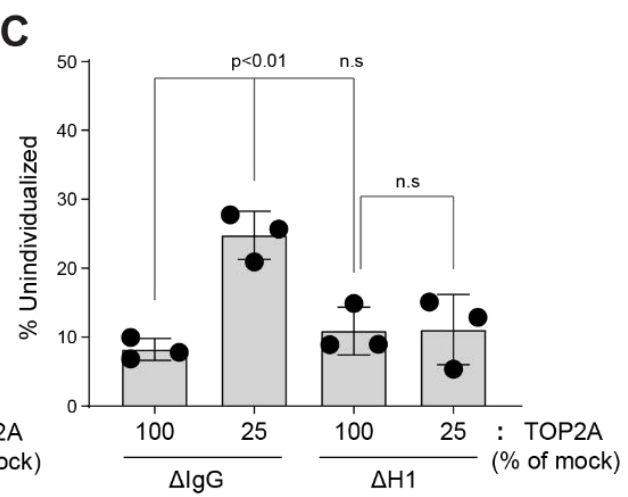

$\mathbf{F}$
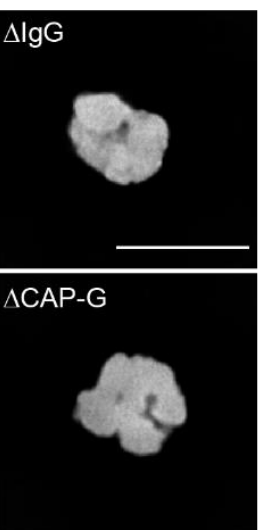

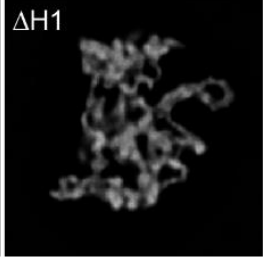

$\triangle H 1 \triangle C A P-G$

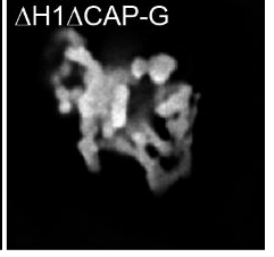

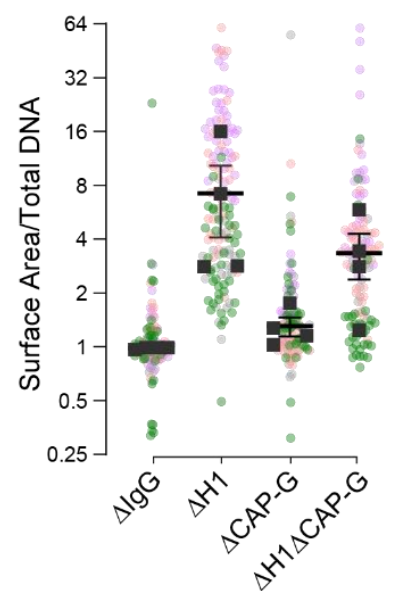

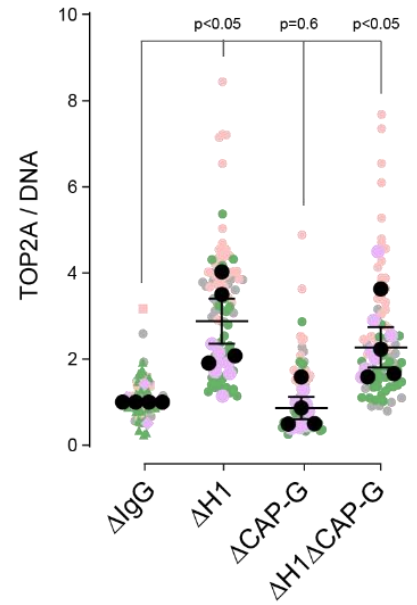

G

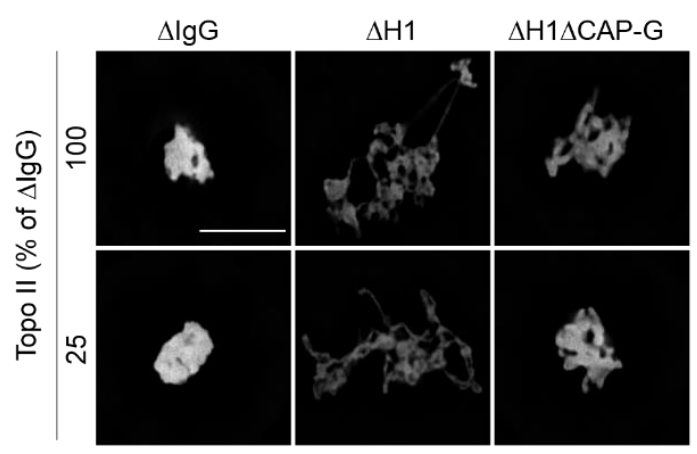

$\mathbf{H} \quad \mathrm{n}=\begin{array}{llllll}31 & 35 & 33 & 40 & 35 & 29\end{array}$

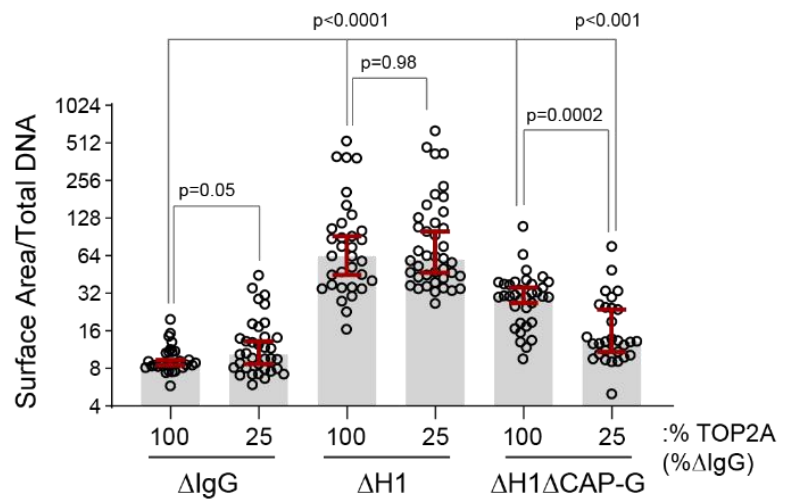

Figure 6. H1.8 suppresses hyper-individualization through condensins and topo II

A) Schematic of partial TOP2A depletion to test sensitivity of chromosome individualization to TOP2A levels. B) Quantification of chromosomeassociated TOP2A upon partial TOP2A depletion. Each dot represents the mean of TOP2A intensity normalized to DNA intensity of a single chromosome cluster (from one nucleus). The data plotted is median +/- $95 \%$ C.I. C) Percent frequency of DNA clusters categorized as unindividualized nuclei (Figure S9B) upon partial TOP2A depletion. Mean and S.E.M from three independent experiments. Each dot represents the percentage of unindividualized chromosome clusters in the indicated condition in an independent biological replicate. D) Representative images of nuclei using DNA (Cy5-dUTP) showing the clustering phenotype in the indicated conditions. Scale bar, $10 \mu \mathrm{m}$. E) Quantification of the threedimensional surface area of the chromosome clusters in D) normalized to DNA (Cy5-dUTP) signal. Each gray, magenta, green or orange dot represents the normalized surface area of single nucleus or chromosome cluster and each black square represents the median surface area of a single experiment. Data plotted is mean and S.E.M of four independent experiments. F) Quantification of TOP2A immunofluorescence intensity normalized to the DNA signal for the indicated conditions. Each grey or magenta dot represents the average signal intensity of a single chromosome cluster (from one nucleus). Each grey, magenta, orange or grey dot represents the median signal intensity from a single experiment. Mean and S.E.M of the median of four independent experiments are also shown. G) Representative images of nuclei using DNA (Cy3-dUTP) showing the clustering phenotype in the indicated conditions. Scale bar, $10 \mu \mathrm{m}$. H) Quantification of the three-dimensional surface area of the chromosome clusters in G) normalized to DNA (Cy3-dUTP) signal. Each black open circle represents the normalized surface area of single nucleus or chromosome cluster. Data plotted is median and $95 \%$ C.I. The p-values in C and F were calculated by an unpaired Student's t-test and the pvalues in $\mathrm{H}$ were calculated by a two-tailed Mann-Whitney $U$ test. The number of nuclei imaged in each condition for each experiment in $\mathrm{E}, \mathrm{F}$ and $\mathrm{H}$ are indicated above the figure.

Figure S9. H1.8 suppresses over-individualization through condensins and topo II 
Upon reduction of TOP $2 A$ to $25 \%$, the frequency of unindividualized chromosome clusters increased about 3 -fold in $\Delta \mathrm{IgG}$ background (Figure 6C). However, in the absence of H1.8, extracts with $25 \%$ levels of TOP2A were still able to support maximum level of chromosome individualization as chromosome-associated levels of TOP2A became equivalent to untreated control extracts (Figure 6C). These data suggest that chromosome individualization is sensitive to TOP2A levels on chromatin, and that H1.8 suppression of TOP2A plays a role in suppressing chromosome individualization.

Since the purpose of mitosis is to equally segregate chromosomes to dividing cells, it may seem odd that H1.8 suppresses TOP2A and condensins to limit chromosome individualization. In many cells, the spindle gathers the individualized mitotic chromosomes at the metaphase plate before chromosomes are ready for segregation. In Xenopus egg extracts, however, even when spindle assembly is inhibited using nocodazole, all chromosomes from one nucleus tightly cluster into a single mass (Figures 1C, 6D). In contrast, individual chromosomes were more readily distinguished by DNA staining and spread to larger area in $\Delta \mathrm{H} 1$ extracts, suggesting that the H1.8 mediated suppression of chromosome individualization is responsible for the chromosome clustering when spindle assembly is compromised. To quantify this phenotype, we measured the three-dimensional surface area of these chromosomes. The severe chromosome clustering defect in $\mathrm{H} 1.8$ depleted $(\Delta \mathrm{H} 1)$ extracts resulted in higher surface area than chromosomes in control $(\Delta \mathrm{IgG})$ extracts (Figure 6D, 6E). While condensin I depletion alone ( $\triangle \mathrm{CAP}-\mathrm{G})$ showed no significant differences to control $(\Delta \mathrm{IgG})$ extracts, condensin I co-depletion partially rescued the chromosome clustering defect of H1.8 depletion $(\Delta \mathrm{H} 1 \Delta \mathrm{CAP}-\mathrm{G})$. Notably, chromosomes were more spread in $\triangle \mathrm{H} 1 \Delta \mathrm{CAP}-\mathrm{G}$ extracts than in $\triangle \mathrm{IgG}$ extracts, despite the shorter average chromosome length in $\Delta \mathrm{H} 1 \Delta \mathrm{CAP}-\mathrm{G}$ extracts (Figure 3D, 3F), suggesting that chromosome spreading upon $\mathrm{H} 1.8$ depletion is not primarily driven by chromosome elongation but by chromosome hyper-individualization. Since TOP2A is enriched on chromosomes upon H1.8 depletion in a condensin-independent manner (Figure 6F, S9C), we then asked if this increased TOP2A plays a role in this increased chromosome spreading. Partial TOP2A depletion had no effect on clustering in control $(\triangle \mathrm{IgG})$ background since these nuclei were already tightly packed together (Figure
6G, 6H- $25 \%$ TOP2A). TOP2A depletion in H1.8 depleted extracts also did not revert the chromosome spreading despite that TOP2A levels on these chromosomes became comparable to control $(\Delta \mathrm{IgG}-$ $100 \%$ ) levels (Figure 6G, 6H), perhaps because increased condensin loading can compensate for reduced TOP2A activity. However, partial TOP2A depletion reduced chromosome spreading in $\mathrm{H} 1.8 /$ condensin I co-depleted $(\Delta \mathrm{H} 1 \Delta \mathrm{CAP}-\mathrm{G})$ extracts, suggesting that suppression of both condensin and topo II by $\mathrm{H} 1.8$ keeps egg extract chromosomes together during mitosis even in the absence of spindle microtubules.

\section{$\underline{\text { Discussion }}$}

It has been thought that the linker histone H1 promotes local chromatin compaction through stabilizing linker DNA and facilitating nucleosomenucleosome interaction (Li et al., 2016; Song et al., 2014; White et al., 2016). Here we demonstrated that $\mathrm{H} 1.8$ also plays a major role in regulation of longrange DNA interaction through controlling chromatin loading of condensins and topo II. Although condensins and topo II are activated in mitosis to drive chromosome segregation (Hirano and Mitchison, 1991; Kimura et al., 1998), we showed that their functionalities are antagonized by H1.8 to tune chromosome length and prevent hyperindividualization, which increases surface area (Figure 7). Thus, the linker histone H1, which can promote local chromatin compaction through promoting nucleosome-nucleosome interaction, can also suppress chromosome dispersion that is driven by condensins and topo II that organize the longrange DNA folding.

Nucleosomes reduce binding of condensins to DNA in vitro (Kong et al., 2020), in vivo (ToselliMollereau et al., 2016) and in Xenopus egg extracts (Shintomi et al., 2017; Zierhut et al., 2014). Now we showed that the linker histone H1.8 limits binding of condensin I and II to chromatin both in vitro and in Xenopus egg extracts. H1.8 suppressed condensin binding on both mononucleosomes and nucleosome arrays, suggesting that $\mathrm{H} 1.8$ is able to compete out condensins for the same linker DNA targets, though the capacity of linker histones to promote higher order structures or phase separation may also limit the access of condensin (Gibson et al., 2019; Song et al., 2014). Since chromosome lengths can be dictated by the amount of condensins (Figure 3F), we propose that regulating the linker histone that limits 
chromatin-loading of condensins could serve as a rheostat to control chromosome length (Figure 7).

Since the average loop size is an aggregate result of loop extrusion rate, processivity and number of loop extruders (Alipour and Marko, 2012; Goloborodko et al., 2016b), it is unclear from our data whether H1.8 affects the loop extrusion kinetics of a single condensin molecule. However, our observation is consistent with the in silico simulation showing that increasing the number of loop extruders makes chromosomes thinner and longer by reducing average loop size (Goloborodko et al., 2016a). Similar DNA loop shortening accompanied with increased condensin I loading was also reported on integrated fission yeast genome DNA segments in mouse and human chromosomes (Fitz-James et al., 2020). Reduced condensin loading due to mutations in condensin I or expression of phosphomimetic H3 mutants in human cells also lead to reduced chromosome length (Elbatsh et al., 2019). Condensin binding is similarly suppressed by nucleosomes, but loop extrusion proceeds unhindered through sparsely distributed nucleosomes (Kong et al., 2020). Since the length of chromosomes with similar condensin I levels is unaffected by the presence of H1.8 (Figure 3E, 3F), H1.8 may increase the loop size by simply reducing the number of condensin molecules on chromatin but may not necessarily inhibit the loop extrusion rate or processivity.

The regulatory mechanisms of TOP $2 \mathrm{~A}$ recruitment to mitotic chromatin are less clear than those of condensins. TOP2A is a DNA binding protein that may also bind histone tails (Lane et al., 2013). Similar to condensin, both TOP $2 A$ and TOP2B preferentially localize at active and highly transcribed chromatin indicating a possible preference for nucleosome free regions (Canela et al., 2017; Thakurela et al., 2013; Yu et al., 2017). We observe that TOP2A levels on chromatin increase upon linker histone depletion in egg extracts and that linker histone inhibits TOP2A binding to nucleosome arrays in vitro, suggesting that a similar rheostat like mechanism for controlling TOP2A levels on mitotic chromatin by controlling $\mathrm{H} 1$ stoichiometry is possible. The preference of topo II for binding linker DNA may also explain the observation of well-spaced TOP2B binding peaks around the well-spaced nucleosomes around the CTCF- binding sites (Canela et al., 2017, 2019). However, in contrast to our finding that more TOP2A associates with elongated chromosomes in $\Delta \mathrm{H} 1$ extracts, depletion of topo II leads to elongated chromosomes in vertebrate somatic cell lines and in early embryos of Caenorhabditis elegans (Farr et al., 2014; Ladouceur et al., 2017; Nielsen et al., 2020; Samejima et al., 2012). It is unclear whether these observations suggest that increased topo II activity would lead to shorter chromosomes. One possibility is that impaired decatenation due to reduced topo II may interfere with condensin-mediated loop formation, leading to shorter loop size and thinner chromosomes as reported. On the other hand, excess topo II on chromatin, as seen in $\Delta \mathrm{H} 1$ extracts, may not affect chromosome shape.

Our data also suggest that condensins and topo II combine to resolve extensive and persistent interchromosomal topological entanglement during mitotic compaction in Xenopus egg extracts (Figure S8), but these activities are counterbalanced by H1.8. In HeLa cells, some variants of $\mathrm{H} 1$ are phosphorylated and evicted along the interchromatid axis. This partial $\mathrm{H} 1$ eviction in prophase seems to be required for complete decatenation along the chromosome arms (Krishnan et al., 2017). This suggests that local enrichment of condensin II upon H1 eviction may play a role in sister chromatid decatenation. In contrast, $\mathrm{H} 1.8$ binding to nucleosomes is enhanced upon transition from interphase to $\mathrm{M}$ phase in Xenopus egg extracts (Arimura et al., 2020). It might be counterintuitive that activities of condensins and topo II are actively antagonized by $\mathrm{H} 1.8$ to suppress chromosome individualization. Since spindle assembly in oocytes relies on chromatin-induced microtubule nucleation (Heald et al., 1996), keeping chromosomes at metaphase plate might be important for maintaining robust bipolar spindle. As we showed that H1.8 is important for chromosome clustering when spindle assembly is inhibited (Figure 6), this microtubuleindependent chromosome clustering may be particularly important for the large oocyte and early embryonic cells since it would be difficult to assemble a bipolar spindle onto all the chromosomes once they disperse into the large space of the cytoplasm. Clustering chromosomes through incomplete individualization may also avoid generation of chromosomes that do not associate with the spindle. Such a mechanism may be particularly important during early embryonic cell divisions when the spindle checkpoint cannot be activated by unattached chromosomes (Gerhart et al., 1984; Hara et al., 1980; Mara et al., 2019). 


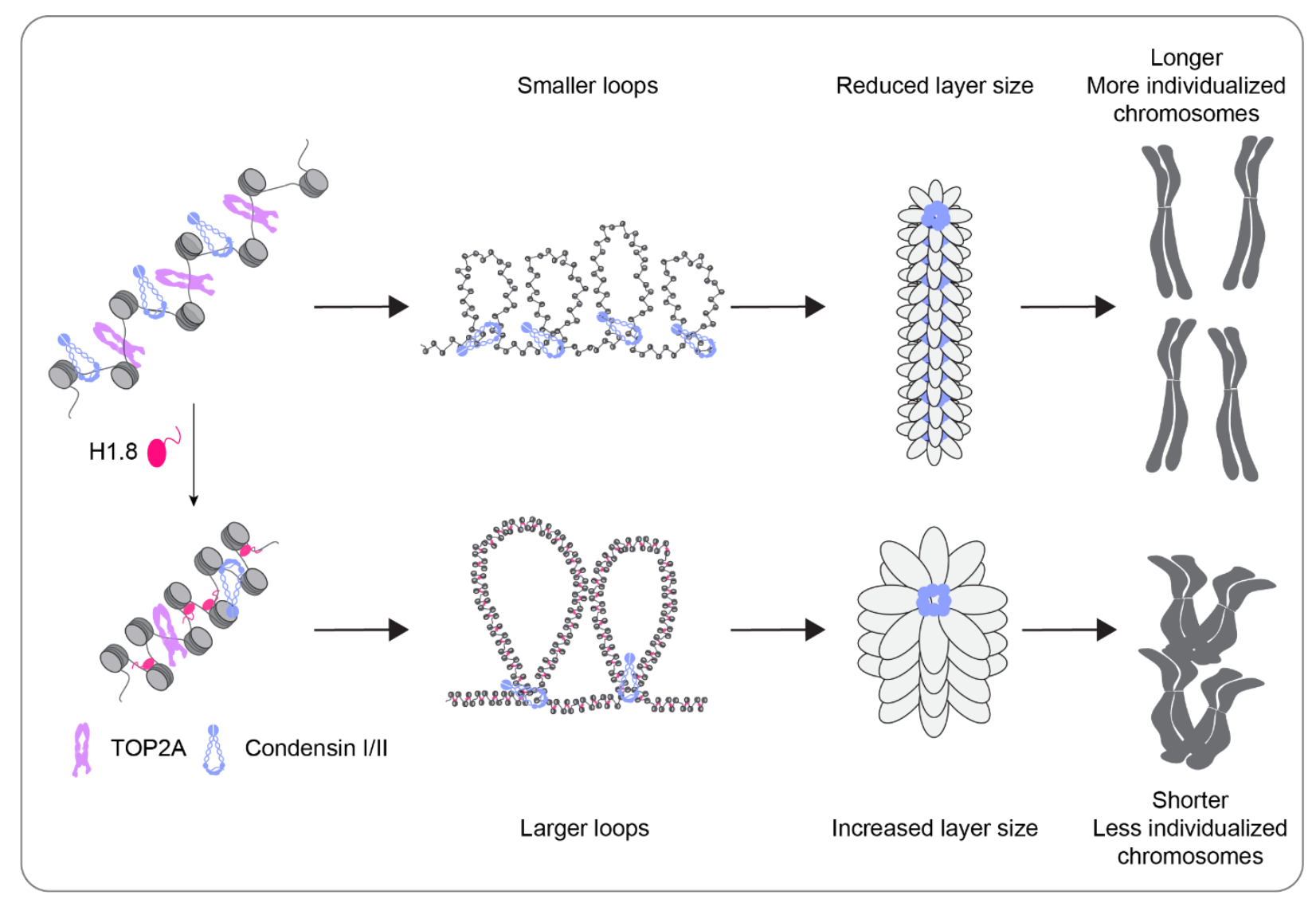

Figure 7. A graphical model of how $\mathbf{H 1 . 8}$ controls mitotic chromosome length

In the absence of H1.8, more condensins and topo II bind to more DNA loops of shorter length, resulting in longer and more individualized chromosomes (top). H1.8 limits chromatin levels of condensins and topo II to generate longer and thus fewer DNA loops, resulting in shorter and less individualized chromosomes (bottom).

Another possible reason for the suppressed individualization is related to the fact that oocyte chromosomes completely lose cohesion from arms at the end of meiosis I, while maintaining sister chromatid cohesion only at the centromeres (Lister et al., 2010). Normally, this centromeric cohesion is critical for supporting the kinetochore tension to establish bipolar attachment. During long natural arrest at meiotic metaphase II, these centromeres undergo cohesion fatigue, where centromeres prematurely separate. However, proper segregation may still be accomplished due to apparent interchromatids DNA linkages (Gruhn et al., 2019). Resolution of these DNA linkages may be prevented by H1.8-mediated suppression of condensin and TOP2A. However, our data do not eliminate the possibility that H1.8 plays a condensin and TOP2A independent role in regulating chromosome individualization. Regulation of Ki-67, which coats the surface of chromosomes, may be a good candidate of H1-mediated regulation (Cuylen et al., 2016; Gibson et al., 2019; White et al., 2016).

Linker histones are a dynamic component of chromatin (Misteli et al., 2000). Linker histone occupancy varies widely (Woodcock et al., 2006), and can be controlled by both the linker histone variant and their posttranslational modifications (Christophorou et al., 2014; Hergeth and Schneider, 2015; Th'ng et al., 2005). We expect that changing the $\mathrm{H} 1$ stoichiometry on chromatin by changing the amount, subtype and/or affinity (e.g., through posttranslational modifications) of $\mathrm{H} 1$ affects the length and individualization of chromosomes through regulating the levels of condensins and topo II. In Xenopus embryos, exogenously added somatic linker histone variants, but not $\mathrm{H} 1.8$, are evicted from mitotic chromatin (Freedman and Heald, 2010). H1.8 is also more preferentially enriched on mitotic chromatin than on interphase chromatin in Xenopus egg extracts (Arimura et al., 2020), suggesting that loading of condensins and topo II to chromatin is actively limited by modulating mitotic $\mathrm{H} 1$ loading in oocytes and early embryos. Shortening chromosome length would reduce time and distance to complete chromosome segregation in rapidly dividing early embryonic cells. In addition, reducing the chromosome surface by shortening chromosomes may contribute to rapid completion of nuclear envelope formation. This is particularly important during early embryonic cell cycle in Xenopus, since 
the nuclear envelope encapsulates each individual chromosome in late anaphase to form the karyomere, in which DNA replication can be accomplished (Lemaitre et al., 1998).

Linker histones serve important interphase roles through regulation of transcription (Izzo et al., 2008), and the epigenetic landscape of the chromatin determines the linker histone variant on chromatin (Izzo et al., 2013; Parseghian et al., 2001; Th'ng et al., 2005). Since H1.8 competitively inhibits

\section{Data availability}

The Hi-C datasets used in the paper are available in the GEO under accession no. GSE164434.

\section{$\underline{\text { Acknowledgments }}$}

We thank C. Zierhut for providing $\Delta \mathrm{H} 3-\mathrm{H} 4$ depleted extracts for Hi-C analysis; S. Rankin, T. Hirano, Y. Azuma for sharing reagents; C. Jenness for anti-H1.8 antibodies; J. F. Martinez and M. P. Rout for their help with purifying TOP2A; A. North, C. Rico and K. Cialowicz at Bioimaging resource center (BIRC) for help with imaging; Y. Arimura, R. Heald, L. Mirny, A. Vannini and C. Zierhut and members of the Funabiki lab for helpful discussions. This work was supported by NIH grant R35 GM132111 to H.F and NIH grant HG003143 to J.D. J.D. is an investigator of the Howard Hughes Medical Institute. A.V is supported by a Cancer Research UK Programme Foundation (CR-UK C47547/A21536) and a Wellcome Trust Investigator Award (200818/Z/16/Z).

\section{$\underline{\text { Author Contributions }}$}

P.C. conducted all experiments except for Hi-C library preparation, which was done by B.D. P.C., B.D., J.D. and H.F. analyzed Hi-C data. E.E.C. prepared human condensin I and II complexes. P.C., E.E.C., A.V. and H.F. analyzed in vitro condensin binding data. P.C. and H.F. designed the experiments and wrote the paper. B.D., E.E.C. and J.D. edited the paper. A.V. commented on the paper. H.F. oversaw the entire project. condensin binding in mitosis, it is tempting to speculate that linker histones also inhibit condensin II and cohesin binding in interphase. We suggest that local and global regulation of chromatin structure and function can be regulated by controlling differential expression of linker histone $\mathrm{H} 1$ variants and their modifications not just through promoting inter-nucleosomal interactions but also by controlling accessibility of SMC proteins and topo II.

\section{$\underline{\text { Experimental Model and Subject Details }}$}

\section{Xenopus laevis frogs}

Mature female pigmented $X$. laevis frogs (NASCOLM00535MX) were maintained in a temperaturecontrolled room $\left(16-18^{\circ} \mathrm{C}\right)$ using a recirculating water system at The Rockefeller Comparative BioScience Center (CBC). Frogs were temporarily moved to a satellite facility for ovulation and egglaying according to protocols approved by the IACUC (Protocol number 20031).

\section{$\underline{\text { Method Details }}$}

\section{Antibodies}

H3 was detected with ab1791 (Abcam; $1 \mu \mathrm{g} / \mathrm{ml}$ for western blots). H2B was detected with ab1790 (Abcam; $1 \mu \mathrm{g} / \mathrm{ml}$ for western blots). $\alpha$-tubulin was detected with T9026 (Sigma; 1:10000 for western blots).

H1.8 was detected using anti-H1M (H1.8) antibody (Jenness et al. 2018; $1 \mu \mathrm{g} / \mathrm{ml}$ for western blots). AntiTOP2A was a gift from Y. Azuma (Ryu et al. 2010; $1 \mu \mathrm{g} / \mathrm{ml}$ for western blots and IF). Anti-CAPD2 was a gift from T. Hirano (Hirano, Kobayashi, and Hirano 1997; $2 \mu \mathrm{g} / \mathrm{ml}$ for western blots). Anti-CAPG2 was a gift from S. Rankin $(4 \mu \mathrm{g} / \mathrm{ml}$ for IF, $2 \mu \mathrm{g} / \mathrm{ml}$ for western blots). xCAP-G (Zierhut et al., 2014) and xCAP-D3 custom antibodies were used at $2 \mu \mathrm{g} / \mathrm{ml}$ for western blots and $1 \mu \mathrm{g} / \mathrm{ml}$ for IF. CENP-A was detected using an antibody against N-terminal 50 amino acids of CENP-A (Wynne and Funabiki, 2015) and used at $4 \mu \mathrm{g} / \mathrm{ml}$ for IF.

xCAP-G antibody was also conjugated to Alexa488 using the Alexa488-NHS ester (Thermo-Fisher Scientific) using the manufacturer's instructions. The conjugated antibody was purified using the Sephadex G-25 in PD-10 desalting column (Cytiva). The 
conjugated antibody was dialyzed into $\mathrm{PBS}+50 \%$ glycerol and stored in aliquots at $-80^{\circ} \mathrm{C}$ after freezing with liquid nitrogen. The labelled antibody was used at $4 \mu \mathrm{g} / \mathrm{ml}$ for IF.

IRDye 680LT Goat anti-Mouse IgG (H+L), IRDye 680LT Goat anti-Rabbit IgG (H+L), IRDye $800 \mathrm{CW}$ Goat anti-Mouse $\operatorname{IgG}(\mathrm{H}+\mathrm{L})$ and IRDye $800 \mathrm{CW}$ Goat anti-Rabbit $\operatorname{IgG}(\mathrm{H}+\mathrm{L})$ were used at 1:15000 (LI-COR Biosciences) dilution for western blots. Alexa 488, Alexa 555 and Alexa 647 conjugated secondary antibodies (Jackson Immunoresearch) were used for IF.

\section{Antibody production}

XCAP-D3 C-terminal peptide

(CRQRISGKAPLKPSN) was synthesized at The Rockefeller University Proteomics Resource Center). The peptide was then coupled to the keyhole limpet hemocyanin according to the manufacturer's protocol (Thermo-Fisher Scientific) and used to immunize rabbits (Cocalico Biologicals). Antibody was purified from the immunized rabbit sera using affinity purification against the same peptide coupled to SulfoLink resin (Thermo-Fisher Scientific). The antibody was dialyzed into PBS+ 50\% glycerol and stored with the addition of $0.05 \%$ sodium azide.

\section{Xenopus egg extracts and Immunodepletion}

Cytostatic Factor (CSF) arrested X. laevis egg extracts were generated as previously described (Murray, 1991). To generate replicated mitotic chromosomes, $0.3 \mathrm{mM} \mathrm{CaCl} 2$ was added to CSF arrested extracts containing $X$. laevis sperm to cycle the extracts into interphase at $20^{\circ} \mathrm{C}$. Ninety minutes after adding $\mathrm{CaCl}_{2}$, half the volume of fresh CSF extract and $40 \mathrm{nM}$ of the non-degradable cyclin $\mathrm{B} \Delta 90$ fragment were added to interphase extracts to induce mitotic entry (Glotzer et al., 1991; Holloway et al., 1993). After $60 \mathrm{~min}$ of incubation, extracts were processed for morphological and biochemical assessments. For all experiments involving immunofluorescence, $10 \mathrm{nM}$ nocodazole was added along with the cyclin $\mathrm{B} \Delta 90$.

For immunodepletions of 50-100 $\mu$ l extracts, 250 $\mu \mathrm{g} / \mathrm{ml}$ antibodies were conjugated to Protein-A coupled Dynabeads (Thermo Fisher Scientific) either at room temperature for $60 \mathrm{~min}$ or overnight at $4{ }^{\circ} \mathrm{C}$. Mock (IgG) and H1.8 (H1) antibody beads were crosslinked using $4 \mathrm{mM} \mathrm{BS}_{3}$ (Thermo Fisher Scientific) at room temperature for $45 \mathrm{~min}$ and quenched using $10 \mathrm{mM}$ Tris-HCl (Sigma). All antibody beads were washed extensively using Sperm Dilution Buffer (SDB; 10 mM HEPES, 1mM
$\mathrm{MgCl}_{2}, 100 \mathrm{mM} \mathrm{KCl}, 150 \mathrm{mM}$ Sucrose) and separated from the buffer using a magnet before addition of extract. H1.8 depletions $(\Delta \mathrm{H} 1)$ were performed with two 45 min rounds of depletion at 4 ${ }^{\circ} \mathrm{C}$ using 2 volumes of antibody-coupled beads for each round. For condensin I and condensin II depletions, 1.5-2 volumes of xCAP-G or xCAP-D3 antibody-coupled beads were used in a single round for depletion for $60 \mathrm{~min}$ at $4{ }^{\circ} \mathrm{C}$. For double depletion of condensin I and II, a single round of depletion using 1.5 volume each of $\mathrm{xCAP}-\mathrm{G}$ and $\mathrm{xCAP}-\mathrm{D} 3$ antibody-coupled beads was performed. For TopoII depletions $(\triangle \mathrm{TOP} 2 \mathrm{~A})$, a single round of depletion was performed using 1.2 volume of anti-TopoII $\alpha$ coupled antibody beads for $60 \mathrm{~min}$ at $4{ }^{\circ} \mathrm{C}$. After the incubations, the beads were separated using a magnet.

\section{$\underline{\text { Western blots }}$}

For total egg extract samples, $1 \mu \mathrm{l}$ sample was added to 25 ul $1 \mathrm{x}$ sample buffer $(50 \mathrm{mM}$ Tris- $\mathrm{HCl} \mathrm{pH} 6.8$, $2 \%$ SDS, 10\% Glycerol, $2.5 \% \beta$-mercaptoethanol) and boiled for $10 \mathrm{~min}$. Samples were spun at 8000 $\mathrm{rpm}$ for $3 \mathrm{~min}$ before gel electrophoresis and overnight transfer at $4{ }^{\circ} \mathrm{C}$. Blotting membranes were blocked with $4 \%$ powdered skim-milk (Difco). Primary and secondary antibodies were diluted in LICOR Odyssey blocking buffer-PBS (LI-COR Biotechnology). Western blots were imaged on a LICOR Odyssey. Quantifications were done using Image-J.

\section{$\underline{\mathrm{Hi}-\mathrm{C}}$}

\section{Standard samples}

$10^{6} \mathrm{X}$. laevis sperm nuclei were added to $150 \mu 1$ interphase extract and allowed to replicate at $21{ }^{\circ} \mathrm{C}$ for $90 \mathrm{~min}$. The extracts were cycled back into mitosis by adding $100 \mu \mathrm{l} \mathrm{CSF}$ extract, $40 \mathrm{nM}$ of the non-degradable cyclin $\mathrm{B} \Delta 90$ and $10 \mu \mathrm{M}$ nocodazole (Sigma). After $60 \mathrm{~min}$ at metaphase, the samples were diluted into $12 \mathrm{ml}$ of fixing solution $(80 \mathrm{mM} \mathrm{K}$ PIPES pH 6.8, $1 \mathrm{mM} \mathrm{MgCl2}, 1 \mathrm{mM}$ EGTA, 30\% glycerol, $0.1 \%$ Triton X-100, $1 \%$ formaldehyde) and incubated at room temperature with rocking for 10 min. The samples were then quenched with $690 \mu 1$ $2.5 \mathrm{M}$ glycine for $5 \mathrm{~min}$ at room temperature. The samples were then placed on ice for $15 \mathrm{~min}$ and then centrifuged at $6000 \mathrm{~g}$ at $4{ }^{\circ} \mathrm{C}$ for $20 \mathrm{~min}$. The pellet was then resuspended in $1 \mathrm{ml}$ ice-cold DPBS. The tube was then centrifuged again at $13000 \mathrm{~g}$ for $20 \mathrm{~min}$ at $4{ }^{\circ} \mathrm{C}$. The buffer was aspirated, and the pellet was frozen in liquid nitrogen and then stored at $-80{ }^{\circ} \mathrm{C}$. 


\section{Dispersed chromosome samples}

The metaphase chromosome samples were prepared as above, but nocodazole was omitted. The metaphase extracts were diluted by adding $1.2 \mathrm{ml}$ chromosome dilution buffer (10 mM K-HEPES $\mathrm{pH}$ 8, $200 \mathrm{mM} \mathrm{KCl,} 0.5 \mathrm{mM}$ EGTA, $0.5 \mathrm{mM} \mathrm{MgCl}_{2}, 250$ $\mathrm{mM}$ Sucrose) and incubated at room temperature for 8 min. $6 \mathrm{ml}$ fixation buffer $(5 \mathrm{mM}$ K-HEPES pH 8 , $0.1 \mathrm{mM}$ EDTA, $100 \mathrm{mM} \mathrm{NaCl}, 2 \mathrm{mM} \mathrm{KCl}, 1 \mathrm{mM}$ $\mathrm{MgCl}_{2}, 2 \mathrm{mM} \mathrm{CaCl} 2,0.5 \%$ Triton X-100, 20\% glycerol, $1 \%$ formaldehyde) was added to the tube, mixed by rotation $10 \mathrm{~min}$ at room temperature. 420 ul 2.5 M glycine was added to quench the formaldehyde and the mixture was incubated for 5 min at room temperature. The samples were then placed on ice for $15 \mathrm{~min}$ and then centrifuged at 6500 $\mathrm{g}$ at $4{ }^{\circ} \mathrm{C}$ for $20 \mathrm{~min}$. The pellet was then resuspended in $1 \mathrm{ml}$ ice-cold DPBS. The tube was then centrifuged again at $13000 \mathrm{~g}$ for $20 \mathrm{~min}$ at $4{ }^{\circ} \mathrm{C}$. The buffer was aspirated, and the pellet was frozen in liquid nitrogen and then stored at $-80{ }^{\circ} \mathrm{C}$.

Two biological replicates were performed for each sample, and they confirmed similar behavior among the replicates.

\section{Library prep and sequencing}

$\mathrm{Hi}-\mathrm{C}$ protocol was performed as previously described (Belaghzal et al., 2017), with exception that cell disruption by douncing was omitted. Briefly, pellets were digested by DpnII overnight at $37{ }^{\circ} \mathrm{C}$ prior to biotin fill-in with biotin-14-dATP for $4 \mathrm{~h}$ at $23{ }^{\circ} \mathrm{C}$. After ligation at $16{ }^{\circ} \mathrm{C}$ for $4 \mathrm{~h}$, crosslinking was reversed by proteinase $\mathrm{K}$ at $65^{\circ} \mathrm{C}$ overnight. Purified ligation products were sonicated with $200 \mathrm{bp}$ average size, followed by $100-350$ bp size selection. End repair was performed on size selected ligation products, prior to purifying biotin tagged DNA fragments with streptavidin beads. A-tailing was done on the purified DNA fragments followed by Illumina Truseq adapter ligation. Hi-C library was finished by PCR amplification and purification to remove PCR primers. Final library was sequenced on Illumina HiSeq 4000 with PE50.

\section{Hi-C Data Processing}

Hi-C fastq files were mapped to the Xenopus laevis 9.2 genome with the distiller-nf pipeline (https://github.com/open2c/distiller-nf). The reads were aligned with bwa-mem, afterwards duplicate reads were filtered out. These valid pair reads were aggregated in genomic bins of 10, 25, 50, 100, 250, $500 \mathrm{~kb}$ using the cooler format (Abdennur and Mirny,
2019). Cooler files were balanced using Iterative balancing correction (Imakaev et al., 2012), ignoring first two diagonals to avoid artifacts within the first bin such as re-ligation products. Contact heatmaps from balanced cooler files were viewed and exported with Higlass (Kerpedjiev et al., 2018).

\section{Contact Probability $(P(s))$ and derivatives}

Contacts probability were calculated by contact frequency $(P)$ as function of genomic distance $(s)$. Interaction pairs were selected for genomic distance from $1 \mathrm{~kb}$ till $100 \mathrm{mb}$ binned at log-scale. Within each genomic bin observed number of interactions were divided by total possible number of interactions within the bin. Distance decay plots were normalized by total number interactions, derivative plots were made from corresponding $P(s)$. The derivative plots plotted in Figure 4C, 4D, Figure S6D were drawn using LOESS smoothing.

\section{$\underline{\text { Immunofluorescence }}$}

Immunofluorescence was performed according to previously published protocols (Desai et al., 1998). $10 \mu 1$ metaphase extracts containing chromosomes were diluted into $2 \mathrm{ml}$ of fixing solution $(80 \mathrm{mM} \mathrm{K}$ PIPES pH 6.8, $1 \mathrm{mM} \mathrm{MgCl}, 1 \mathrm{mM}$ EGTA, $30 \%$ glycerol, $0.1 \%$ Triton $\mathrm{X}-100,2 \%$ formaldehyde) and incubated at room temperature for $7 \mathrm{~min}$. The fixed chromosomes were then laid onto a cushion $(80 \mathrm{mM}$ K-PIPES pH 6.8, 1 mM MgCl 2,1 mM EGTA, 50\% glycerol) with a coverslip placed at the bottom of the tube and centrifuged at $5000 \mathrm{~g}$ for $15 \mathrm{~min}$ at $18^{\circ} \mathrm{C}$ in a swinging bucket rotor. The coverslips were recovered and fixed with methanol $\left(-20^{\circ} \mathrm{C}\right)$ for $4 \mathrm{~min}$. The coverslips were then blocked overnight with antibody dilution buffer (50 mM Tris-Cl pH 7.5, 150 $\mathrm{mM} \mathrm{NaCl}, 2 \% \mathrm{BSA})$. Primary and secondary antibodies were diluted in antibody dilution buffer and sealed in Prolong Gold AntiFade mounting media (Thermo-Fisher Scientific).

For coverslips stained with Alexa488-anti-CAP-G antibody (Figure 1C, 3E, 5D, 5E), coverslips stained with primary and secondary antibodies were washed three times with PBS-T (1x PBS +0.5\% Tween-20). Then, they were blocked with $100 \mu \mathrm{g} / \mathrm{ml}$ rabbit IgG or $30 \mathrm{~min}$ and were incubated with Alexa488-antixCAP-G antibody without any washing steps in between. The coverslips were then washed three times with PBS-T and then sealed in Prolong Gold AntiFade mounting media (Thermo-Fisher Scientific).

Chromosome individualization 
bioRxiv preprint doi: https://doi.org/10.1101/2020.12.20.423657; this version posted April 12, 2021. The copyright holder for this preprint (which was not certified by peer review) is the author/funder, who has granted bioRxiv a license to display the preprint in perpetuity. It is made available under aCC-BY-NC-ND 4.0 International license.

Choppakatla et al., April 2021-preprint copy- BioRxiv

Chromosome dilution was performed as before with some modifications (Funabiki and Murray, 2000). 40 $\mu 1$ Chromosome Dilution Buffer (10 mM K-HEPES $\mathrm{pH} \mathrm{8,} 200 \mathrm{mM} \mathrm{KCl}, 0.5 \mathrm{mM}$ EGTA, $0.5 \mathrm{mM} \mathrm{MgCl}$, $250 \mathrm{mM}$ Sucrose) was added to $10 \mu \mathrm{l}$ metaphase extract containing chromosomes and incubated at room temperature for $8 \mathrm{~min}$. $200 \mathrm{ul}$ fixation buffer $(5$ mM K-HEPES pH 8, $0.1 \mathrm{mM}$ EDTA, $100 \mathrm{mM} \mathrm{NaCl}$, $2 \mathrm{mM} \mathrm{KCl}, 1 \mathrm{mM} \mathrm{MgCl}, 2 \mathrm{mM} \mathrm{CaCl}_{2}, 0.5 \%$ Triton $\mathrm{X}-100,20 \%$ glycerol, $2 \%$ formaldehyde) was added to the tube and incubated for $10 \mathrm{~min}$ at room temperature. The samples were laid over a cushion $(5$ mM K-HEPES pH 8, 0.1 mM EDTA, $100 \mathrm{mM} \mathrm{NaCl}$, $2 \mathrm{mM} \mathrm{KCl}, 1 \mathrm{mM} \mathrm{MgCl} 2,2 \mathrm{mM} \mathrm{CaCl}_{2}, 50 \%$ glycerol) with a coverslip placed under the cushion and centrifuged at $7000 \mathrm{~g}$ for $20 \mathrm{~min}$ at $18{ }^{\circ} \mathrm{C}$ in a swinging bucket rotor. The coverslips were recovered and fixed with ice-cold methanol for $4 \mathrm{~min}$, washed extensively and blocked overnight with antibody dilution buffer (50 mM Tris- $\mathrm{Cl} \mathrm{pH} 7.5,150$ $\mathrm{mM} \mathrm{NaCl}, 2 \%$ BSA). CENP-A immunofluorescence was performed on these coverslips for Figure 5B, 5C, S8D, E.

\section{Chromosome purification}

One volume of metaphase extracts with $\sim 3000 / \mu 1$ sperm nuclei was diluted into 3 volumes of DB2 (10 mM K-HEPES, $50 \mathrm{mM} \beta$-glycerophosphate, $50 \mathrm{mM}$ NaF, 20 mM EGTA, 2 mM EDTA, $0.5 \mathrm{mM}$ spermine, $1 \mathrm{mM}$ phenylmethylsulfonyl fluoride, $200 \mathrm{mM}$ sucrose) and laid over $1 \mathrm{ml}$ cushion (DB2 with 50\% sucrose). The tube was centrifuged in a swinging bucket rotor at $10,000 \mathrm{~g}$ for $30 \mathrm{~min}$ at $4{ }^{\circ} \mathrm{C}$. Most of the cushion was aspirated and the pellet was resupended in the remaining solution and transferred to a fresh tube. The sample was centrifuged again at $13000 \mathrm{~g}$ for $15 \mathrm{~min}$ at $4{ }^{\circ} \mathrm{C}$. The pellet was then resuspended in 1x sample buffer and boiled for 10 min before being subject to gel electrophoresis.

\section{Image acquisition and analysis}

All the quantitative immunofluorescence imaging and some of the spindle imaging was performed on a DeltaVision Image Restoration microscope (Applied Precision) which is a wide-field inverted microscope equipped with a pco.edge sCMOS camera (pco). The immunofluorescence and surface area measurement samples were imaged with $\mathrm{z}$-sections of $200 \mathrm{~nm}$ width with a 100x (1.4 NA) objective and were processed with a iterative processive deconvolution algorithm using the SoftWoRx (Applied Precision). The dispersed chromosomes imaged for length measurements and chromosome individualization were imaged in five $1 \mu \mathrm{m}$ z-sections with a $63 \mathrm{x}(1.33$ NA) silicone oil objective.

More than twenty nuclei imaged for immunofluorescence and three-dimensional surface area quantification for most of the experiments for each condition. The differences in each experiment were analyzed using a two-tailed Mann-Whitney $U$ test. The data in Figures 1D, 1G, 3D, 5D, 5E, 6E, 6F, Figure S9C were combined data from multiple experiments, where the data were normalized to the control $(\Delta \operatorname{IgG})$ levels, whose medians were normalized to 1 for all conditions (Lord et al., 2020). The aggregate data were then analyzed using an unpaired Student's $t$-test.

For all the immunofluorescence quantifications, the maximum intensity single slice was selected, background subtraction was performed, and average intensities were calculated on a mask generated using the DNA signal. The analysis was performed using custom MATLAB (Mathworks) code available at https://github.com/pavancss/PC2021_microscopy

For surface area measurements, images were interpolated into stacks of $67 \mathrm{~nm}$ width. A surface mask was built in three-dimensional space and surface area and DNA signal was calculated using the regionprops3 MATLAB function. Only large objects $\left(>10000\right.$ pixel $\left.^{3}\right)$ were analyzed to compare significant fractions of each nucleus. The analysis was done automatically using custom MATLAB (Mathworks) code available at https://github.com/pavancss/PC2021_microscopy.

For the CENP-A foci counting in Figure 5C and Figure S8D, E, DNA and CENP-A were segmented by Otsu's thresholding algorithm. Each independent object in a binarized DNA image was treated as a single chromosomal mass and CENP-A foci were counted in each mass. This was done using custom MATLAB code available at https://github.com/pavancss/PC2021_microscopy.

For the categorization of unindividualized chromosomes in Figure 6C, a large area of coverslip was imaged in panels and all the observed DNA masses were counted and categorized as in Figure S9B in an unblinded fashion. The number of DNA masses counted in each condition in Figure 6C were: $\triangle \mathrm{IgG}-100 \%$ TOP2A $(201,128,146), \Delta \mathrm{IgG}-25 \%$ TOP2A $(155,177,144), \Delta H 1-100 \%$ TOP2A (447, $135,208), \Delta \mathrm{H} 1-25 \%$ TOP $2 \mathrm{~A}(232,187,171)$. 
For chromosome length measurements, > 54 chromosomes were measured in each experiment to ensure that a relatively even sampling of the 18 different chromosomes of each sperm nucleus was possible. Chromosome length measurements were done by manually tracing the chromosomes on a single maximum intensity slice in ImageJ $1.52 \mathrm{p}$.

\section{Mononucleosomes and nucleosome arrays}

Nucleosome arrays were prepared as previously noted (Guse et al., 2011; Zierhut et al., 2014). The plasmid pAS696 which contains 19 repeats of the Widom 601 nucleosome position sequence (Lowary and Widom, 1998) was digested with EcoRI, XbaI, HaeII and DraI. The fragment containing the array was isolated using polyethylene glycol-based precipitation. The ends of the DNA fragment were filled in with dATP, dGTP, dCTP and Bio-16-dUTP (Chemcyte) using Klenow DNA polymerase (NEB) and purified using Sephadex G-50 Nick columns (Cytiva Biosciences).

Mononucleosomal DNA were prepared by digesting pAS696 using AvaI. The 196 bp fragment was isolated using polyethylene glycol-based precipitation. The ends of the fragment were filled in with dATP, dGTP, dTTP and Alexa647-aha-dCTP (Thermo-Fisher Scientific) using Klenow DNA polymerase (NEB) and purified using Sephadex G50 Nick columns (Cytiva Biosciences).

For nucleosome deposition, $10 \mu \mathrm{g}$ of DNA arrays or mononucleosomal DNA was mixed with equimolar amount of $X$. laevis $\mathrm{H} 3-\mathrm{H} 4$ tetramer and twice equimolar amount of $X$. laevis $\mathrm{H} 2 \mathrm{~A}-\mathrm{H} 2 \mathrm{~B}$ dimers in 1x TE with $2 \mathrm{M} \mathrm{NaCl}$. The mixture was added into in a Slide-A-Lyzer dialysis cassette (Thermo-Fisher Scientific) and placed into $500 \mathrm{ml}$ High salt buffer (10 mM Tris-Cl pH $7.5 @ 4{ }^{\circ} \mathrm{C}, 2 \mathrm{M} \mathrm{NaCl}, 1 \mathrm{mM}$ EDTA, $5 \mathrm{mM} \beta$-mercaptoethanol, $0.01 \%$ Triton X$100)$. Salt was reduced in a gradient by pumping in 2 L of Low salt buffer $\left(10 \mathrm{mM}\right.$ Tris-Cl $\mathrm{pH} 7.5$ at $4{ }^{\circ} \mathrm{C}$, $100 \mathrm{mM} \mathrm{NaCl}, 1 \mathrm{mM}$ EDTA, $5 \mathrm{mM} \beta-$ mercaptoethanol, $0.01 \%$ Triton X-100) at constant volume at $1 \mathrm{ml} / \mathrm{min}$. The quality of the nucleosome arrays was ascertained by digesting the nucleosome arrays with AvaI overnight in low magnesium buffer (5 $\mathrm{mM}$ potassium acetate, $2 \mathrm{mM}$ Tris-acetate, 0.5 $\mathrm{mM}$ magnesium acetate, $1 \mathrm{mM}$ DTT, $\mathrm{pH}$ 7.9) and electrophoresed in a $5 \%$ polyacrylamide gel made in $0.5 \mathrm{x}$ TBE (45 mM Tris-borate, $1 \mathrm{mM}$ EDTA). The mononucleosomes were assayed by direct electrophoresis.

$\underline{\text { Nucleosome binding assays }}$
Nucleosome arrays were bound to M280 Streptavidin DynaBeads (Thermo-Fisher Scientific) in chromatin bead binding buffer $(50 \mathrm{mM}$ Tris-Cl $\mathrm{pH}$ $8,150 \mathrm{mM} \mathrm{NaCl}, 0.25 \mathrm{mM}$ EDTA, $0.05 \%$ Triton X$100,2.5 \%$ polyvinylalcohol) by shaking at $1300 \mathrm{rpm}$ for $3.5 \mathrm{~h}$. To block the Step tagged condensin complexes from binding the unconjugated streptavidin on the beads during the condensin pull downs, the beads were washed once in chromatin binding buffer and then incubated in $1 \mathrm{mM}$ Biotin in chromatin binding buffer by shaking at $1300 \mathrm{rpm}$ for 1 hour. The beads were then washed with chromatin binding buffer (50 mM Tris-Cl pH 8, $150 \mathrm{mM} \mathrm{NaCl}$, $0.25 \mathrm{mM}$ EDTA, $0.05 \%$ Triton X-100) three times, moved to a new tube, washed twice with SDB (10 $\mathrm{mM}$ HEPES, $1 \mathrm{mM} \mathrm{MgCl} 2,100 \mathrm{mM} \mathrm{KCl}, 150 \mathrm{mM}$ Sucrose) and split into two tubes. SDB with $0.0008 \%$ poly-glutamic acid (Sigma)(Stein and Künzler, 1983) was mixed with $400 \mathrm{nM}$ recombinant $\mathrm{xH} 1.8$ (buffer for control) and incubated for $5 \mathrm{~min}$ at room temperature. This mixture was incubated with the beads (half with buffer, half with $\mathrm{xH} 1.8$ ) with rotation at $16{ }^{\circ} \mathrm{C}$. The beads were then washed $1 \mathrm{x}$ with SDB and $1 \mathrm{x}$ with binding buffer $(10 \mathrm{mM}$ HEPES pH 8, $40 \mathrm{mM} \mathrm{NaCl}, 2.5 \mathrm{mM} \mathrm{MgCl} 2,0.5 \mathrm{mM}$ DTT, $0.05 \%$ Triton X-100). Beads were washed 2x with binding buffer with indicated assay salt concentration and resuspended in binding buffer with $100 \mathrm{nM}$ recombinant TOP2A, $380 \mathrm{nM}$ human condensin I, condensin I Q loop mutant or $320 \mathrm{nM}$ condensin II or condensin II Q loop mutant. The beads were rotated at room temperature for $30 \mathrm{~min}$. Total reaction samples were taken and the beads were washed three times on a magnet in binding buffer and moved to a new tube. The beads were collected on a magnet and resuspended in $1 \mathrm{x}$ sample buffer $(50 \mathrm{mM}$ Tris-HCl pH 6.8, $2 \%$ SDS, 10\% Glycerol, $2.5 \% \beta$ mercaptoethanol) and boiled for $5 \mathrm{~min}$. Gel electrophoresis was performed and the gels were stained with GelCode Blue Stain reagent (ThermoFisher Scientific).

\section{Condensin Gel Shift assays}

200 nM Alexa 647 labelled 196 bp mononucleosomes were mixed with $0.0008 \%$ polyglutamic acid (Sigma)(Stein and Künzler, 1983) and half was mixed with $400 \mathrm{nM}$ recombinant $\mathrm{xH} 1.8$ in $1 \mathrm{x}$ binding buffer $(10 \mathrm{mM}$ HEPES $\mathrm{pH} 8,50 \mathrm{mM}$ $\mathrm{NaCl}, 2.5 \mathrm{mM} \mathrm{MgCl}$, $5 \mathrm{mM}$ ATP, $0.5 \mathrm{mM}$ DTT, $0.05 \%$ Triton $\mathrm{X}-100$ ) and incubated for $30 \mathrm{~min}$ at room temperature. $100 \mathrm{nM}$ of the mononucleosomes with or H1.8 were mixed with the indicated concentration of condensin $\mathrm{I}$ in $1 \mathrm{x}$ binding buffer at 
bioRxiv preprint doi: https://doi.org/10.1101/2020.12.20.423657; this version posted April 12, 2021. The copyright holder for this preprint (which was not certified by peer review) is the author/funder, who has granted bioRxiv a license to display the preprint in perpetuity. It is made available under aCC-BY-NC-ND 4.0 International license.

$4{ }^{0} \mathrm{C}$ for 30 min and subject to electrophoresis onto a $5 \%$ polyacrylamide gel in $0.5 x \mathrm{TBE}$ at room temperature. The gels were imaged on a LICOR Odyssey (LI-COR Biotechnology). The binding curves were fitted using Graphpad Prism 8.4.3 using the sigmoidal binding curve option of the non-linear curve fitting.

\section{$\underline{\text { Protein purification }}$}

\section{H1.8}

A pET51b vector expressing Xenopus laevis H1.8 with an N-terminal Strep-Tag II and C-terminal 6x Histidine-tag was a gift from Rebecca Heald (UC Berkeley). E. coli Rosetta2 (DE3 pLysS) cells containing expression plasmids were grown in TBGM9 media (15 g/l tryptone, $7.5 \mathrm{~g} / 1$ yeast extract, $5 \mathrm{~g} / 1$ $\mathrm{NaCl}, 0.15 \mathrm{~g} / \mathrm{l} \mathrm{MgSO} 4,1.5 \mathrm{~g} / \mathrm{l} \mathrm{NH} 4 \mathrm{Cl}, 3 \mathrm{~g} / 1 \mathrm{KH}_{2} \mathrm{PO}_{4}$, $6 \mathrm{~g} / \mathrm{l} \mathrm{Na} \mathrm{HPO}_{4} ; 0.4 \%$ glucose) at $37{ }^{\circ} \mathrm{C}$ until they reach OD 0.6 and were supplemented with $1 \mathrm{mM}$ isopropylthio- $\beta$-galactoside (IPTG) and grown at 18 ${ }^{\circ} \mathrm{C}$ for $14 \mathrm{~h}$. Cells were collected and resuspend in lysis buffer (1x PBS, $500 \mathrm{mM} \mathrm{NaCl}, 10 \%$ glycerol, $20 \mathrm{mM}$ Imidazole, $0.1 \%$ Triton $\mathrm{X}-100,10 \mathrm{mM} \beta-$ mercaptoethanol, $1 \mathrm{mM}$ phenylmethylsulfonyl fluoride, $10 \mu \mathrm{g} / \mathrm{ml}$ leupeptin, $10 \mu \mathrm{g} / \mathrm{ml}$ pepstatin, 10 $\mu \mathrm{g} / \mathrm{ml}$ chymostatin ). All subsequent steps were carried out at $4{ }^{\circ} \mathrm{C}$. After $30 \mathrm{~min}$ incubation, the cell suspension was sonicated and centrifuged at $45000 \mathrm{~g}$ for $45 \mathrm{~min}$ at $4{ }^{\circ} \mathrm{C}$. The supernatant was added to $\mathrm{Ni}$ NTA beads (BioRad) and rotated for $60 \mathrm{~min}$. The beads were then washed with Wash Buffer 1 (1x PBS, $20 \mathrm{mM}$ imidazole, $500 \mathrm{mM} \mathrm{NaCl}, 4 \mathrm{mM} \beta$ mercaptoethanol, $10 \mathrm{mM}$ ATP, $2.5 \mathrm{mM} \mathrm{MgCl}_{2}$, cOmplete EDTA-free protease inhibitor cocktailRoche). The beads were eluted with NTA elution buffer (1x PBS, $400 \mathrm{mM}$ Imidazole, $500 \mathrm{mM} \mathrm{NaCl}$ ). The correct fractions were collected and dialyzed into PBS supplement with $500 \mathrm{mM} \mathrm{NaCl}$, concentrated using Amicon Ultra centrifugal filters (10k cutoff), flash frozen, aliquoted and stored at -80 ${ }^{\circ} \mathrm{C}$.

\section{TopoIIa}

$X$. laevis TOP2A tagged with calmodulin binding protein (CBP) was purified from $P$. pastoris yeast as reported (Ryu et al., 2010) with some modifications. Pichia pastoris integrated with a CBP tagged TOP2A cassette under the influence of an alcohol oxidase (AOX) promoter (a gift from Yoshiaki Azuma) were grown in BMGY media (1\% Yeast Extract, 2\% Peptone, $100 \mathrm{mM}$ potassium phosphate $\mathrm{pH} \mathrm{6,1.34 \%}$ Yeast Nitrogen Base, $4 \times 10^{-5} \%$ biotin, $1 \%$ glycerol) containing $50 \mu \mathrm{g} / \mathrm{ml}$ G418 (Thermo-Fisher
Scientific) at $30{ }^{\circ} \mathrm{C}$ until OD 4.0. The cells were collected by centrifugation and split into BMMY media (1\% Yeast Extract, 2\% Peptone, $100 \mathrm{mM}$ potassium phosphate $\mathrm{pH} 6,1.34 \%$ Yeast Nitrogen Base, $4 \times 10^{-5} \%$ biotin, $0.5 \%$ methanol) and grown at $22{ }^{\circ} \mathrm{C}$ for $14 \mathrm{~h}$. The cells were collected, packed into a syringe and extruded into liquid nitrogen in the form of noodles. These frozen noodles were lysed using a Retsch PM100 cryomill (Retsch) with continuous liquid nitrogen cooling. The cyromilled cells were then resuspended in Lysis Buffer $(150 \mathrm{mM}$ $\mathrm{NaCl}, 18 \mathrm{mM} \beta$-glycerophosphate, $1 \mathrm{mM} \mathrm{MgCl}_{2}$, 40mM HEPES ( $\mathrm{pH} 7.8$ ), 5\% glycerol, $0.1 \%$ Triton $\mathrm{X}-100,1 \mathrm{mM}$ DTT, cOmplete EDTA-free protease inhibitor tablet) and sonicated on ice. The cells were centrifuged at $35,000 \mathrm{~g}$ for $45 \mathrm{~min}$ at $4{ }^{\circ} \mathrm{C} .2 \mathrm{mM}$ $\mathrm{CaCl}_{2}$ was added to the supernatant along with Calmodulin-sepharose beads (Strategene) and the mixture was incubated at $4{ }^{\circ} \mathrm{C}$ for $120 \mathrm{~min}$. The beads were then washed with ATP-Wash Buffer (Lysis Buffer+ $5 \mathrm{mM} \mathrm{MgCl}_{2}, 2 \mathrm{mM} \mathrm{CaCl}_{2}, 1 \mathrm{mM}$ ATP), Wash Buffer 1 (Lysis Buffer $+2 \mathrm{mM} \mathrm{CaCl}_{2}$ ), Wash Buffer $2\left(300 \mathrm{mM} \mathrm{NaCl}, 1 \mathrm{mM} \mathrm{MgCl}, 2 \mathrm{mM} \mathrm{CaCl}_{2}\right.$, 20mM HEPES (pH 7.8), 5\% Glycerol, 1mM DTT) and then eluted into Elution Buffer $(300 \mathrm{mM} \mathrm{NaCl}$, $1 \mathrm{mM} \mathrm{MgCl} 2$, 5mM EGTA, 20mM HEPES (pH 7.8), $5 \%$ glycerol, $1 \mathrm{mM}$ DTT).

The eluted protein was then passed through a MonoQ anion exchange column (Cytiva) on an AKTA-FPLC (Cytiva) to separate co-purified DNA. The flowthrough was then digested with TEV protease to cleave the CBP tag and then loaded on a HiTrap Heparin HP column (Cytiva) on an AKTA-FPLC and eluted using a salt gradient of $150 \mathrm{mM} \mathrm{NaCl}$ to $1 \mathrm{M}$ $\mathrm{NaCl}$. The selected fractions were then loaded on a Superose 6 gel filtration column (Cytiva) and eluted in Freezing buffer $\left(250 \mathrm{mM} \mathrm{NaCl}, 1 \mathrm{mM} \mathrm{MgCl}_{2}\right.$, 20mM HEPES pH 7.8, 5\% glycerol, 1mM DTT). The protein was then concentrated and frozen in aliquots at $-80{ }^{\circ} \mathrm{C}$.

\section{Condensins}

Human condensin complexes were purified as described previously (Kong et al., 2020). Briefly, the five subunits of human condensin I and II, subcomplexes and Q-loop mutations and were assembled into biGBac vectors (Weissmann et al., 2016) to create baculovirus for protein expression in HighFive insect cells. Cell were lysed in condensin purification buffer (20 mM HEPES [pH 8], $300 \mathrm{mM}$ $\mathrm{KCl}, 5 \mathrm{mM} \mathrm{MgCl}_{2}, 1 \mathrm{mM}$ DTT, $10 \%$ glycerol) supplemented with Pierce protease inhibitor EDTAfree tablet (Thermo Scientific) and Benzonase 
(Sigma). Cleared lysate was loaded on to a StrepTrap HP (GE), washed with condensin purification buffer and eluted with condensin purification buffer supplemented with $5 \mathrm{mM}$ Desthiobiotin (Sigma). Protein containing fractions were pooled, diluted 2fold with Buffer A (20 mM HEPES [pH 8], $5 \mathrm{mM}$ $\mathrm{MgCl}_{2}, 5 \%$ glycerol, $1 \mathrm{mM}$ DTT), loaded on to HiTrap Heparin HP column (GE), washed with Buffer A with $250 \mathrm{mM} \mathrm{NaCl}$, then eluted with buffer A with $500 \mathrm{mM} \mathrm{NaCl}$. Finally, size exclusion chromatography was performed using Condensin purification buffer and a Superose $616 / 70$ or increase 10/300 column (GE).

\section{Mass spectrometry}

Sperm chromosomes were purified as previously described (Funabiki and Murray, 2000). Briefly, extracts containing 8000/ $\mu \mathrm{l}$ sperm nuclei were replicated along with $5 \mathrm{mM}$ biotin-dUTP for $90 \mathrm{~min}$ and cycled back into metaphase with the addition of 1 volume of fresh CSF depleted (correspondingly

\section{$\underline{\text { References }}$}

Abdennur, N., and Mirny, L.A. (2019). Cooler: scalable storage for $\mathrm{Hi}-\mathrm{C}$ data and other genomically labeled arrays. Bioinformatics 36, 311316.

Abramo, K., Valton, A., Venev, S. V, Ozadam, H., Fox, A.N., and Dekker, J. (2019). A chromosome folding intermediate at the condensin-to-cohesin transition during telophase. Nat. Cell Biol. 21, 1393-1402.

Adachi, Y., Luke, M., and Laemmli, U.K. (1991).

Chromosome assembly in vitro: topoisomerase II is required for condensation. Cell 64, 137-148.

Alipour, E., and Marko, J.F. (2012). Selforganization of domain structures by DNA-loopextruding enzymes. Nucleic Acids Res. 40, 1120211212.

Arimura, Y., Shih, R.M., Froom, R., and Funabiki, H. (2020). Nucleosome structural variations in interphase and metaphase chromosomes. BioRxiv 2020.11.12.380386.

Bakhrebah, M., Zhang, T., Mann, J.R., Kalitsis, P., and Hudson, D.F. (2015). Disruption of a conserved CAP-D3 threonine alters condensin loading on mitotic chromosomes leading to chromosome hypercondensation. J. Biol. Chem. 290, 6156-6167. Banigan, E.J., and Mirny, L.A. (2020). Loop extrusion: theory meets single-molecule experiments. Curr. Opin. Cell Biol. 64, 124-138. Bauer, C.R., Hartl, T.A., and Bosco, G. (2012).
$\Delta \mathrm{IgG}$ or $\Delta \mathrm{H} 1)$. After $60 \mathrm{~min}$ in metaphase, these chromosomes were diluted in 3 volumes of DB (10 mM K-HEPES [pH 7.6], 100 mM KCl, 2 mM EDTA, $0.5 \mathrm{mM}$ EGTA, $0.5 \mathrm{mM}$ spermine, $250 \mathrm{mM}$ Sucrose, $1 \mathrm{mM}$ PMSF, and $10 \mu \mathrm{g} / \mathrm{ml}$ each of leupeptin, pepstatin, and chymostatin) and centrifuged through a $60 \mathrm{DB}$ cushion (DB with $60 \%(\mathrm{w} / \mathrm{v})$ sucrose). The collected chromosome enriched pellet was then incubated with $15 \mu \mathrm{l}$ streptavidin coupled DynaBeads (M280) and rotated at $4{ }^{0} \mathrm{C}$ for $2 \mathrm{~h}$. The beads were then collected, washed and boiled in sample buffer before running on a $6 \%$ polyacrylamide gel for $10 \mathrm{~min}$. The gel was stained with commassie blue and the protein containing gel fragments were cut out and processed for mass spectrometry. The mass spectrometry was performed at the Rockefeller University Proteomics Resource Center as previously described (Zierhut et al., 2014), but the peptides were queried against the $X$. laevis database (Wühr et al., 2014) using the MaxQuant software (Max-Planck Institute).

Condensin II Promotes the Formation of Chromosome Territories by Inducing Axial Compaction of Polyploid Interphase Chromosomes. PLoS Genet. 8, 1-12.

Bednar, J., Garcia-Saez, I., Boopathi, R., Cutter, A.R., Papai, G., Reymer, A., Syed, S.H., Lone, I.N., Tonchev, O., Crucifix, C., et al. (2017). Structure and Dynamics of a $197 \mathrm{bp}$ Nucleosome in Complex with Linker Histone H1. Mol. Cell 66, 384-397.e8. Belaghzal, H., Dekker, J., and Gibcus, J.H. (2017). Hi-C 2 . 0: An optimized Hi-C procedure for highresolution genome-wide mapping of chromosome conformation. Methods 123, 56-65.

Bernad, R., Sánchez, P., Rivera, T., Rodríguezcorsino, M., Boyarchuk, E., Vassias, I., Ray-gallet, D., Arnaoutov, A., Dasso, M., Almouzni, G., et al. (2011). HJURP and condensin II are required for CENP-A assembly. 192, 569-582.

Brahmachari, S., and Marko, J.F. (2019).

Chromosome disentanglement driven via optimal compaction of loop-extruded brush structures. Proc. Natl. Acad. Sci. U. S. A. 116, 24956-24965.

Brandão, H.B., Paul, P., van den Berg, A.A., Rudner, D.Z., Wang, X., and Mirny, L.A. (2019). RNA polymerases as moving barriers to condensin loop extrusion. Proc. Natl. Acad. Sci. 116, 2048920499.

Canela, A., Maman, Y., Jung, S., Wong, N., Callen, E., Day, A., Kieffer-Kwon, K.R., Pekowska, A., Zhang, H., Rao, S.S.P., et al. (2017). Genome Organization Drives Chromosome Fragility. Cell 
bioRxiv preprint doi: https://doi.org/10.1101/2020.12.20.423657; this version posted April 12, 2021. The copyright holder for this preprint (which was not certified by peer review) is the author/funder, who has granted bioRxiv a license to display the preprint in perpetuity. It is made available under aCC-BY-NC-ND 4.0 International license.

Choppakatla et al., April 2021-preprint copy- BioRxiv

170, 507-521.e18.

Canela, A., Maman, Y., Huang, S.N., Wutz, G., Tang, W., Zagnoli-Vieira, G., Callen, E., Wong, N., Day, A., Peters, J.-M., et al. (2019). Topoisomerase II-Induced Chromosome Breakage and

Translocation Is Determined by Chromosome Architecture and Transcriptional Activity. Mol. Cell $1-15$.

Chereji, R. V., Bryson, T.D., and Henikoff, S. (2019). Quantitative MNase-seq accurately maps nucleosome occupancy levels. Genome Biol. 20, 198.

Christophorou, M.A., Castelo-Branco, G., HalleyStott, R.P., Oliveira, C.S., Loos, R., Radzisheuskaya, A., Mowen, K.A., Bertone, P., Silva, J.C.R., Zernicka-Goetz, M., et al. (2014). Citrullination regulates pluripotency and histone H1 binding to chromatin. Nature 507, 104-108. Cremer, T., and Cremer, M. (2010). Chromosome territories. Cold Spring Harb. Perspect. Biol. 2, 123.

Cutts, E.E., and Vannini, A. (2020). Condensin complexes: understanding loop extrusion one conformational change at a time. Biochem. Soc. Trans. 48, 2089-2100.

Cuvier, O., and Hirano, T. (2003). A role of topoisomerase II in linking DNA replication to chromosome condensation. J. Cell Biol. 160, 645655.

Cuylen, S., Blaukopf, C., Politi, A.Z., MüllerReichert, T., Neumann, B., Poser, I., Ellenberg, J., Hyman, A.A., and Gerlich, D.W. (2016). Ki-67 acts as a biological surfactant to disperse mitotic chromosomes. Nature 535, 308-312.

Dasso, M., Dimitrov, S., and Wolffe, A.P. (1994).

Nuclear assembly is independent of linker histones. Proc. Natl. Acad. Sci. U. S. A. 91, 12477-12481. Datta, S., Lecomte, L., and Haering, C.H. (2020). Structural insights into DNA loop extrusion by SMC protein complexes. Curr. Opin. Struct. Biol. 65, 102-109.

Desai, A., Murray, A.W., Mitchison, T., and Walczak, C.E. (1998). Chapter 20 The Use of Xenopus Egg Extracts to Study Mitotic Spindle Assembly and Function in Vitro. Methods Cell Biol. 61, 385-412.

Du, Z., Zheng, H., Huang, B., Ma, R., Wu, J., Zhang, X., He, J., Xiang, Y., Wang, Q., Li, Y., et al. (2017). Allelic reprogramming of 3D chromatin architecture during early mammalian development. Nature 547, 232-235.

Dworkin-Rastl, E., Kandolf, H., and Smith, R.C. (1994). The maternal histone H1 variant, H1M (B4 protein), is the predominant $\mathrm{H} 1$ histone in Xenopus pregastrula embryos. Dev. Biol. 161, 425-439.

Earnshaw, W.C., and Laemmli, U.K. (1983).

Architecture of metaphase chromosomes and chromosome scaffolds. J. Cell Biol. 96, 84-93. Elbatsh, A.M.O., Kim, E., Eeftens, J.M.,

Raaijmakers, J.A., van der Weide, R.H., GarcíaNieto, A., Bravo, S., Ganji, M., uit de Bos, J., Teunissen, H., et al. (2019). Distinct Roles for Condensin's Two ATPase Sites in Chromosome Condensation. Mol. Cell 76, 724-737.e5. Eltsov, M., MacLellan, K.M., Maeshima, K., Frangakis, A.S., and Dubochet, J. (2008). Analysis of cryo-electron microscopy images does not support the existence of 30-nm chromatin fibers in mitotic chromosomes in situ. Proc. Natl. Acad. Sci. 105, 19732-19737.

Farcas, A., Uluocak, P., Helmhart, W., and Nasmyth, K.A. (2011). Cohesin's concatenation of sister DNAs maintains their intertwining. Mol. Cell 44, 97-107.

Farr, C.J., Antoniou-Kourounioti, M., Mimmack, M.L., Volkov, A., and Porter, A.C.G. (2014). The $\alpha$ isoform of topoisomerase II is required for hypercompaction of mitotic chromosomes in human cells. Nucleic Acids Res. 42, 4414-4426.

Finch, J.T., and Klug, A. (1976). Solenoidal model for superstructure in chromatin. Proc. Natl. Acad. Sci. 73, 1897-1901.

Fitz-James, M.H., Tong, P., Pidoux, A.L., Ozadam, H., Yang, L., White, S.A., Dekker, J., and Allshire, R.C. (2020). Large domains of heterochromatin direct the formation of short mitotic chromosome loops. Elife 9.

Freedman, B.S., and Heald, R. (2010). Functional comparison of $\mathrm{H} 1$ histones in Xenopus reveals isoform-specific regulation by Cdk1 and RanGTP. Curr. Biol. 20, 1048-1052.

Funabiki, H., and Murray, A.W. (2000). The Xenopus chromokinesin Xkid is essential for metaphase chromosome alignment and must be degraded to allow anaphase chromosome movement. Cell 102, 411-424.

Gandhi, R., Gillespie, P.J., and Hirano, T. (2006). Human Wapl Is a Cohesin-Binding Protein that Promotes Sister-Chromatid Resolution in Mitotic Prophase. Curr. Biol. 16, 2406-2417. Ganji, M., Shaltiel, I.A., Bisht, S., Kim, E., Kalichava, A., Haering, C.H., and Dekker, C. (2018). Real-time imaging of DNA loop extrusion by condensin. Science (80-. ). 360, 102-105. Gassler, J., Brandão, H.B., Imakaev, M., Flyamer, I.M., Ladstätter, S., Bickmore, W.A., Peters, J.-M., 
bioRxiv preprint doi: https://doi.org/10.1101/2020.12.20.423657; this version posted April 12, 2021. The copyright holder for this preprint (which was not certified by peer review) is the author/funder, who has granted bioRxiv a license to display the preprint in perpetuity. It is made available under aCC-BY-NC-ND 4.0 International license.

Choppakatla et al., April 2021-preprint copy- BioRxiv

Mirny, L.A., and Tachibana, K. (2017). A mechanism of cohesin-dependent loop extrusion organizes zygotic genome architecture. EMBO J. $36,3600-3618$.

Gerhart, J., Wu, M., and Kirschner, M. (1984). Cell cycle dynamics of an M-phase-specific cytoplasmic factor in Xenopus laevis oocytes and eggs. J. Cell Biol. 98, 1247-1255.

Gibcus, J.H., Samejima, K., Goloborodko, A., Samejima, I., Naumova, N., Nuebler, J., Kanemaki, M.T., Xie, L., Paulson, J.R., Earnshaw, W.C., et al. (2018). A pathway for mitotic chromosome formation. Science (80-. ). 359.

Gibson, B.A., Doolittle, L.K., Schneider, M.W.G., Jensen, L.E., Gamarra, N., Henry, L., Gerlich, D.W., Redding, S., and Rosen, M.K. (2019). Organization of Chromatin by Intrinsic and Regulated Phase Separation. Cell 1-15. Glotzer, M., Murray, A.W., and Kirschner, M.W. (1991). Cyclin is degraded by the ubiquitin pathway. 349.

Golfier, S., Quail, T., Kimura, H., and Brugués, J. (2020). Cohesin and condensin extrude DNA loops in a cell-cycle dependent manner. Elife 9.

Goloborodko, A., Imakaev, M. V., Marko, J.F., and Mirny, L.A. (2016a). Compaction and segregation of sister chromatids via active loop extrusion. Elife 5, 1-16.

Goloborodko, A., Marko, J.F., and Mirny, L.A. (2016b). Chromosome Compaction by Active Loop Extrusion. Biophys. J. 110, 2162-2168.

Goundaroulis, D., Lieberman Aiden, E., and Stasiak, A. (2020). Chromatin Is Frequently Unknotted at the Megabase Scale. Biophys. J. 118, 2268-2279.

Green, L.C., Kalitsis, P., Chang, T.M., Cipetic, M., Kim, J.H., Marshall, O., Turnbull, L., Whitchurch, C.B., Vagnarelli, P., Samejima, K., et al. (2012).

Contrasting roles of condensin I and condensin II in mitotic chromosome formation. J. Cell Sci. 125, 1591-1604.

Grigoryev, S.A., Bascom, G., Buckwalter, J.M., Schubert, M.B., Woodcock, C.L., and Schlick, T. (2016). Hierarchical looping of zigzag nucleosome chains in metaphase chromosomes. Proc. Natl. Acad. Sci. 113, 1238-1243.

Gruhn, J.R., Zielinska, A.P., Shukla, V., Blanshard, R., Capalbo, A., Cimadomo, D., Nikiforov, D., Chan, A.C.-H., Newnham, L.J., Vogel, I., et al. (2019). Chromosome errors in human eggs shape natural fertility over reproductive life span. Science (80-. ). 365, 1466-1469.

Guacci, V., Hogan, E., and Koshland, D. (1994).
Chromosome condensation and sister chromatid pairing in budding yeast. J. Cell Biol. 125, 517-530. Guse, A., Carroll, C.W., Moree, B., Fuller, C.J., and Straight, A.F. (2011). In vitro centromere and kinetochore assembly on defined chromatin templates. Nature 477, 354-358.

Hara, K., Tydeman, P., and Kirschner, M. (1980). A cytoplasmic clock with the same period as the division cycle in Xenopus eggs. Proc. Natl. Acad. Sci. U. S. A. 77, 462-466.

Hassler, M., Shaltiel, I.A., Kschonsak, M., Simon, B., Merkel, F., Thärichen, L., Bailey, H.J., Macošek, J., Bravo, S., Metz, J., et al. (2019). Structural Basis of an Asymmetric Condensin ATPase Cycle. Mol. Cell 74, 1175-1188.e9. Heald, R., and Gibeaux, R. (2018). ScienceDirect Subcellular scaling : does size matter for cell division ? Curr. Opin. Cell Biol. 52, 88-95. Hergeth, S.P., and Schneider, R. (2015). The H1 linker histones: multifunctional proteins beyond the nucleosomal core particle. EMBO Rep. 16, 14391453.

Hirano, T., and Mitchison, T.J. (1991). Cell cycle control of higher-order chromatin assembly around naked DNA in vitro. J. Cell Biol. 115, 1479-1489. Hirano, T., and Mitchison, T.J. (1994). A heterodimeric coiled-coil protein required for mitotic chromosome condensation in vitro. Cell 79, 449-458.

Hirano, T., Kobayashi, R., and Hirano, M. (1997). Condensins, Chromosome Condensation Protein Complexes Containing XCAP-C, XCAP-E and a Xenopus Homolog of the Drosophila Barren Protein. Cell 89, 511-521.

Hirota, T., Gerlich, D.W., Koch, B., Ellenberg, J., and Peters, J.-M. (2004). Distinct functions of condensin I and II in mitotic chromosome assembly. J. Cell Sci. 117, 6435-6445.

Holloway, S.L., Glotzer, M., King, R.W., and Murray, A.W. (1993). Anaphase is initiated by proteolysis rather than by the inactivation of maturation-promoting factor. Cell 73, 1393-1402. Hopfner, K.P., Karcher, A., Shin, D.S., Craig, L., Arthur, L.M., Carney, J.P., and Tainer, J.A. (2000). Structural biology of Rad50 ATPase: ATP-driven conformational control in DNA double-strand break repair and the ABC-ATPase superfamily. Cell 101, 789-800.

Hsieh, T.-H.S., Cattoglio, C., Slobodyanyuk, E., Hansen, A.S., Rando, O.J., Tjian, R., and Darzacq, X. (2020). Resolving the 3D Landscape of Transcription-Linked Mammalian Chromatin Folding. Mol. Cell 78, 539-553.e8. 
bioRxiv preprint doi: https://doi.org/10.1101/2020.12.20.423657; this version posted April 12, 2021. The copyright holder for this preprint (which was not certified by peer review) is the author/funder, who has granted bioRxiv a license to display the preprint in perpetuity. It is made available under aCC-BY-NC-ND 4.0 International license.

Choppakatla et al., April 2021-preprint copy- BioRxiv

Imakaev, M., Fudenberg, G., McCord, R.P., Naumova, N., Goloborodko, A., Lajoie, B.R., Dekker, J., and Mirny, L.A. (2012). Iterative correction of Hi-C data reveals hallmarks of chromosome organization. Nat. Methods 9, 9991003.

Izzo, A., Kamieniarz, K., and Schneider, R. (2008). The histone H1 family: Specific members, specific functions? Biol. Chem. 389, 333-343.

Izzo, A., Kamieniarz-Gdula, K., Ramírez, F., Noureen, N., Kind, J., Manke, T., vanSteensel, B., and Schneider, R. (2013). The Genomic Landscape of the Somatic Linker Histone Subtypes H1.1 to H1.5 in Human Cells. Cell Rep. 3, 2142-2154. Jenness, C., Giunta, S., Müller, M.M., Kimura, H., Muir, T.W., and Funabiki, H. (2018). HELLS and CDCA7 comprise a bipartite nucleosome remodeling complex defective in ICF syndrome. Proc. Natl. Acad. Sci. 201717509.

Kerpedjiev, P., Abdennur, N., Lekschas, F., McCallum, C., Dinkla, K., Strobelt, H., Luber, J.M., Ouellette, S.B., Azhir, A., Kumar, N., et al. (2018). HiGlass: web-based visual exploration and analysis of genome interaction maps. Genome Biol. 19, 125. Kimura, K., Hirano, M., Kobayashi, R., and Hirano, T. (1998). Phosphorylation and activation of $13 \mathrm{~S}$ condensin by Cdc2 in vitro. Science 282, 487-490. Kimura, K., Cuvier, O., and Hirano, T. (2001). Chromosome condensation by a human condensin complex in Xenopus egg extracts. J. Biol. Chem. 276, 5417-5420.

Kinoshita, K., and Hirano, T. (2017). Dynamic organization of mitotic chromosomes. Curr. Opin. Cell Biol. 46, 46-53.

Kong, M., Cutts, E.E., Pan, D., Beuron, F., Kaliyappan, T., Xue, C., Morris, E.P., Musacchio, A., Vannini, A., and Greene, E.C. (2020). Human Condensin I and II Drive Extensive ATP-Dependent Compaction of Nucleosome-Bound DNA. Mol. Cell 683540.

Krietenstein, N., Abraham, S., Venev, S. V., Abdennur, N., Gibcus, J.H., Hsieh, T.-H.S., Parsi, K.M., Yang, L., Maehr, R., Mirny, L.A., et al. (2020). Ultrastructural Details of Mammalian Chromosome Architecture. Mol. Cell 78, 554565.e7.

Krishnan, S., Smits, A.H., Vermeulen, M., and Reinberg, D. (2017). Phospho-H1 Decorates the Inter-chromatid Axis and Is Evicted along with Shugoshin by SET during Mitosis. Mol. Cell 67, 579-593.e6.

Kschonsak, M., and Haering, C.H. (2015). Shaping mitotic chromosomes: From classical concepts to molecular mechanisms. BioEssays 37, 755-766. Ladouceur, A.-M., Dorn, J.F., and Maddox, P.S. (2015). Mitotic chromosome length scales in response to both cell and nuclear size. J. Cell Biol. 209, 645-652.

Ladouceur, A.-M., Ranjan, R., Smith, L., Fadero, T., Heppert, J., Goldstein, B., Maddox, A.S., and Maddox, P.S. (2017). CENP-A and topoisomeraseII antagonistically affect chromosome length. J. Cell Biol. 216, jcb.201608084.

Lane, A.B., Giménez-Abián, J.F., and Clarke, D.J. (2013). A novel chromatin tether domain controls topoisomerase II $\alpha$ dynamics and mitotic chromosome formation. J. Cell Biol. 203, 471-486. Lee, W., Tillo, D., Bray, N., Morse, R.H., Davis, R.W., Hughes, T.R., and Nislow, C. (2007). A highresolution atlas of nucleosome occupancy in yeast. Nat. Genet. 39, 1235-1244.

Lemaitre, J.M., Géraud, G., and Méchali, M. (1998). Dynamics of the genome during early Xenopus laevis development: karyomeres as independent units of replication. J. Cell Biol. 142, 1159-1166.

Li, W., Chen, P., Yu, J., Dong, L., Liang, D., Feng, J., Yan, J., Wang, P.Y., Li, Q., Zhang, Z., et al. (2016). FACT Remodels the Tetranucleosomal Unit of Chromatin Fibers for Gene Transcription. Mol. Cell 64, 120-133.

Lieberman-Aiden, E., van Berkum, N.L., Williams, L., Imakaev, M., Ragoczy, T., Telling, A., Amit, I., Lajoie, B.R., Sabo, P.J., Dorschner, M.O., et al. (2009). Comprehensive Mapping of Long-Range Interactions Reveals Folding Principles of the Human Genome. Science (80-. ). 326, 289-293.

Lister, L.M., Kouznetsova, A., Hyslop, L.A., Kalleas, D., Pace, S.L., Barel, J.C., Nathan, A., Floros, V., Adelfalk, C., Watanabe, Y., et al. (2010). Age-related meiotic segregation errors in mammalian oocytes are preceded by depletion of cohesin and Sgo2. Curr. Biol. 20, 1511-1521. Lord, S.J., Velle, K.B., Mullins, R.D., and FritzLaylin, L.K. (2020). SuperPlots: Communicating reproducibility and variability in cell biology. $\mathrm{J}$. Cell Biol. 219.

Lowary, P.., and Widom, J. (1998). New DNA sequence rules for high affinity binding to histone octamer and sequence-directed nucleosome positioning. J. Mol. Biol. 276, 19-42.

Löwe, J., Cordell, S.C., and Van Den Ent, F. (2001). Crystal structure of the SMC head domain: An ABC ATPase with 900 residues antiparallel coiled-coil inserted. J. Mol. Biol. 306, 25-35.

Mara, L., Paim, G., and Fitzharris, G. (2019). Cell- 
bioRxiv preprint doi: https://doi.org/10.1101/2020.12.20.423657; this version posted April $12,2021$. The copyright holder for this preprint (which was not certified by peer review) is the author/funder, who has granted bioRxiv a license to display the preprint in perpetuity. It is made available under aCC-BY-NC-ND 4.0 International license.

Choppakatla et al., April 2021-preprint copy- BioRxiv

Size-Independent Spindle Checkpoint Failure Underlies Chromosome Segregation Error in Mouse Report Cell-Size-Independent Spindle Checkpoint Failure Underlies Chromosome Segregation Error. 865-873.

Maresca, T.J., Freedman, B.S., and Heald, R. (2005). Histone H1 is essential for mitotic chromosome architecture and segregation in Xenopus laevis egg extracts. J. Cell Biol. 169, 859869.

Marko, J.F. (2008). Micromechanical studies of mitotic chromosomes. Chromosom. Res. 16, 469497.

Marko, J.F. (2009). Linking topology of tethered polymer rings with applications to chromosome segregation and estimation of the knotting length. Phys. Rev. E - Stat. Nonlinear, Soft Matter Phys. 79, 1-16.

Micheli, G., Luzzatto, A.R., Carrì, M.T., de Capoa, A., and Pelliccia, F. (1993). Chromosome length and DNA loop size during early embryonic development of Xenopus laevis. Chromosoma 102, 478-483.

Misteli, T., Gunjan, a, Hock, R., Bustin, M., and Brown, D.T. (2000). Dynamic binding of histone H1 to chromatin in living cells. Nature 408, 877881.

Murray, A.W. (1991). Chapter 30 Cell Cycle Extracts. In Methods in Cell Biology, pp. 581-605.

Nagasaka, K., Hossain, M.J., Roberti, M.J., Ellenberg, J., and Hirota, T. (2016). Sister chromatid resolution is an intrinsic part of chromosome organization in prophase. Nat. Cell Biol. 18, 692-699.

Nasmyth, K.A. (2001). Disseminating the Genome: Joining, Resolving, and Separating Sister Chromatids During Mitosis and Meiosis. Annu. Rev. Genet. 35, 673-745.

Naumova, N., Imakaev, M., Fudenberg, G., Zhan, Y.Y.Y., Lajoie, B.R., Mirny, L.A., and Dekker, J. (2013). Organization of the Mitotic Chromosome. Science (80-. ). 342, 948-953.

Nielsen, C.F., Zhang, T., Barisic, M., Kalitsis, P., and Hudson, D.F. (2020). Topoisomerase IIa is essential for maintenance of mitotic chromosome structure. Proc. Natl. Acad. Sci. U. S. A. 117. Ohsumi, K., Katagiri, C., and Kishimoto, T. (1993). Chromosome condensation in Xenopus mitotic extracts without histone H1. Science (80-. ). 262, 2033-2035.

Ono, T., Losada, A., Hirano, M., Myers, M.P., Neuwald, A.F., and Hirano, T. (2003). Differential contributions of condensin I and condensin II to mitotic chromosome architecture in vertebrate cells. Cell 115, 109-121.

Ono, T., Fang, Y., Spector, D.L., and Hirano, T. (2004). Spatial and temporal regulation of condensins I and II in mitotic chromosome assembly in human cells. Mol. Biol. Cell 15, 32963308.

Ou, H.D., Phan, S., Deerinck, T.J., Thor, A., Ellisman, M.H., and O'Shea, C.C. (2017).

ChromEMT: Visualizing 3D chromatin structure and compaction in interphase and mitotic cells. Science (80-. ). 357, eaag0025.

Parseghian, M.H., Newcomb, R.L., and Hamkalo, B.A. (2001). Distribution of somatic H1 subtypes is non-random on active vs. inactive chromatin II: Distribution in human adult fibroblasts. J. Cell. Biochem. 83, 643-659.

Patel, L., Kang, R., Rosenberg, S.C., Qiu, Y., Raviram, R., Chee, S., Hu, R., Ren, B., Cole, F., and Corbett, K.D. (2019). Dynamic reorganization of the genome shapes the recombination landscape in meiotic prophase. Nat. Struct. Mol. Biol. 26. Paulson, J.R., and Laemmli, U.K. (1977). The structure of histone-depleted metaphase chromosomes. Cell 12, 817-828.

Piskadlo, E., Tavares, A., and Oliveira, R.A. (2017). Metaphase chromosome structure is dynamically maintained by condensin I-directed DNA (de)catenation. Elife 6, 1-22.

Potapova, T.A., Unruh, J.R., Yu, Z., Rancati, G., Li, H., Stampfer, M.R., and Gerton, J.L. (2019). Superresolution microscopy reveals linkages between ribosomal DNA on heterologous chromosomes. J. Cell Biol. 218, 2492-2513. Riggs, A.D. (1990). DNA methylation and late replication probably aid cell memory, and type I DNA reeling could aid chromosome folding and enhancer function. Philos. Trans. R. Soc. Lond. B. Biol. Sci. 326, 285-297.

Rosin, L.F., Nguyen, S.C., and Joyce, E.F. (2018). Condensin II drives large-scale folding and spatial partitioning of interphase chromosomes in Drosophila nuclei. PLoS Genet. 14, 1-26.

Ryu, H., Furuta, M., Kirkpatrick, D., Gygi, S.P., and Azuma, Y. (2010). PIASy-dependent SUMOylation regulates DNA topoisomerase II $\alpha$ activity. J. Cell Biol. 191, 783-784.

Samejima, K., Samejima, I., Vagnarelli, P., Ogawa, H., Vargiu, G., Kelly, D.A., Alves, F. de L., Kerr, A., Green, L.C., Hudson, D.F., et al. (2012). Mitotic chromosomes are compacted laterally by KIF4 and condensin and axially by topoisomerase II $\alpha$. J. Cell Biol. 199, 755-770. 
Shakya, A., Park, S., Rana, N., and King, J.T. (2020). Liquid-Liquid Phase Separation of Histone Proteins in Cells: Role in Chromatin Organization. Biophys. J. 118, 753-764.

Shamu, C.E., and Murray, A.W. (1992). Sister Chromatid Separation in Frog Egg Extracts Requires DNA Topoisomerase II Activity during Anaphase. 117, 921-934.

Shechter, D., Nicklay, J.J., Chitta, R.K., Shabanowitz, J., Hunt, D.F., and David Allis, C. (2009). Analysis of histones in Xenopus laevis I. a distinct index of enriched variants and modifications exists in each cell type and is remodeled during developmental transitions. J. Biol. Chem. 284, 1064-1074.

Shintomi, K., and Hirano, T. (2011). The relative ratio of condensin I to II determines chromosome shapes. Genes Dev. 25, 1464-1469.

Shintomi, K., Inoue, F., Watanabe, H., Ohsumi, K., Ohsugi, M., and Hirano, T. (2017). Mitotic chromosome assembly despite nucleosome depletion in Xenopus egg extracts. Science (80-. ). 356, 1284-1287.

Song, F., Chen, P., Sun, D., Wang, M., Dong, L., Liang, D., Xu, R.-M., Zhu, P., and Li, G. (2014). Cryo-EM Study of the Chromatin Fiber Reveals a Double Helix Twisted by Tetranucleosomal Units. Science (80-. ). 344, 376-380.

Stein, A., and Künzler, P. (1983). Histone H5 can correctly align randomly arranged nucleosomes in a defined in vitro system. Nature 302, 548-550. Stigler, J., Çamdere, G., Koshland, D.E., and Greene, E.C. (2016). Single-Molecule Imaging Reveals a Collapsed Conformational State for DNA-Bound Cohesin. Cell Rep. 15, 988-998. Sun, M., Biggs, R., Hornick, J., and Marko, J.F. (2018). Condensin controls mitotic chromosome stiffness and stability without forming a structurally contiguous scaffold. Chromosom. Res. 26, 277-295. Sundin, O., and Varshavsky, A. (1981). Arrest of Segregation Leads to Accumulation of Highly Intertwined Catenated Dimers : Dissection of the Final Stages of SV40 DNA Replication. Cell 25, 659-669.

Szabo, Q., Bantignies, F., and Cavalli, G. (2019). Principles of genome folding into topologically associating domains. Sci. Adv. 5.

Tavares-Cadete, F., Norouzi, D., Dekker, B., Liu, Y., and Dekker, J. (2020). Multi-contact 3C reveals that the human genome during interphase is largely not entangled. Nat. Struct. Mol. Biol. 27, 11051114.

Terakawa, T., Bisht, S., Eeftens, J.M., Dekker, C.,
Haering, C.H., and Greene, E.C. (2017). The condensin complex is a mechanochemical motor that translocates along DNA. Science 358, 672-676. Th'ng, J.P.H., Sung, R., Ye, M., and Hendzel, M.J. (2005). H1 Family Histones in the Nucleus. J. Biol. Chem. 280, 27809-27814.

Thakurela, S., Garding, A., Jung, J., Schübeler, D., Burger, L., and Tiwari, V.K. (2013). Gene regulation and priming by topoisomerase II $\alpha$ in embryonic stem cells. Nat. Commun. 4. Toselli-Mollereau, E., Robellet, X., Fauque, L., Lemaire, S., Schiklenk, C., Klein, C., Hocquet, C., Legros, P., N'Guyen, L., Mouillard, L., et al. (2016). Nucleosome eviction in mitosis assists condensin loading and chromosome condensation. EMBO J. 35, 1565-1581.

Umesono, K., Hiraoka, Y., Toda, T., and Yanagida, M. (1983). Visualization of chromosomes in mitotically arrested cells of the fission yeast Schizosaccharomyces pombe. Curr. Genet. 7, 123128.

Walther, N., Hossain, M.J., Politi, A.Z., Koch, B., Kueblbeck, M., Ødegård-Fougner, Ø., Lampe, M., and Ellenberg, J. (2018). A quantitative map of human Condensins provides new insights into mitotic chromosome architecture. J. Cell Biol. 217, 2309-2328.

Weissmann, F., Petzold, G., VanderLinden, R., Huis in 't Veld, P.J., Brown, N.G., Lampert, F., Westermann, S., Stark, H., Schulman, B.A., and Peters, J.-M. (2016). biGBac enables rapid gene assembly for the expression of large multisubunit protein complexes. Proc. Natl. Acad. Sci. 113, E2564-E2569.

White, A.E., Hieb, A.R., and Luger, K. (2016). A quantitative investigation of linker histone interactions with nucleosomes and chromatin. Sci. Rep. 6, 1-14.

Woodcock, C.L., Skoultchi, A.I., and Fan, Y. (2006). Role of linker histone in chromatin structure and function: $\mathrm{H} 1$ stoichiometry and nucleosome repeat length. Chromosom. Res. 14, 17-25.

Wühr, M., Freeman, R.M., Presler, M., Horb, M.E., Peshkin, L., Gygi, S., and Kirschner, M.W. (2014). Deep proteomics of the Xenopus laevis egg using an mRNA-derived reference database. Curr. Biol. 24, 1467-1475.

Wynne, D.J., and Funabiki, H. (2015). Kinetochore function is controlled by a phosphodependent coexpansion of inner and outer components. J. Cell Biol. 210, 899-916.

Yu, X., Davenport, J.W., Urtishak, K.A., Carillo, M.L., Gosai, S.J., Kolaris, C.P., Byl, J.A.W., 
bioRxiv preprint doi: https://doi org/10.1101/2020.12.20.423657; this version posted April 12 2021. The copyright holder for this preprint (which was not certified by peer review) is the author/funder, who has granted bioRxiv a license to display the preprint in perpetuity. It is made available under aCC-BY-NC-ND 4.0 International license.

Choppakatla et al., April 2021-preprint copy- BioRxiv

Rappaport, E.F., Osheroff, N., Gregory, B.D., et al. (2017). Genome-wide TOP2A DNA cleavage is biased toward translocated and highly transcribed loci. Genome Res. 27, 1238-1249.

Zhou, B., Jiang, J., Feng, H., Ghirlando, R., Xiao, S., Bai, Y., Zhou, B., Jiang, J., Feng, H., Ghirlando, R., et al. (2015). Structural Mechanisms of Nucleosome Recognition by Linker Histones Article Structural Mechanisms of Nucleosome Recognition by Linker Histones. Mol. Cell 59, 628638.
Zhou, B., Feng, H., Kale, S., Fox, T., Khant, H., de Val, N., Ghirlando, R., Panchenko, A.R., and Bai, Y. (2021). Distinct Structures and Dynamics of Chromatosomes with Different Human Linker Histone Isoforms. Mol. Cell 81, 166-182.e6.

Zierhut, C., Jenness, C., Kimura, H., and Funabiki, H. (2014). Nucleosomal regulation of chromatin composition and nuclear assembly revealed by histone depletion. Nat. Struct. Mol. Biol. 21, 617625. 
bioRxiv preprint doi: https://doi.org/10.1101/2020.12.20.423657; this version posted April 12, 2021. The copyright holder for this preprint (which was not certified by peer review) is the author/funder, who has granted bioRxiv a license to display the preprint in perpetuity. It is made available under aCC-BY-NC-ND 4.0 International license.

Choppakatla et al., April 2021-preprint copy- BioRxiv

A

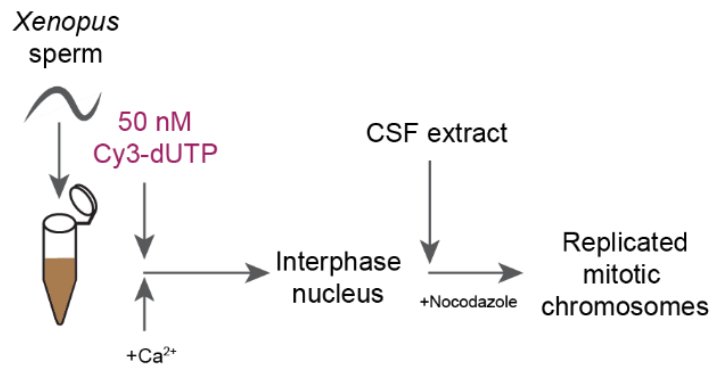

$\Delta \lg \mathrm{G} / \Delta \mathrm{H} 1$

CSF extract

B

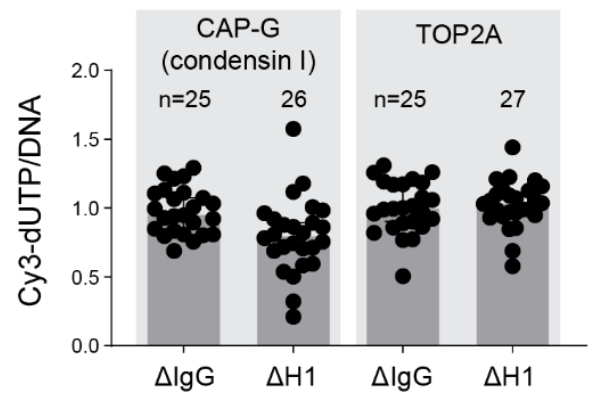

D
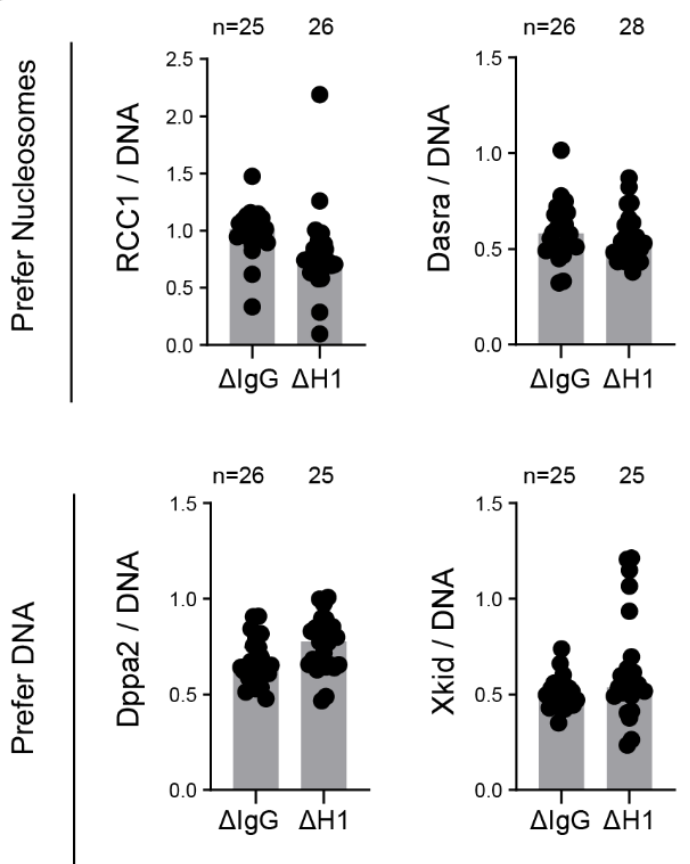

$\mathbf{E}$

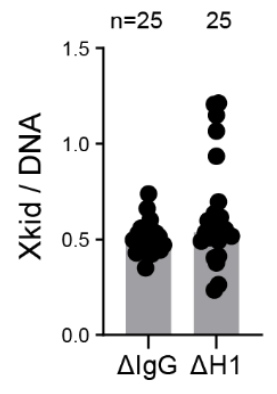

C
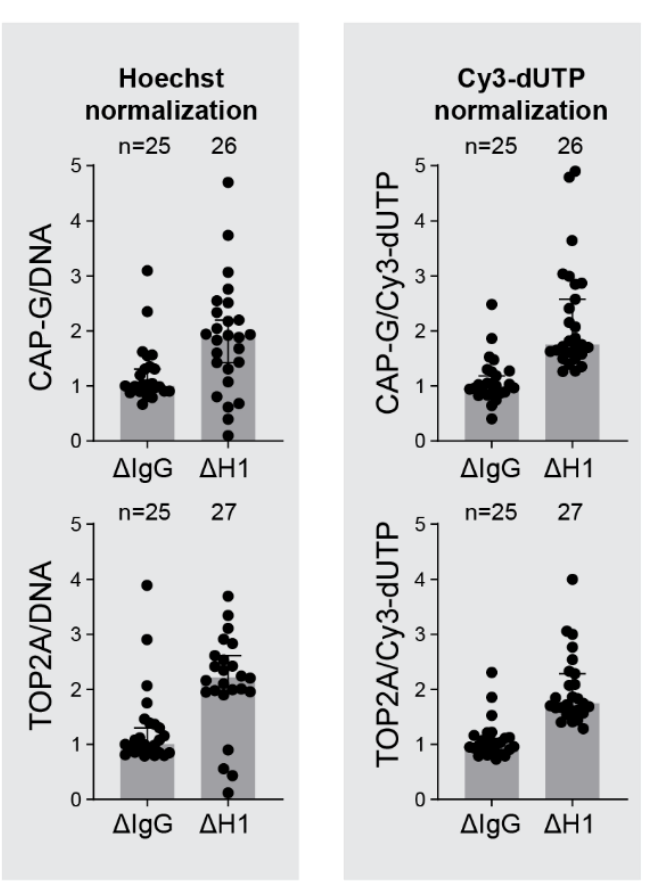

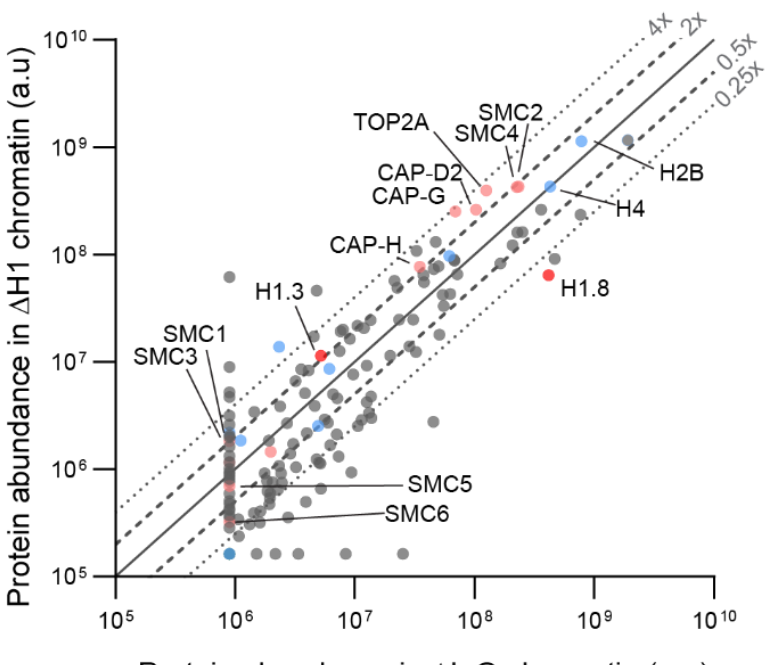

Protein abundance in $\Delta \mathrm{lgG}$ chromatin (a.u)

Figure S1. Linker histone H1.8 depletion does not lead to global accumulation of DNA-binding proteins (related to Figure 1)

A) Experimental scheme to incorporate Cy3-labelled nucleotides to use normalization of immunofluorescence signals on chromosomes. B) Quantification of Cy3-dUTP signals normalized to Hoechst 33342 signals, showing uniform normalization across two coverslips used for quantification of condensin I and TOP2A. The result also indicates no detectable defect in DNA replication in $\Delta \mathrm{H} 1$ extracts. C) CAP-G (condensin I) and TOP2A immunofluorescence signal levels on chromosomes normalized with Hoechst and incorporated Cy3-dUTP. Normalization using Hoechst 33342 and Cy3-dUTP/Cy5-dUTP signals were shown to be consistent across many experiments. D) Quantification of immunofluorescence signal levels of two proteins that prefer nucleosomes (RCC1 and Dasra A) and two that prefer to bind nucleosome-free DNA (Dppa2 and Xkid) (Zierhut et al., 2014). In B-D, distribution of signal intensity per chromosome cluster (dots), and median and SEM from one experiment are shown. This analysis was performed twice and the similar results were obtained. E) Protein abundance on metaphase sperm chromosomes purified from mock and H1.8 depleted extracts. Subunits from the SMC family complexes are labelled in pink. Core histones and their variants are in blue and linker histone variants are shown in red. The lines for $0.25 \mathrm{x}, 0.5 \mathrm{x}, 1,2 \mathrm{x}$ and $4 \mathrm{x}$ abundance on $\Delta \mathrm{H} 1 \mathrm{compared}$ to $\Delta \mathrm{IgG}$ chromosomes are shown. The mass spectrometry analysis was performed once. The number of nuclei imaged in each condition for each experiment in $\mathrm{B}, \mathrm{C}$ and $\mathrm{D}$ are indicated above the figure. 


\begin{tabular}{|l|l|c|}
\hline \multicolumn{1}{|c|}{ Description } & Gene ID & $\boldsymbol{\Delta H} \mathbf{H} \mathbf{\Delta l g G}$ \\
\hline Structural maintenance of chromosomes protein 4 & SMC4 & 1.83 \\
\hline Structural maintenance of chromosomes protein 2 & SMC2 & 1.87 \\
\hline DNA topoisomerase 2-alpha & TOP2A & 3.13 \\
\hline Condensin complex subunit 3 & NCAPG & 2.54 \\
\hline Condensin complex subunit 1 & NCAPD2 & 3.65 \\
\hline SWI/SNF-related matrix-associated actin-dependent & & \\
regulator of chromatin subfamily A member 5 & SMARCA5 & 2.75 \\
\hline Condensin complex subunit 2 & NCAPH & 2.22 \\
\hline DNA replication licensing factor MCM7 & MCM7 & 2.17 \\
\hline DNA replication licensing factor MCM5 & MCM5 & 2.64 \\
\hline FACT complex subunit SPT16 & SUPT16H & 1.80 \\
\hline FACT complex subunit SSRP1 & SSRP1 & 1.74 \\
\hline Shugoshin-like 1 & SGOL1 & 1.79 \\
\hline Mediator of DNA damage checkpoint protein 1 & MDC1 & 2.50 \\
\hline Fanconi anemia group I protein & FANCl & 2.52 \\
\hline Histone H1.3 & HIST1H1D & 2.20 \\
\hline
\end{tabular}

Table S1- High abundance proteins with the highest increases in $\Delta \mathrm{H} 1$ depleted chromosomes

High abundance proteins ( $>10^{7}$ ion current) showing the highest increase in $\Delta \mathrm{H} 1$ depleted chromosomes. 


\begin{tabular}{|l|l|c|}
\hline \multicolumn{1}{|c|}{ Description } & Gene ID & $\Delta \mathbf{H} \mathbf{l} \mathbf{\Delta l g G}$ \\
\hline DNA damage-binding protein 1 & DDB1 & 0.19 \\
\hline Histone H1oo & H1FOO & 0.15 \\
\hline Bromodomain and WD repeat-containing protein 3 & BRWD3 & 0.35 \\
\hline GTP-binding nuclear protein Ran & RAN & 0.50 \\
\hline Lymphoid-specific helicase & HELLS & 0.38 \\
\hline DNA topoisomerase 2-binding protein 1 & TOPBP1 & 0.49 \\
\hline Telomere-associated protein RIF1 & RIF1 & 0.01 \\
\hline Exportin-2 & CSE1L & 0.22 \\
\hline Probable ATP-dependent RNA helicase DDX6 & DDX6 & 0.35 \\
\hline Polyadenylate-binding protein 1 & PABPC1 & 0.25 \\
\hline Prohibitin & PHB & 0.34 \\
\hline Importin subunit beta-1 & KPNB1 & 0.10 \\
\hline RuvB-like 1 & RUVBL1 & 0.02 \\
\hline Importin alpha 5.1 & Imp 5.1 & 0.25 \\
\hline Nuclear pore complex protein Nup98-Nup96 & NUP98 & 0.24 \\
\hline
\end{tabular}

Table S2- High abundance proteins with the highest decreases in $\Delta H 1$ depleted chromosomes

High abundance proteins ( $>10^{7}$ ion current) showing the highest increase in $\Delta \mathrm{H} 1$ depleted chromosomes. 
A

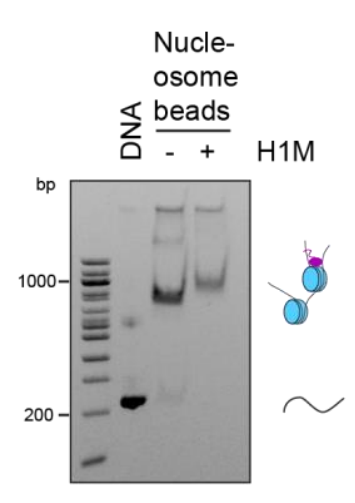

C

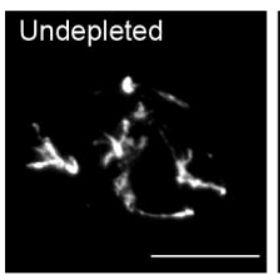

B
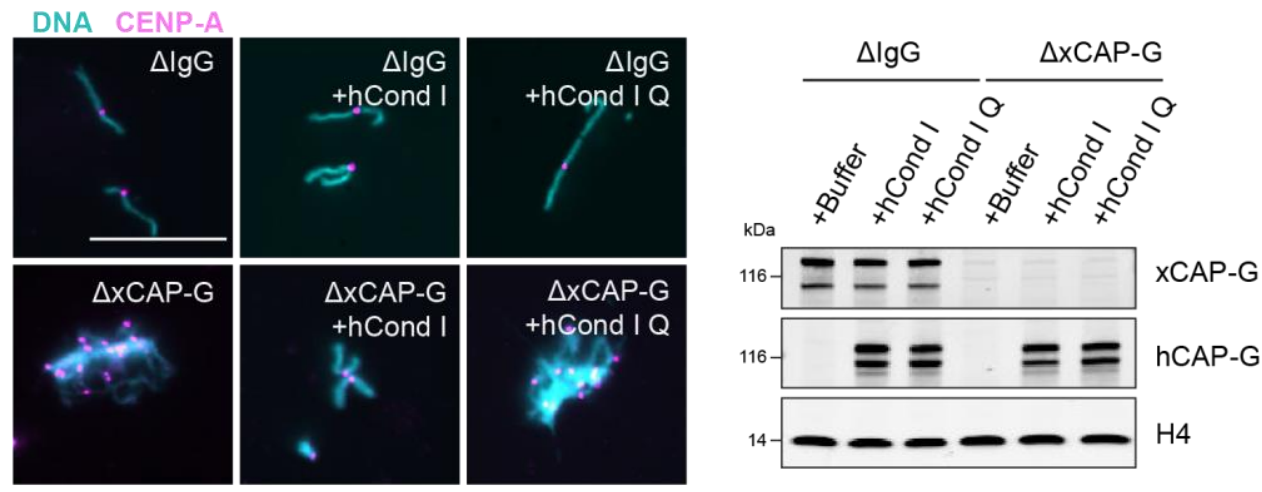

D

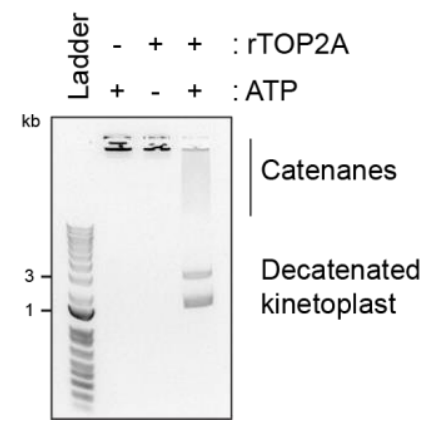

\section{Figure S2- Recombinant human condensin I and $X$. laevis TOP2A are functional}

A) Native PAGE gel analysis of nucleosome array beads loaded with or without H1.8 after digestion of the array with $A v a \mathrm{I}$, which released monomers of nucleosome positioning sequence. A complete shift of monomer bands by $\mathrm{H} 1.8$ addition indicates the saturated occupancy of nucleosome and H1.8. B) Representative Hoechst (DNA) and CENP-A immunofluorescence images of chromosomes in indicated metaphase egg extracts after dilution, which disperses individualized chromosomes (left). Extracts depleted of condensin I ( $\Delta$ CAP-G) were complemented with recombinant human condensin I and condensin I Q loop mutant protein complexes. Total egg extract western blots of depletion and the rescue conditions (right). C) Recombinant X. laevis TOP2A is functional in Xenopus egg extracts. Sperm nuclei were added to undepleted, TOP2A-depelted CSF extracts $(\triangle \mathrm{TOP} 2 \mathrm{~A})$, or $\triangle \mathrm{TOP} 2 \mathrm{~A}$ extracts with purified recombinant TOP2A. Representative Hoechst (DNA) images of sperm are shown. In undepleted or $\triangle \mathrm{TOP} 2 \mathrm{~A}$ extracts with supplemented TOP2A, proper sperm remodeling led to mitotic chromosomes formation. In $\triangle \mathrm{TOP} 2 \mathrm{~A}$ extracts, sperm remodeling failed and sperm nuclei remained compact crescent-like shape. Bar, $20 \mu \mathrm{m}$. D) Recombinant X. laevis TOP2A possesses decatenating activity in vitro. Agarose gel of kinetoplast decatenation assay. Recombinant TOP2A promoted ATP-dependent decatenation of kinetoplast DNA. 
A

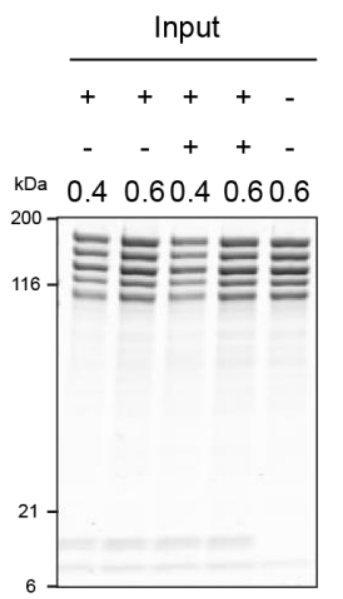

B
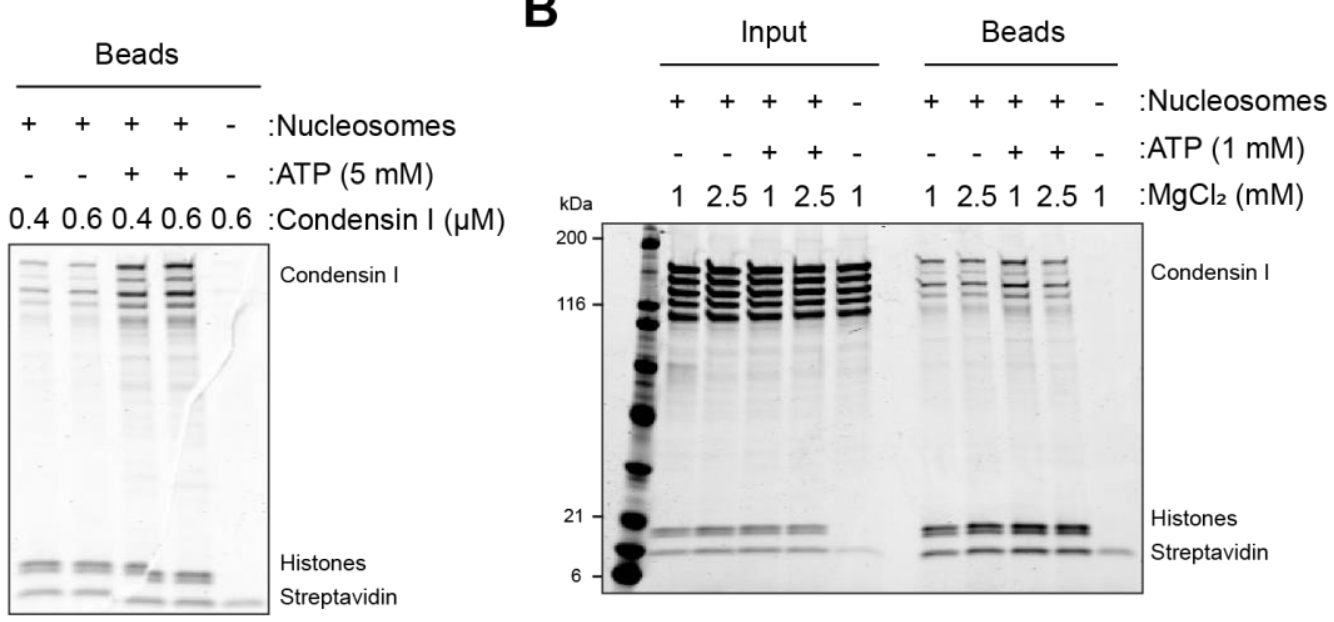

C

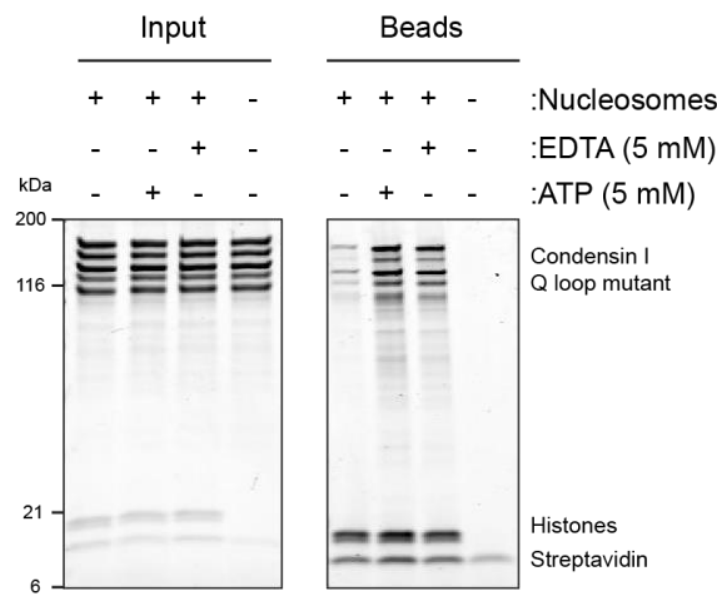

D

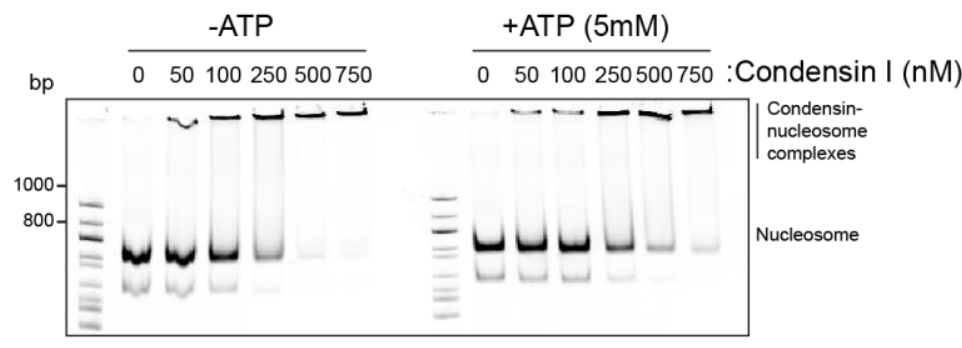

Figure S3- Condensin binding is inhibited by magnesium

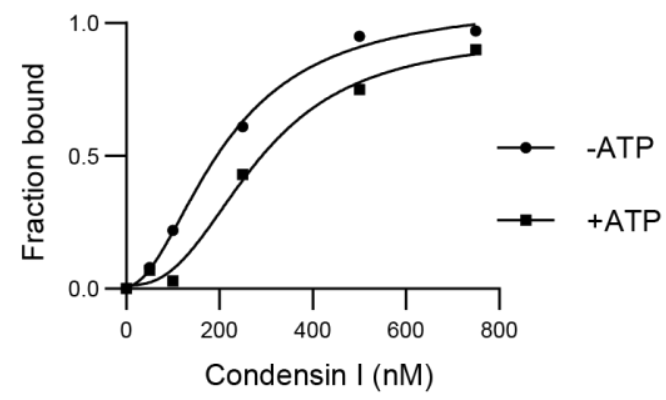

A) Purified recombinant human condensin I was incubated with nucleosome array beads in buffer containing $2.5 \mathrm{mM}$ $\mathrm{MgCl}_{2}$ with and without $5 \mathrm{mM}$ ATP. Coomassie staining of input and bead fractions are shown. B) Purified human condensin I was incubated with nucleosome array beads in buffer containing 1 or $2.5 \mathrm{mM} \mathrm{MgCl} 2$ with and without 1 mM ATP. Coomassie staining of input and bead fractions are shown. C) Purified human condensin I Q-loop mutant was incubated with nucleosome array beads in buffer containing $2.5 \mathrm{mM} \mathrm{MgCl} 2$ with the addition of $5 \mathrm{mM}$ ATP or 5 mM EDTA. Coomassie staining of input and bead fractions are shown. D) Alexa647-labelled 196 bp mononucleosomes were incubated with indicated concentrations of condensin $\mathrm{I}$ in the presence of $2.5 \mathrm{mM} \mathrm{MgCl} 2$ and with or without 5 mM ATP and electrophoresed on a $5 \%$ native PAGE (above). Bands at the well represent the nucleosome-condensin complex. Absence of signals at the well in the absence of Condensin I indicates that mononucleosomes do not form large aggregates in the tested experimental conditions. Quantification of the condensin bound fraction of the nucleosomes showing no increase in binding affinity due to ATP. 

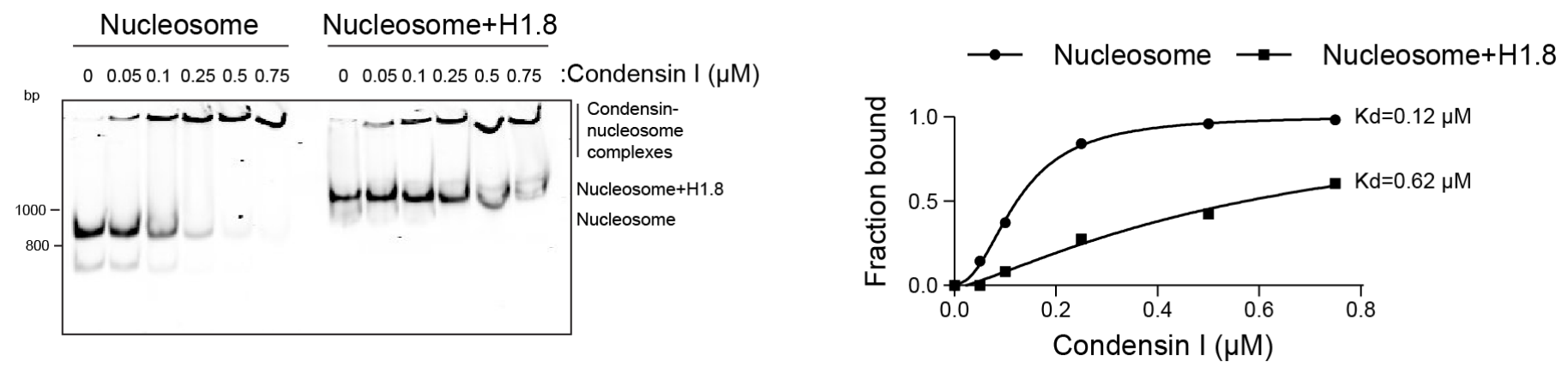

\section{Figure S4- H1.8 inhibits condensin binding to mononucleosomes}

Alexa647-labelled 196 bp mononucleosomes with or without H1.8 were incubated with indicated concentrations of condensin I and electrophoresed on a $5 \%$ native PAGE. Alexa647-labeled DNAs are shown. Condensin I binding curves with mononucleosomes with and without H1.8, showing the large increase in binding constant in the presence of H1.8. The binding constants derived from fitting the data to a sigmoidal binding curve are shown. The data reproducibility was confirmed by another biological replicate. 
A

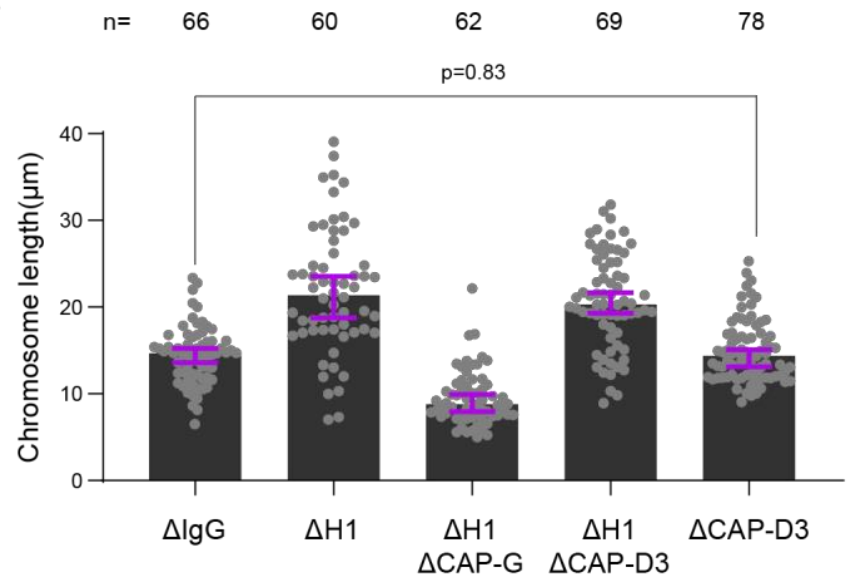

B

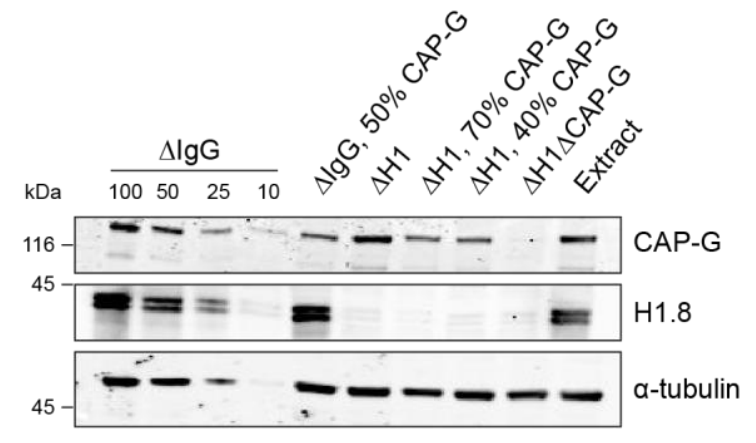

Figure S5- Condensin II depletion does not affect chromosome length

A) Length of mitotic chromosomes in the indicated conditions after extract dilution showing no effect of CAPD3 (condensin II) depletion in both mock and H1.8 depletion background. Each dot represents length of a single chromosome. Bars represent median $+/-95 \%$ C.I. The length of $>50$ chromosomes were measured in each condition for every experiment. B) Total egg extract blots showing the partial depletions of condensin in the indicated conditions. The p-value in A was calculated by a two-tailed Mann-Whitney $U$ test. The number of chromosomes imaged in each condition for each experiment in A are indicated above the figure. 
bioRxiv preprint doi: https://doi org/10.1101/2020.12.20.423657; this version posted April 12,2021 . The copyright holder for this preprint (which was not certified by peer review) is the author/funder, who has granted bioRxiv a license to display the preprint in perpetuity. It is made available under aCC-BY-NC-ND 4.0 International license.

Choppakatla et al., April 2021-preprint copy- BioRxiv

A

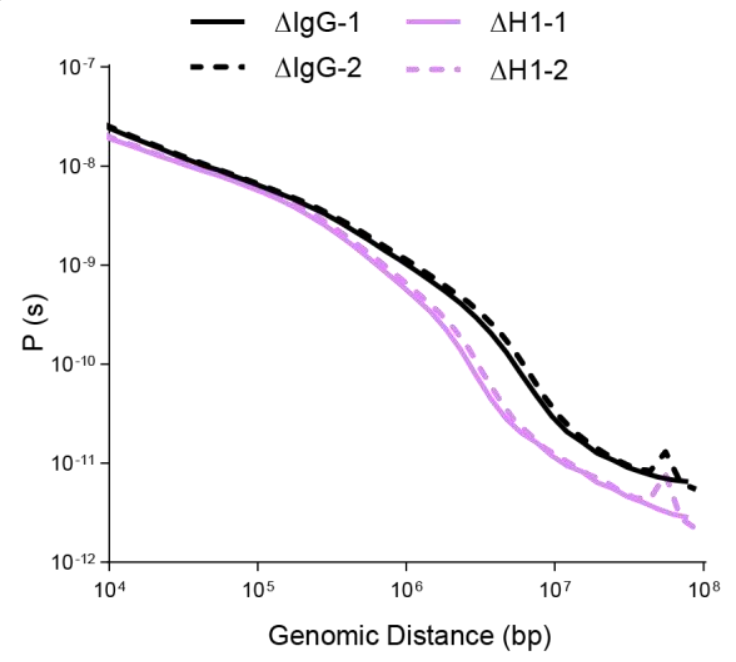

B

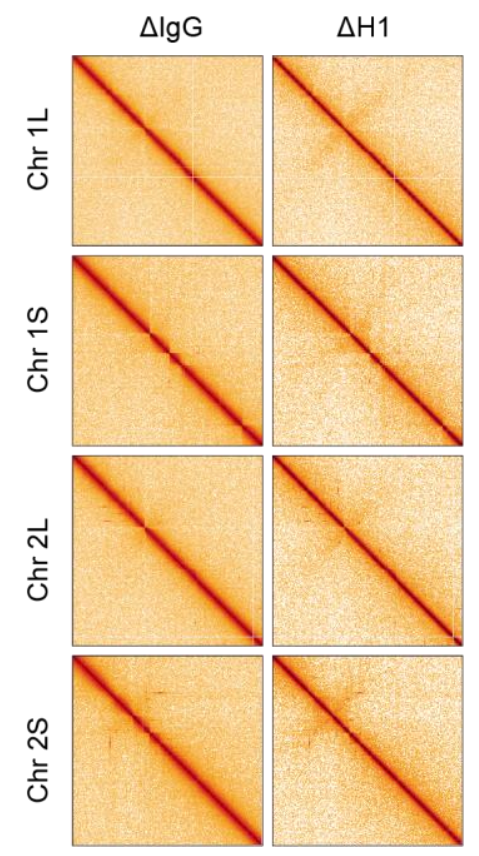

C

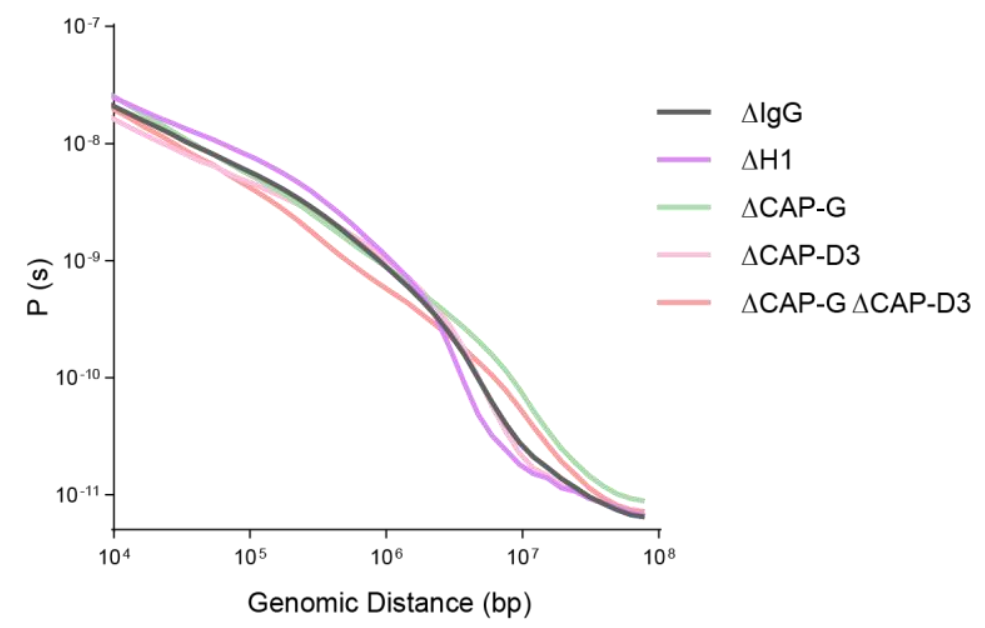

D
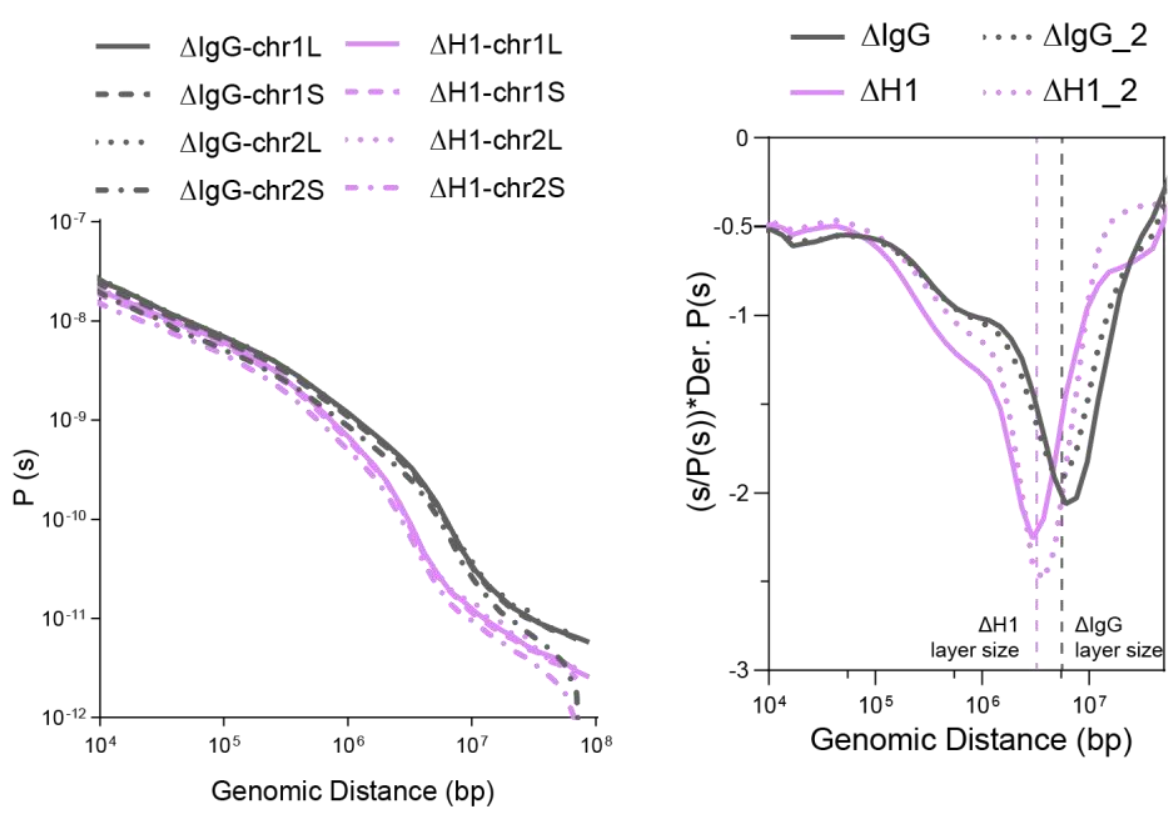

\section{Figure S6- Effects of H1, condensin I and condensin II depletion on mitotic genome folding}

A) Contact probability decay curves of mitotic chromosomes in mock $(\Delta \operatorname{IgG})$ and $\mathrm{H} 1$-depleted $(\Delta \mathrm{H} 1)$ extracts from two different experiments showing the replicability of the Hi-C features. The solid and dashed lines are from biological replicates. B) Hi-C maps (left) binned to $500 \mathrm{~kb}$, and contact probability curves (right) of single chromosomes showing the uniform effects of $\mathrm{H} 1.8$ depletion genome wide. C) Genome average contact probability decay curves upon H1.8, CAP-G and CAP-D3 depletions. D) Genome average contact probability derivative curves of metaphase chromosomes in undiluted mock $(\Delta \mathrm{IgG})$ and $\mathrm{H} 1.8$ depleted $(\Delta \mathrm{H} 1)$ extracts. The layer size estimates from the valley in the derivative plots are indicated. The dotted lines are a biological replicate. 

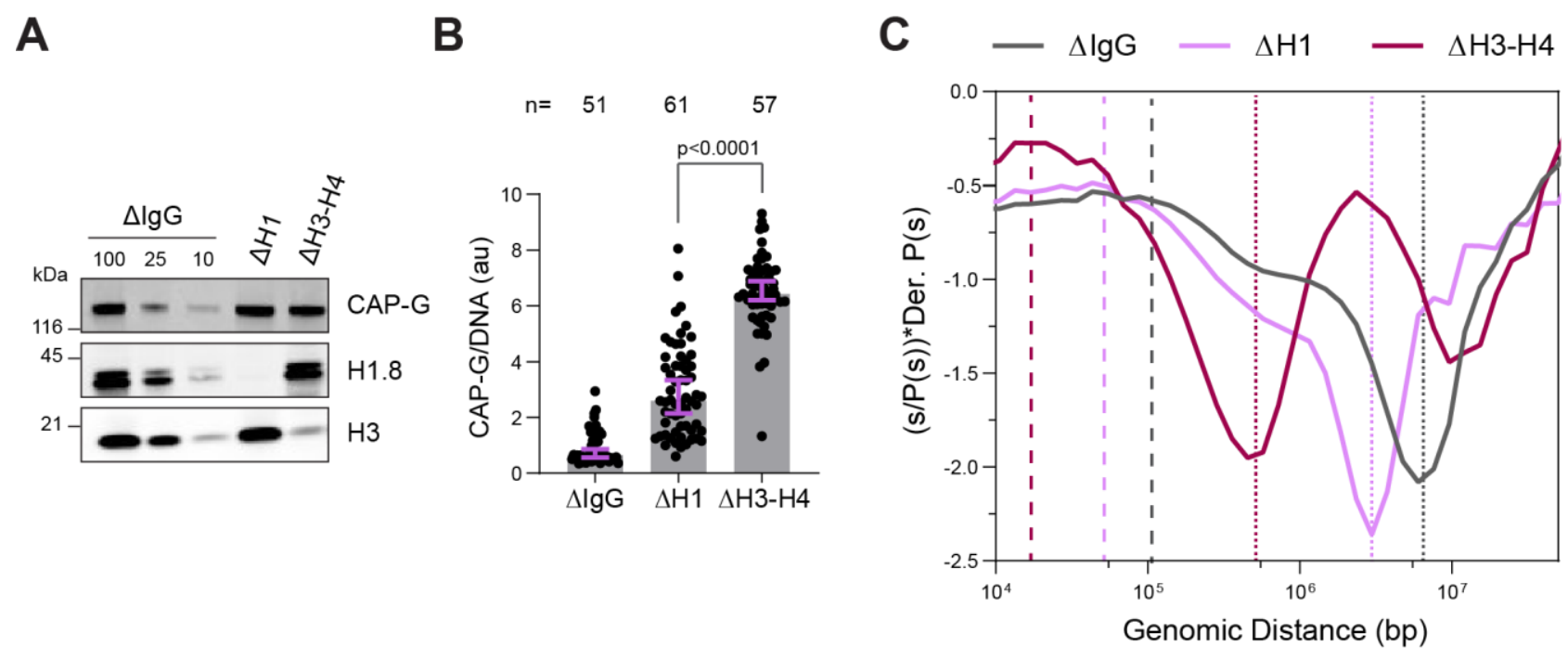

\section{Figure S7- H3-H4 depletion leads to even smaller loop sizes}

A) Western blotting showing the depletion of H3-H4 in total egg extract using the H4K12ac antibody (Zierhut et al., 2014). B) Quantification of condensin I (CAP-G) immunofluorescence levels on chromosomes normalized to DNA in $\Delta \mathrm{H} 1$ and $\Delta \mathrm{H} 3-\mathrm{H} 4$ extracts. Each dot represents the average signal intensity of a single chromosome cluster (from one nucleus). Data plotted is median and $95 \%$ C.I. $>40$ nuclei were quantified for each condition plotted. The statistical significance between $\Delta \mathrm{H} 1$ and $\Delta \mathrm{H} 3-\mathrm{H} 4$ was analyzed by a two-tailed Mann-Whitney U-test. C) Hi-C probability decay derivative plots estimating the loop sizes in $\Delta \mathrm{H} 1$ and $\Delta \mathrm{H} 3-\mathrm{H} 4$ extracts. The dashed lines indicate the loop sizes in the corresponding conditions and the dotted lines indicated the layer size. Two biological replicates for Hi-C on chromosomes from $\Delta \mathrm{H} 3-\mathrm{H} 4$ extracts were performed and similar results were obtained from both experiments. The number of nuclei imaged in B are indicated above the figure. 
bioRxiv preprint doi: https://doi.org/10.1101/2020.12.20.423657; this version posted April 12, 2021. The copyright holder for this preprint (which was not certified by peer review) is the author/funder, who has granted bioRxiv a license to display the preprint in perpetuity. It is made available under aCC-BY-NC-ND 4.0 International license.

Choppakatla et al., April 2021-preprint copy- BioRxiv

A

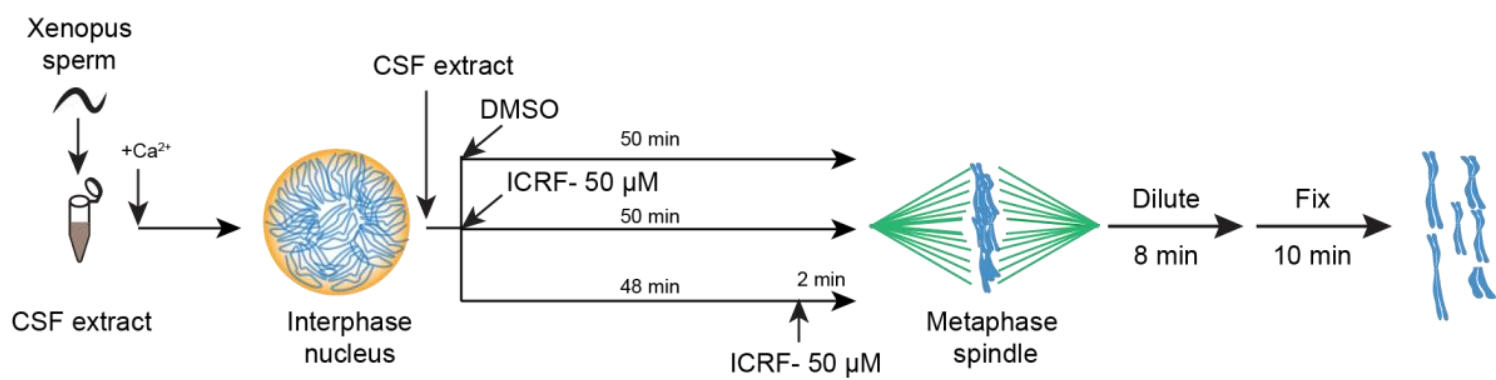

B

DMSO
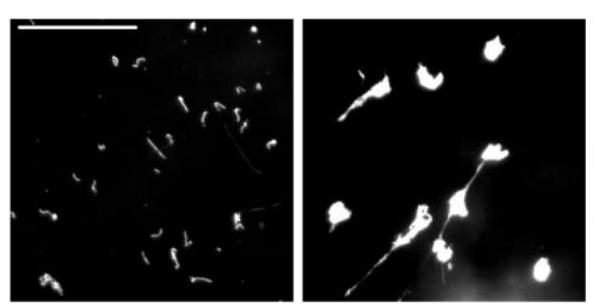

D$$
\begin{aligned}
& 2 \\
& \text { 일 } \\
& \frac{1}{\pi} \\
& 0 \\
& 0
\end{aligned}
$$

궁
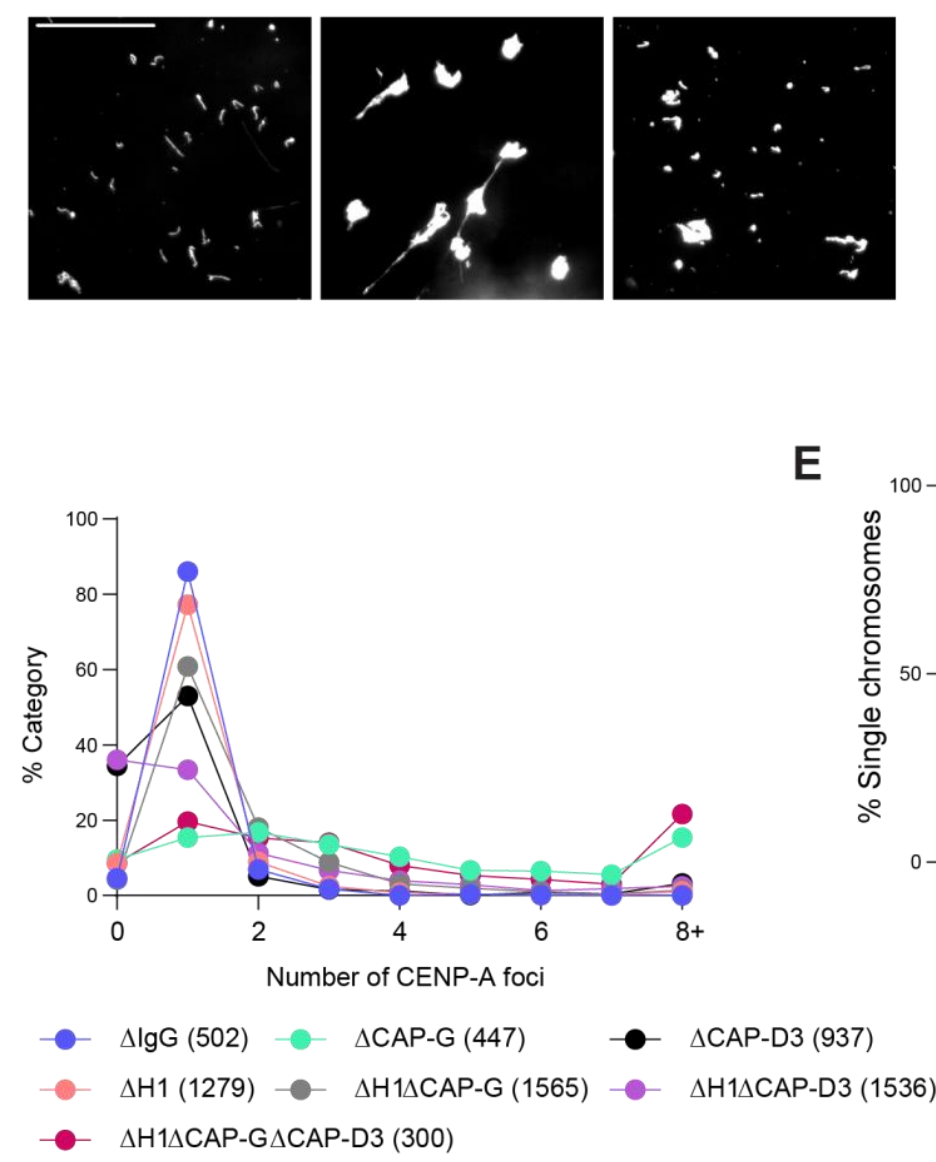

E

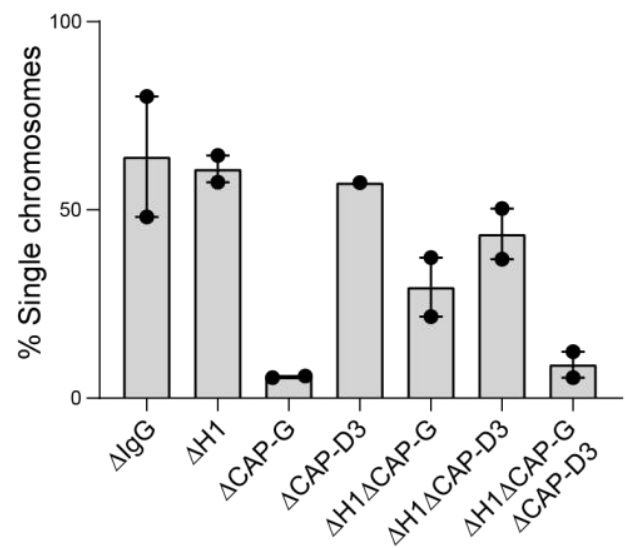

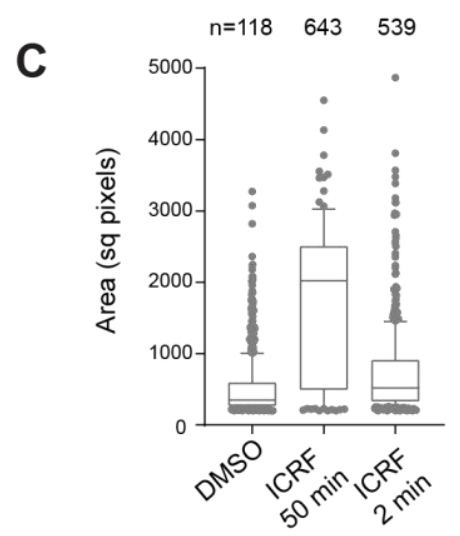

Figure S8. Regulation of chromosome individualization by topo II, condensins and H1.8 in Xenopus egg extracts

A) Schematic of ICRF-193 addition to check for requirement of topo II activity in individualizing chromosomes. Interphase nuclei were first formed in $\Delta \mathrm{IgG}$ or $\Delta \mathrm{H} 1$ extracts, topo II inhibitor ICRF-193 $(50 \mu \mathrm{M})$ was added to egg extracts, either together with corresponding depleted egg extracts and incubated for $50 \mathrm{~min}$ (ICRF-50 min), or $48 \mathrm{~min}$ after adding the depleted extracts, followed by 2 min incubation with ICRF-193 (ICRF-2 min). B) Metaphase extracts processed as A were diluted to disperse individualized chromosomes. Representative Hoechst images of chromosomes are shown. Bar, $20 \mu \mathrm{m}$. C) Quantification of the Hoechst-stained area of chromosomes in B. Each dot represents the area of a single chromosome or a chromosome cluster. Large values indicate the extent of chromosome clusters. The box shows the $10^{\text {th }}-90^{\text {th }}$ percentile limits of the sample values. The number of DNA masses imaged in each condition are indicated above the figure. D) Distribution of CENP-A foci per DNA mass in the experiment shown in Figure 5A-C. Clusters of unresolved chromosomes are represented by higher numbers (>2) of CENP-A foci per DNA mass indicates clusters. No detectable CENP-A focus in $\triangle$ CAP-D3 ( $\triangle$ condensin II) extracts is due to low CENP-A signal, reflecting the reported role of condensin II in CENP-A loading (Bernad et al., 2011). The number noted in each sample label is the number of chromosomes/clusters counted in each condition. E) Percent frequency of single chromosomes (chromosomes in DNA masses with <2 CENP-A foci) in the indicated conditions showing that the cutoff for number of CENP-A foci does not change the relative individualization measured. The number of DNA masses imaged in each condition are the same as in Figure 5C. 


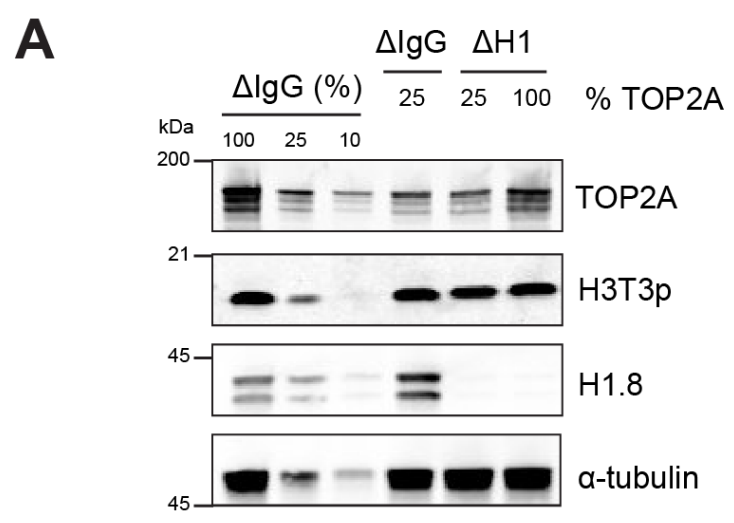

B
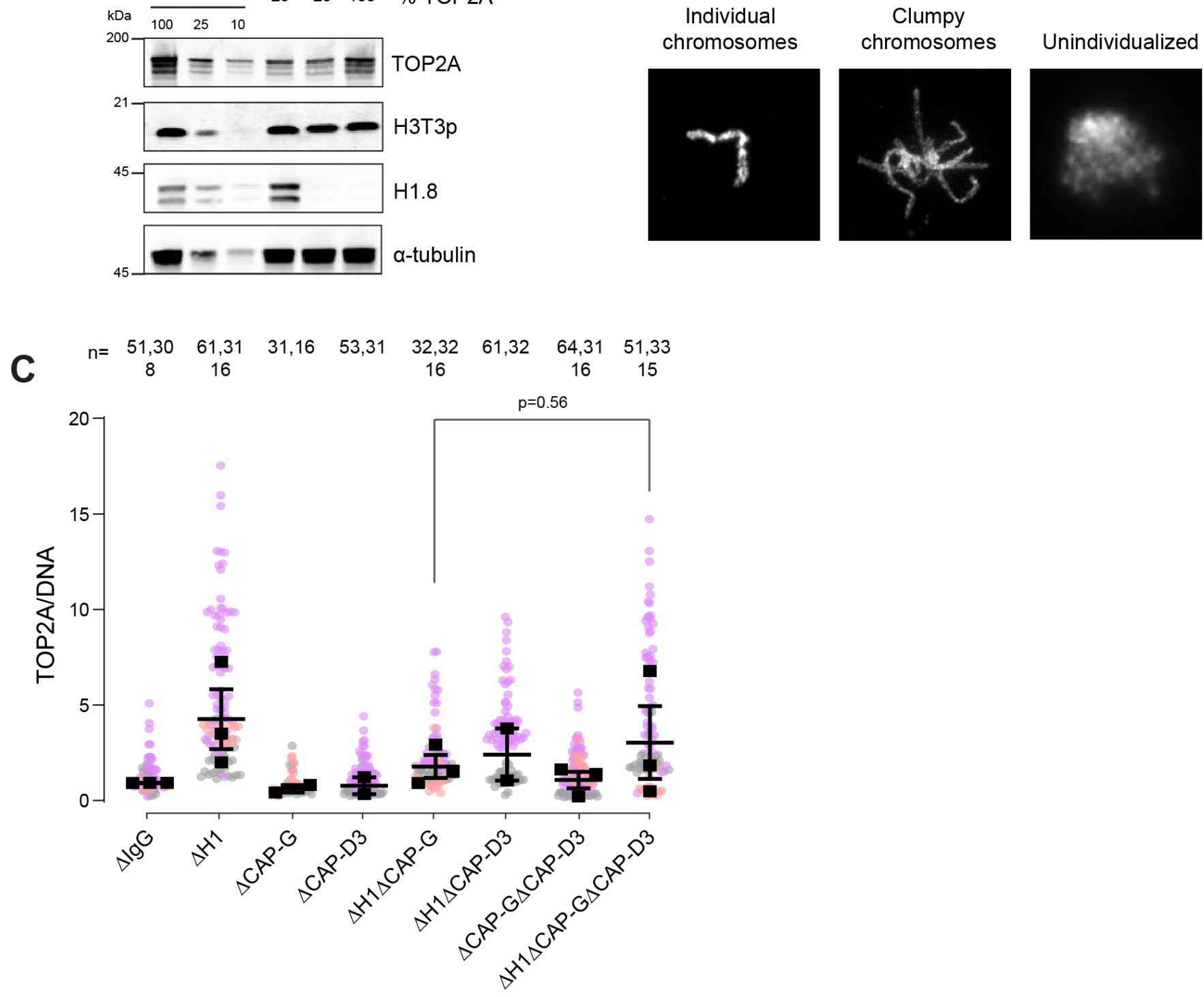

Figure S9. H1.8 suppresses over-individualization through condensins and topo II

A) Western blots of total egg extracts showing partial depletion of TOP2A. Left three lanes; dilution series of total mock-depleted extracts $(\Delta \mathrm{IgG})$ for signal quantitation. Middle $\Delta \mathrm{IgG}$ lane; extracts with $25 \%$ level of TOP2A. right two $\Delta \mathrm{H} 1$ lanes; extracts depleted of $\mathrm{H} 1.8$ with either $25 \%$ or $100 \%$ levels of TOP2A. B) Categories of chromosome clusters observed upon performing chromosome individualization assay. C) Quantification of TOP2A signal normalized to the DNA signal in the indicated conditions. Each gray, orange or violet dot represents the mean normalized TOP2A level in a single nucleus. The black squares represent the median of the TOP2A values of all the nuclei in a single experiment. Data plotted is mean and S.E.M. The p-value in $C$ was calculated using an unpaired Student's t-test. The number of nuclei imaged in $C$ in each condition are indicated above the figure. 